\title{
8NREL
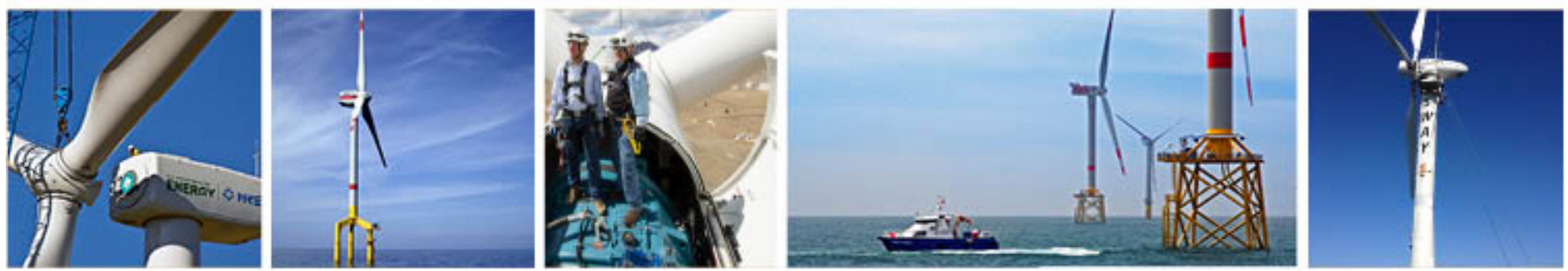

\section{Assessment of Offshore Wind Energy Leasing Areas for the BOEM Massachusetts Wind Energy Area}

W. Musial, Z. Parker, J. Fields, G. Scott, D. Elliott, and C. Draxl National Renewable Energy Laboratory

Produced under direction of the Bureau of Ocean Energy Management (BOEM) by the National Renewable Energy Laboratory (NREL) under Interagency Agreement M13PG00002 and Task No. WFS3. 1000

NREL is a national laboratory of the U.S. Department of Energy Office of Energy Efficiency \& Renewable Energy Operated by the Alliance for Sustainable Energy, LLC

This report is available at no cost from the National Renewable Energy Laboratory (NREL) at www.nrel.gov/publications.

Technical Report

NREL/TP-5000-60942

December 2013

Contract No. DE-AC36-08GO28308 


\section{Assessment of Offshore Wind Energy Leasing Areas for the BOEM Massachusetts Wind Energy Area}

W. Musial, Z. Parker, J. Fields, G. Scott, D. Elliott, and C. Draxl

Prepared under Task No. WFS3.1000

NREL is a national laboratory of the U.S. Department of Energy Office of Energy Efficiency \& Renewable Energy Operated by the Alliance for Sustainable Energy, LLC

This report is available at no cost from the National Renewable Energy Laboratory (NREL) at www.nrel.gov/publications.

December 2013 


\title{
NOTICE
}

This manuscript has been authored by employees of the Alliance for Sustainable Energy, LLC ("Alliance") under Contract No. DE-AC36-08GO28308 with the U.S. Department of Energy. This report was prepared as an account of work sponsored by an agency of the United States government. Neither the United States government nor any agency thereof, nor any of their employees, makes any warranty, express or implied, or assumes any legal liability or responsibility for the accuracy, completeness, or usefulness of any information, apparatus, product, or process disclosed, or represents that its use would not infringe privately owned rights. Reference herein to any specific commercial product, process, or service by trade name, trademark, manufacturer, or otherwise does not necessarily constitute or imply its endorsement, recommendation, or favoring by the United States government or any agency thereof. The views and opinions of authors expressed herein do not necessarily state or reflect those of the United States government or any agency thereof.

This report is available at no cost from the National Renewable Energy Laboratory (NREL) at www.nrel.gov/publications.

Available electronically at http://www.osti.gov/bridge

Available for a processing fee to U.S. Department of Energy and its contractors, in paper, from:

\author{
U.S. Department of Energy \\ Office of Scientific and Technical Information \\ P.O. Box 62 \\ Oak Ridge, TN 37831-0062 \\ phone: 865.576 .8401 \\ fax: 865.576 .5728 \\ email: mailto:reports@adonis.osti.gov
}

Available for sale to the public, in paper, from:

U.S. Department of Commerce National Technical Information Service 5285 Port Royal Road Springfield, VA 22161 phone: 800.553 .6847 fax: 703.605.6900

email: orders@ntis.fedworld.gov

online ordering: http://www.ntis.gov/help/ordermethods.aspx 


\section{Acknowledgments}

The National Renewable Energy Laboratory (NREL) would like to acknowledge the support and cooperation of the Bureau of Ocean Energy Management (BOEM). Additionally, as part of this work, NREL received cooperative assistance from the Massachusetts Clean Energy Center, Massachusetts Office of Coastal Zone Management, and other members of the BOEM Massachusetts Renewable Energy Task Force.

The following NREL reviewers and contributors are acknowledged: Sheri Anstedt, Ian BaringGould, Donna Heimiller, Fort Felker, Pat Moriarty, Brian Smith, and Suzanne Tegen. 


\section{Executive Summary}

The U.S. Department of Energy's (DOE) National Renewable Energy Laboratory (NREL), under an interagency agreement with the Bureau of Ocean Energy Management (BOEM), is providing technical assistance to identify and delineate leasing areas for offshore wind energy development within the Atlantic Coast Wind Energy Areas (WEAs) established by BOEM. This report focuses on NREL's development of three delineated leasing area options for the Massachusetts (MA) WEA and the technical evaluation of these leasing areas.

The overarching objective of this study is to develop a logical process by which the MA WEA can be subdivided into non-overlapping leasing areas for BOEM's use in developing an auction process in a renewable energy lease sale. NREL worked with BOEM to identify an appropriate number of leasing areas and proposed three delineation alternatives within the MA WEA based on the boundaries announced in May 2012. A primary output of the interagency agreement is this report, which documents the methodology, including key variables and assumptions, by which the leasing areas were identified and delineated.

As part of the study, NREL researchers:

1. Developed a process and criteria to create four to five leasing areas within the BOEM MA WEA announced by BOEM in May 2012.

2. Presented their preliminary methodology and technical approach for analysis at a webinar with the intergovernmental BOEM Massachusetts Task Force on May 15, 2013 (Musial 2013).

3. Reviewed and assessed the proposed development parameters provided in eight responses to the 2011 BOEM Massachusetts Request for Interest (RFI) and in 10 responses to the February 2012 Call for Information and Nominations (the "Call").

4. Revised the methodology to delineate the MA WEA and addressed feedback received from the intergovernmental BOEM Massachusetts Task Force, BOEM, Massachusetts Clean Energy Center, and Massachusetts Office of Coastal Zone Management.

5. Identified three alternatives for delineating the MA WEA (Figure ES2) into four to five leasing areas and conducted analyses to compare and evaluate the different delineation scenarios.

6. Evaluated potential phased developments using one and two 500-megawatt (MW) projects in each leasing area (one earlier in shallower water and one later in deeper water) and the effect of different turbine spacing scenarios on wake losses, energy production, and potential development challenges.

7. Prepared this report summarizing the NREL technical approach and final recommendations to BOEM for leasing area delineations within the MA WEA and the effects of different turbine spacing and water depth scenarios on potential development and energy production.

8. Will present the final results of this report in a live webinar to the intergovernmental BOEM Massachusetts Task Force in late 2013. 
In addition to the references in Section 9, NREL reviewed and used information from the following sources for this report:

- The RFI published by BOEM in the Federal Register in December 2010 for offshore Massachusetts and eight responses to the RFI

- The Call published by BOEM in the Federal Register in February 2012 and 10 responses to the Call

- The MA WEA coordinates that were developed by BOEM and provided to NREL for the delineation analysis

- Presentations delivered at the Massachusetts Renewable Energy Task Force webinar held on May 15, 2013

- Verbal input received from a conference call with the Massachusetts Clean Energy Center and Massachusetts Office of Coastal Zone Management on May 20, 2013 and follow-up discussions.

As a result of discussions at the Massachusetts Renewable Energy Task Force webinar on May 15, 2013, and follow-up correspondence with the Massachusetts Clean Energy Center, Massachusetts Coastal Zone Management, and BOEM, NREL obtained feedback that was used in developing the final methodology and delineation options for the analysis of the MA WEA.

The final methodology included:

- Development of delineation alternatives for a four leasing area (Alternative 1) and a five leasing area scenario (Alternative 2) with equal division of shallower water [less than 50 meters $(\mathrm{m})$ ] in each leasing area

- Development of a third delineation option (Alternative 3) for five leasing areas consisting of four leasing areas with equal division of shallower water less than 50 meters and one leasing area with deeper water (greater than $50 \mathrm{~m}$ )

- Evaluation and comparison of the full development nameplate potential capacity (based on total area) of the leasing areas in all three delineation alternatives using turbine array spacing in rotor diameters (D) of $8 \mathrm{D} \times 8 \mathrm{D}, 8 \mathrm{D} \times 12 \mathrm{D}$, and $8 \mathrm{D} \times 15 \mathrm{D}$

- Evaluation and comparison of phased developments of two 500-MW projects in each leasing area (one built earlier in 6-8 years in shallower water and one built later in 10-16 years in deeper water) and the effect of different turbine spacing configurations ( $8 \mathrm{D} \times 8 \mathrm{D}, 8 \mathrm{D} \times 12$ $\mathrm{D}$, and $8 \mathrm{D}$ x $15 \mathrm{D}$ ) on wake losses, energy production, and development challenges.

For each of the delineation options, several quantitative evaluation criteria were examined and other qualitative criteria were considered. These criteria are listed in Table ES1. 
Table ES1. Evaluation Criteria Used to Assess the Massachusetts (MA) WEA

(Source: NREL)

\begin{tabular}{|ll|}
\hline \multicolumn{1}{|c|}{ Quantitative Evaluation Criteria } & \multicolumn{1}{c|}{ Qualitative Evaluation Criteria } \\
\hline Total area $\left(\mathrm{km}^{2}\right.$ and acres) & Distance from shore \\
\hline Maximum nameplate capacity [megawatts (MW)] & Technology challenges \\
\hline Bathymetry [meters $(\mathrm{m})$ ] & Development cost \\
\hline $\begin{array}{l}\text { Annual average wind speed and direction [meters per } \\
\text { second (m/s)] }\end{array}$ & Interconnection logistics \\
\hline 500-MW phased developments & Development timing \\
\hline Wake losses (\%) and array efficiency & \\
\hline Array orientation angle (degrees) & \\
\hline Turbine spacing within array [rotor diameters $(\mathrm{D})]$ & \\
\hline Capacity factor after wake losses (\%) & \\
\hline Annual energy production [gigawatt-hours $(\mathrm{GWh})]$ & \\
\hline
\end{tabular}

The water depth, or bathymetry, map in Figure ES1 shows that water depths range from about 35 $\mathrm{m}$ to $65 \mathrm{~m}$ across the MA WEA.

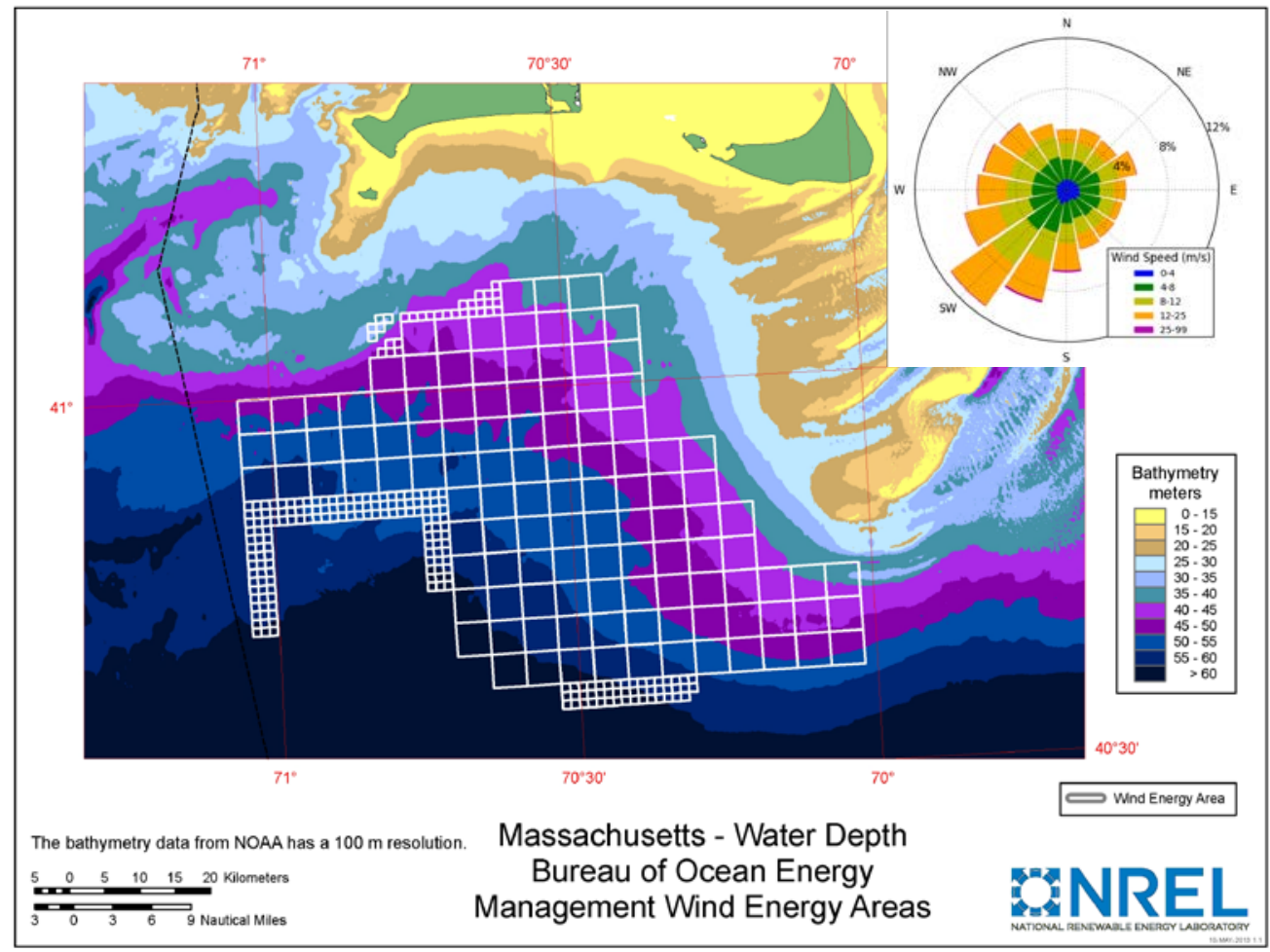

Figure ES1. Water depth map for the MA WEA

(Source: NREL)

This report is available at no cost from the National Renewable Energy Laboratory (NREL) at www.nrel.gov/publications. 
The average water depth was about $50 \mathrm{~m}$ for the entire MA WEA. Deeper water $(50 \mathrm{~m}$ and above) is prevalent over the southern parts of the WEA and shallower water is found in the northern portions of the WEA. Most of the MA WEA leasing areas will be affected significantly by the water depth in terms of cost and development challenges. Note also that the prevailing wind direction, shown in the wind rose in the upper right corner of Figure ES1, is perpendicular to the isobaths (lines of constant depth) in Figure ES1 and parallel to the delineation lines in Figure ES2.

The three alternatives were discussed and agreed upon with BOEM over several iterations and are shown in Figure ES2. The criteria for selecting these delineations were based on the following assumptions and constraints:

- Number of leasing areas. The leasing process was limited to a maximum of five nonoverlapping leasing areas that would together make up the total area of the MA WEA.

- Equalizing shallow water resource. The delineations attempted to equalize the amount of shallow water below $50 \mathrm{~m}$ in each of the leasing areas.

- Minimizing external wake effects. Delineation lines were drawn at a 45-degree southwestto-northeast diagonal to be approximately parallel to the prevailing southwest wind direction (see wind rose in Figure ES1).

- Wind resource. Average wind speed in each leasing area was considered across the MA WEA and found to vary between 9.2 and 9.4 meters per second $(\mathrm{m} / \mathrm{s})$. These variations are low and as a result average wind speed did not play a major role in delineation boundary decisions.

The three delineation options are shown in Figure ES2. 


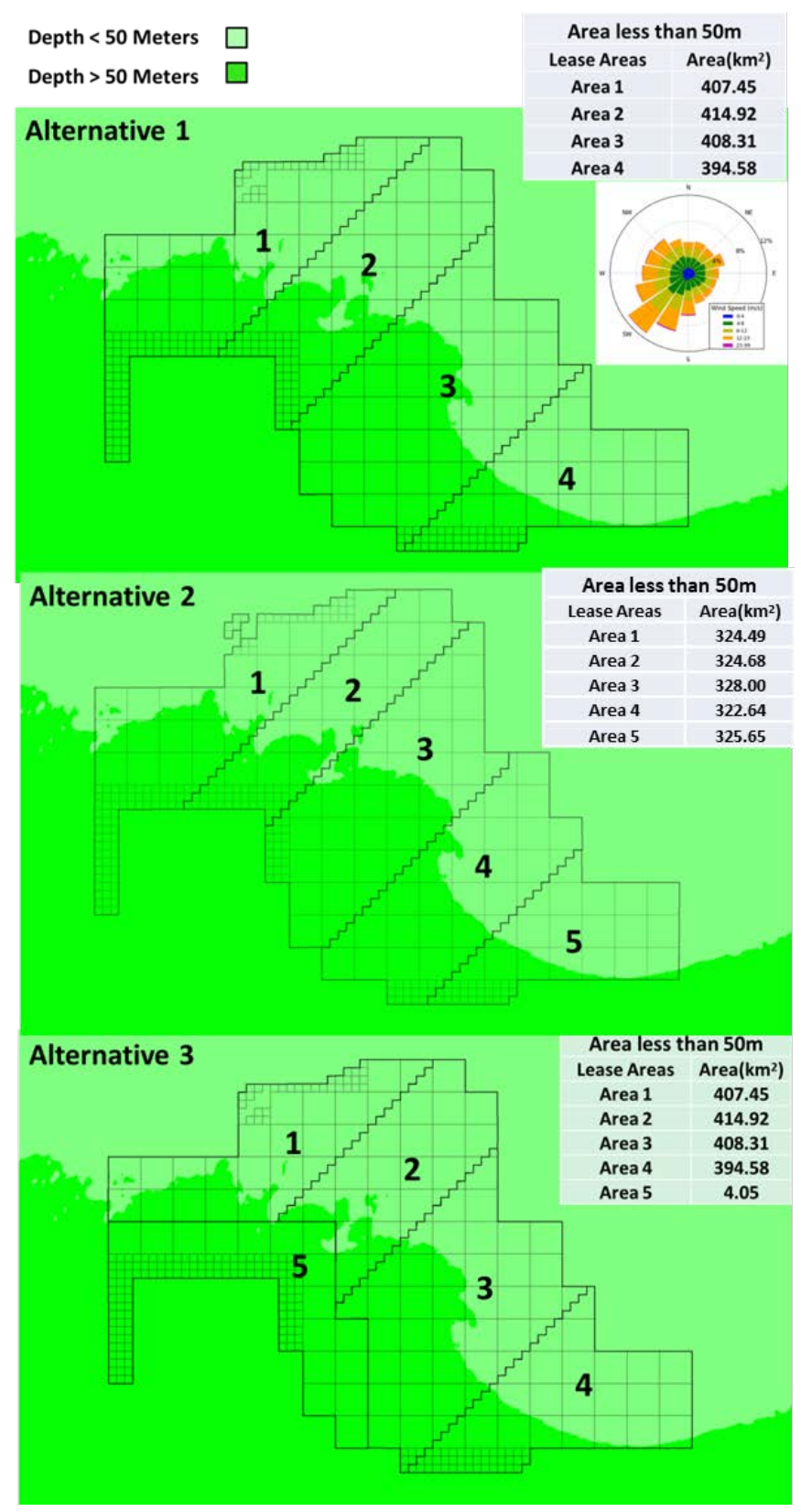

Figure ES2. The three leasing area delineation options that NREL analyzed include: Alternative 1, four diagonal leasing areas; Alternative 2, five diagonal leasing areas; Alternative 3, five leasing areas with one deep area. The lighter green color indicates water depths below $50 \mathrm{~m}$ and the darker green color indicates water depth above $50 \mathrm{~m}$. The MA WEA wind rose is shown at the top right.

(Source: NREL)

Table ES2, Table ES3, and Table ES4 provide a summary of the quantitative results for the three different delineation alternatives assessed by NREL for the MA WEA in Figure ES1. The analysis was conducted primarily with the use of the AWS Truepower OpenWind Enterprise tool (AWS Truepower 2012). Wind turbine array modeling was based on the NREL 5-MW reference turbine (Jonkman et al. 2009). 
Table ES2. MA WEA Delineation Analysis for Alternative 1

(Source: NREL)

\begin{tabular}{|c|c|c|c|c|}
\hline \multirow[b]{2}{*}{ Parameter } & \multicolumn{4}{|c|}{ Delineation Alternative 1} \\
\hline & $\begin{array}{l}\text { Leasing } \\
\text { Area } 1\end{array}$ & $\begin{array}{l}\text { Leasing } \\
\text { Area } 2\end{array}$ & $\begin{array}{l}\text { Leasing } \\
\text { Area } 3\end{array}$ & $\begin{array}{l}\text { Leasing } \\
\text { Area } 4\end{array}$ \\
\hline Total area $\left(\mathrm{km}^{2}\right)$ & 759 & 676 & 1,004 & 569 \\
\hline Total area $(<50 \mathrm{~m})$ & 407 & 415 & 408 & 395 \\
\hline Ave. depth (m) & 47.6 & 51.8 & 47.9 & 49.8 \\
\hline Bathymetry - depth range $(\mathrm{m})$ & $36.0-61.0$ & $37.6-63.0$ & $34.0-62.0$ & $33.0-61.4$ \\
\hline Ave wind speed at $90 \mathrm{~m}(\mathrm{~m} / \mathrm{s})$ & 9.3 & 9.3 & 9.4 & 9.2 \\
\hline \multicolumn{5}{|c|}{8 D x 8 D Full Development } \\
\hline Wake losses (\%) & 10.6 & 12.3 & 12.4 & 10.5 \\
\hline $\begin{array}{c}\text { Gross capacity factor (CF) after wake } \\
\text { losses (\%) }\end{array}$ & 45.2 & 44.4 & 44.4 & 46 \\
\hline Potential capacity (MW) & 3,430 & 2,715 & 4,450 & 2,505 \\
\hline Annual energy production (GWh) & 13,590 & $10,557.6$ & $17,331.8$ & $10,094.9$ \\
\hline \multicolumn{5}{|c|}{8 D x 12 D Full Development } \\
\hline Wake losses (\%) & 8.3 & 9.9 & 10 & 8.3 \\
\hline Gross CF after wake losses (\%) & 46.4 & 45.6 & 45.7 & 47.2 \\
\hline Potential capacity (MW) & 2,305 & 1,855 & 2,955 & 1,695 \\
\hline Annual energy production (GWh) & 9,366 & $7,411.7$ & $11,836.3$ & $7,006.1$ \\
\hline \multicolumn{5}{|c|}{8 D x 15 D Full Development } \\
\hline Wake losses (\%) & 7.2 & 8.7 & 8.8 & 7.3 \\
\hline Gross CF after wake losses (\%) & 46.9 & 46.2 & 46.3 & 47.7 \\
\hline Potential capacity (MW) & 1,850 & 1,455 & 2,360 & 1,360 \\
\hline Annual energy production (GWh) & $7,601.6$ & $5,891.5$ & $9,574.3$ & $5,684.2$ \\
\hline \multicolumn{5}{|c|}{8 D x 8 D Phase 1 (500 MW each) } \\
\hline Wake losses (\%) & 6 & 6.9 & 5.7 & 5.4 \\
\hline Gross CF after wake losses (\%) & 47.7 & 47.4 & 48.2 & 48.8 \\
\hline Potential capacity (MW) & 500 & 500 & 500 & 500 \\
\hline Phase 1 depth range $(\mathrm{m})$ & $33.0-45.0$ & $36.0-42.0$ & $37.6-45.0$ & $34.0-44.0$ \\
\hline Annual energy production (GWh) & 2,091 & $2,078.3$ & $2,114.3$ & $2,138.3$ \\
\hline \multicolumn{5}{|c|}{$8 \mathrm{D} \times 8 \mathrm{D}$ Phase 1 and 2 (1,000 MW each) } \\
\hline Wake losses (\%) & 6.3 & 8.3 & 7 & 6.3 \\
\hline Gross CF after wake losses (\%) & 47.5 & 46.6 & 47.4 & 48.2 \\
\hline Potential capacity (MW) & 1,000 & 1,000 & 1,000 & 1,000 \\
\hline Phase 2 depth range $(\mathrm{m})$ & $44.7-51.0$ & $43.0-50.0$ & $45.0-51.0$ & $46.0-50.0$ \\
\hline Annual energy production (GWh) & $4,162.3$ & $4,083.9$ & $4,159.2$ & $4,229.1$ \\
\hline
\end{tabular}

This report is available at no cost from the National Renewable Energy Laboratory (NREL) at www.nrel.gov/publications. 


\begin{tabular}{|c|c|c|c|c|}
\hline \multicolumn{5}{|c|}{8 D x 12 D Phase 1 (500 MW each) } \\
\hline Wake losses (\%) & 5.2 & 6.2 & 5.1 & 4.9 \\
\hline Gross CF after wake losses (\%) & 48.1 & 47.8 & 48.5 & 49 \\
\hline Potential capacity (MW) & 500 & 500 & 500 & 500 \\
\hline Phase 1 depth range $(\mathrm{m})$ & $33.0-47.0$ & $36.0-45.0$ & $37.2-46.0$ & $34.6-46.0$ \\
\hline Annual energy production (GWh) & $2,109.7$ & $2,093.8$ & $2,127.9$ & 2,148 \\
\hline \multicolumn{5}{|c|}{$8 \mathrm{D} \times 12$ D Phase 1 and 2 (1,000 MW each) } \\
\hline Wake losses (\%) & 5.9 & 7.3 & 6.4 & 5.7 \\
\hline Gross CF after wake losses (\%) & 47.7 & 47 & 47.7 & 48.5 \\
\hline Potential capacity (MW) & 1,000 & 1,000 & 1,000 & 1,000 \\
\hline Phase 2 depth range $(\mathrm{m})$ & $46.0-53.0$ & $46.0-53.3$ & $48.0-54.0$ & $47.0-59.0$ \\
\hline Annual energy production (GWh) & $4,179.6$ & $4,119.6$ & $4,180.4$ & $4,253.5$ \\
\hline \multicolumn{5}{|c|}{8 D x 15 D Phase 1 (500 MW each) } \\
\hline Wake losses (\%) & 5 & 5.8 & 4.9 & 4.5 \\
\hline Gross CF after wake losses (\%) & 48.3 & 47.9 & 48.6 & 49.2 \\
\hline Potential capacity (MW) & 500 & 500 & 500 & 500 \\
\hline Phase 1 depth range $(\mathrm{m})$ & $34.0-48.0$ & $37.0-47.8$ & $37.2-47.3$ & $32.9-46.0$ \\
\hline Annual energy production (GWh) & $2,115.7$ & $2,101.3$ & $2,130.6$ & 2,156 \\
\hline \multicolumn{5}{|c|}{$8 \mathrm{D} \times 15 \mathrm{D}$ Phase 1 and $2(1,000 \mathrm{MW}$ each) } \\
\hline Wake losses (\%) & 5.7 & 6.8 & 6.3 & 5.4 \\
\hline Gross CF after wake losses (\%) & 45.6 & 45.7 & 47.2 & 46.4 \\
\hline Potential capacity (MW) & 1,855 & 2,955 & 1,695 & 2,305 \\
\hline Phase 2 depth range $(\mathrm{m})$ & $47.0-54.0$ & $46.0-56.0$ & $48.0-54.0$ & $49.0-62.2$ \\
\hline Annual energy production (GWh) & $7,411.7$ & $11,836.3$ & $7,006.1$ & 9,366 \\
\hline
\end{tabular}

This report is available at no cost from the National Renewable Energy Laboratory (NREL) at www.nrel.gov/publications. 
Table ES3. MA WEA Delineation Analysis for Alternative 2

(Source: NREL)

\begin{tabular}{|c|c|c|c|c|c|}
\hline & \multicolumn{5}{|c|}{ Delineation Alternative 2} \\
\hline Parameter & $\begin{array}{l}\text { Leasing } \\
\text { Area } 1\end{array}$ & $\begin{array}{l}\text { Leasing } \\
\text { Area } 2\end{array}$ & $\begin{array}{l}\text { Leasing } \\
\text { Area } 3\end{array}$ & $\begin{array}{l}\text { Leasing } \\
\text { Area } 4\end{array}$ & $\begin{array}{c}\text { Leasing Area } \\
5\end{array}$ \\
\hline Total area $\left(\mathrm{km}^{2}\right)$ & 642 & 484 & 792 & 644 & 445 \\
\hline Total area $(<50 \mathrm{~m})$ & 324 & 325 & 328 & 323 & 326 \\
\hline Ave depth (m) & 50 & 47 & 51 & 51 & 48 \\
\hline Bathymetry - depth range $(\mathrm{m})$ & $33.0-61.0$ & $36.1-55.6$ & $37.0-62.0$ & $37.0-63.2$ & $34.0-61.5$ \\
\hline Ave wind speed at $90 \mathrm{~m}(\mathrm{~m} / \mathrm{s})$ & 9.3 & 9.3 & 9.3 & 9.4 & 9.4 \\
\hline \multicolumn{6}{|c|}{8 D x 8 D Full Development } \\
\hline Wake losses (\%) & 10 & 11.9 & 12.4 & 11.8 & 10.2 \\
\hline Gross CF after wake losses (\%) & 45.5 & 44.6 & 44.3 & 44.9 & 46.2 \\
\hline Potential capacity (MW) & 2,755 & 1,830 & 3,375 & 2,675 & 2,015 \\
\hline Annual energy production (GWh) & $10,985.9$ & $7,151.3$ & $13,109.5$ & 10,536 & $8,162.4$ \\
\hline \multicolumn{6}{|c|}{8 D x 12 D Full Development } \\
\hline Wake losses (\%) & 7.9 & 9.4 & 9.9 & 9.3 & 7.9 \\
\hline Gross CF after wake losses (\%) & 46.7 & 45.9 & 45.7 & 46.3 & 47.5 \\
\hline Potential capacity (MW) & 1,910 & 1,220 & 2,240 & 1,795 & 1,315 \\
\hline Annual energy production (GWh) & $7,812.2$ & $4,908.4$ & $8,966.3$ & $7,279.8$ & 5,470 \\
\hline \multicolumn{6}{|c|}{8 D x 15 D Full Development } \\
\hline Wake losses (\%) & 6.9 & 8.2 & 8.8 & 8.2 & 6.9 \\
\hline Gross CF after wake losses (\%) & 47.1 & 46.4 & 46.2 & 46.7 & 47.9 \\
\hline Potential capacity (MW) & 1,530 & 965 & 1,790 & 1,430 & 1,050 \\
\hline Annual energy production (GWh) & $6,312.4$ & $3,925.7$ & $7,244.8$ & $5,860.3$ & $4,406.9$ \\
\hline \multicolumn{6}{|c|}{8 D x 8 D Phase 1 (500 MW each) } \\
\hline Wake losses (\%) & 6.1 & 7.8 & 7.1 & 6.5 & 5.8 \\
\hline Gross CF after wake losses (\%) & 47.7 & 46.9 & 47.4 & 47.9 & 48.6 \\
\hline Potential capacity (MW) & 500 & 500 & 500 & 500 & 500 \\
\hline Phase 1 depth range $(\mathrm{m})$ & $33.0-46.0$ & $36.1-45.7$ & $37.0-44.0$ & $37.0-47.0$ & $34.0-46.0$ \\
\hline Annual energy production (GWh) & $2,089.3$ & 2,054 & $2,076.9$ & $2,100.8$ & $2,130.2$ \\
\hline \multicolumn{6}{|c|}{$8 \mathrm{D} \times 8 \mathrm{D}$ Phase 1 and 2 (1,000 MW each) } \\
\hline Wake losses (\%) & 6.5 & 8.8 & 8.4 & 7.8 & 6.9 \\
\hline Gross CF after wake losses (\%) & 47.3 & 46.2 & 46.6 & 47.1 & 48 \\
\hline Potential capacity (MW) & 1,000 & 1,000 & 1,000 & 1,000 & 1,000 \\
\hline Phase 2 depth range $(\mathrm{m})$ & $47.0-51.0$ & $45.0-55.0$ & $47.0-53.0$ & $48.0-52.0$ & $45.0-51.0$ \\
\hline Annual energy production (GWh) & $4,150.3$ & $4,049.9$ & $4,081.5$ & $4,132.5$ & $4,206.6$ \\
\hline
\end{tabular}

This report is available at no cost from the National Renewable Energy Laboratory (NREL) at www.nrel.gov/publications. 


\begin{tabular}{|c|c|c|c|c|c|}
\hline \multicolumn{6}{|c|}{8 D x 12 D Phase 1 (500 MW each) } \\
\hline Wake losses (\%) & 5.6 & 6.7 & 6.3 & 5.8 & 5.3 \\
\hline Gross CF after wake losses (\%) & 48 & 47.4 & 47.8 & 48.3 & 48.8 \\
\hline Potential capacity (MW) & 500 & 500 & 500 & 500 & 500 \\
\hline Phase 1 depth range $(\mathrm{m})$ & $34.0-46.0$ & $37.0-48.0$ & $36.4-48.0$ & $36.0-48.4$ & $33.0-48.6$ \\
\hline Annual energy production (GWh) & $2,102.7$ & $2,075.9$ & 2,096 & $2,114.8$ & $2,140.3$ \\
\hline
\end{tabular}

$8 \mathrm{D} \times 12 \mathrm{D}$ Phase 1 and 2 (1,000 MW each)

\begin{tabular}{|c|c|c|c|c|c|}
\hline Wake losses (\%) & 6.3 & 7.3 & 7.5 & 7.1 & 6 \\
\hline Gross CF after wake losses (\%) & 47.5 & 46.9 & 47 & 47.4 & 48.4 \\
\hline Potential capacity (MW) & 1,000 & 960 & 1,000 & 1,000 & 900 \\
\hline Phase 2 depth range (m) & $46.0-54.0$ & $47.5-55.0$ & $48.0-54.0$ & $49.0-58.0$ & $48.0-62.0$ \\
\hline Annual energy production (GWh) & $4,160.5$ & $3,944.3$ & $4,118.5$ & $4,157.8$ & $3,817.7$ \\
\hline
\end{tabular}

$8 \mathrm{D} \times 15 \mathrm{D}$ Phase 1 (500 MW each)

\begin{tabular}{|c|c|c|c|c|c|}
\hline Wake losses (\%) & 4.7 & 6.1 & 6 & 5.4 & 4.8 \\
\hline Gross CF after wake losses (\%) & 48.4 & 47.6 & 47.9 & 48.4 & 49.2 \\
\hline Potential capacity (MW) & 500 & 500 & 500 & 500 & 500 \\
\hline Phase 1 depth range (m) & $34.0-50.0$ & $36.1-48.2$ & $37.0-48.0$ & $38.0-49.0$ & $35.0-50.0$ \\
\hline Annual energy production (GWh) & $2,120.4$ & $2,087.4$ & $2,101.2$ & $2,123.1$ & 2,155 \\
\hline
\end{tabular}

$8 \mathrm{D} \times 15 \mathrm{D}$ Phase 1 and 2 (1,000 MW each)

\begin{tabular}{|c|c|c|c|c|c|}
\hline Wake losses (\%) & 5.7 & 6.8 & 7 & 6.6 & 5.563291 \\
\hline Gross CF after wake losses (\%) & 47.7 & 47.2 & 47.1 & 47.6 & 48.58987 \\
\hline Potential capacity (MW) & 1,000 & 790 & 1,000 & 1,000 & 790 \\
\hline Phase 2 depth range (m) & $50.0-59.0$ & $49.0-55.0$ & $50.0-56.0$ & $50.0-62.0$ & $48.0-61.0$ \\
\hline Annual energy production (GWh) & 4,180 & $3,266.3$ & $4,132.9$ & $4,175.3$ & $3,366.4$ \\
\hline
\end{tabular}

This report is available at no cost from the National Renewable Energy Laboratory (NREL) at www.nrel.gov/publications. 
Table ES4. MA WEA Delineation Analysis for Alternative 3

(Source: NREL)

\begin{tabular}{|c|c|c|c|c|c|}
\hline \multirow[b]{2}{*}{ Parameter } & \multicolumn{5}{|c|}{ Delineation Alternative 3} \\
\hline & $\begin{array}{l}\text { Leasing } \\
\text { Area } 1\end{array}$ & $\begin{array}{l}\text { Leasing } \\
\text { Area } 2\end{array}$ & $\begin{array}{l}\text { Leasing } \\
\text { Area } 3\end{array}$ & $\begin{array}{l}\text { Leasing } \\
\text { Area } 4\end{array}$ & $\begin{array}{l}\text { Leasing } \\
\text { Area } 5\end{array}$ \\
\hline Total area $\left(\mathrm{km}^{2}\right)$ & 531 & 496 & 844 & 569 & 567 \\
\hline Total area $(<50 \mathrm{~m})$ & 407 & 411 & 408 & 395 & 4 \\
\hline Ave depth (m) & 47 & 45 & 50 & 48 & 56 \\
\hline Bathymetry - depth range (m) & $33.0-54.0$ & $36.0-54.0$ & $37.6-62.0$ & $34.0-62.0$ & $50.0-62.0$ \\
\hline Ave wind speed at $90 \mathrm{~m}(\mathrm{~m} / \mathrm{s})$ & 9.3 & 9.3 & 9.3 & 9.4 & 9.3 \\
\hline \multicolumn{6}{|c|}{8 D x 8 D Full Development } \\
\hline Wake losses (\%) & 10.8 & 12.1 & 12.5 & 10.3 & 9.5 \\
\hline Gross CF after wake losses (\%) & 45.2 & 44.6 & 44.5 & 46.1 & 45.5 \\
\hline Potential capacity (MW) & 2,255 & 1,845 & 3,430 & 2,425 & 2,265 \\
\hline Annual energy production (GWh) & $8,927.4$ & $7,206.7$ & $13,378.9$ & $9,798.7$ & $9,042.1$ \\
\hline \multicolumn{6}{|c|}{8 D x 12 D Full Development } \\
\hline Wake losses (\%) & 8.5 & 9.6 & 10 & 8.2 & 7.5 \\
\hline Gross CF after wake losses (\%) & 46.4 & 45.8 & 45.7 & 47.2 & 46.6 \\
\hline Potential capacity (MW) & 1,470 & 1,220 & 2,295 & 1,660 & 1,585 \\
\hline Annual energy production (GWh) & 5,975 & $4,900.6$ & $9,201.9$ & $6,869.9$ & $6,472.2$ \\
\hline \multicolumn{6}{|c|}{8 D x 15 D Full Development } \\
\hline Wake losses (\%) & 7.4 & 8.4 & 8.9 & 7.1 & 6.5 \\
\hline Gross CF after wake losses (\%) & 46.9 & 46.4 & 46.3 & 47.7 & 47.1 \\
\hline Potential capacity (MW) & 1,170 & 970 & 1,840 & 1,330 & 1,250 \\
\hline Annual energy production (GWh) & $4,812.2$ & $3,946.8$ & $7,473.2$ & $5,566.9$ & $5,158.5$ \\
\hline \multicolumn{6}{|c|}{8 D x 8 D Phase 1 (500 MW each) } \\
\hline Wake losses (\%) & 6 & 6.9 & 5.7 & 5.4 & $\mathrm{~N} / \mathrm{A}$ \\
\hline Gross CF after wake losses (\%) & 47.7 & 47.4 & 48.2 & 48.8 & N/A \\
\hline Potential capacity (MW) & 500 & 500 & 500 & 500 & N/A \\
\hline Phase 1 depth range $(\mathrm{m})$ & $33.0-45.0$ & $36.0-42.0$ & $37.6-45.0$ & $34.0-44.0$ & N/A \\
\hline Annual energy production (GWh) & 2,091 & $2,078.3$ & $2,114.3$ & $2,138.3$ & N/A \\
\hline \multicolumn{6}{|c|}{$8 \mathrm{D} \times 8 \mathrm{D}$ Phase 1 and $2(1,000 \mathrm{MW}$ each) } \\
\hline Wake losses (\%) & 6.9 & 8.7 & 7.3 & 6.3 & 6.4 \\
\hline Gross CF after wake losses (\%) & 47.2 & 46.4 & 47.3 & 48.2 & 47.1 \\
\hline Potential capacity (MW) & 1,000 & 1,000 & 1,000 & 1,000 & 1,000 \\
\hline Phase 2 depth range $(\mathrm{m})$ & $44.7-51.0$ & $43.0-50.0$ & $45.0-51.0$ & $46.0-50.0$ & $46.0-50.0$ \\
\hline Annual energy production (GWh) & $4,133.6$ & $4,064.2$ & $4,146.3$ & 4,228 & $4,129.3$ \\
\hline
\end{tabular}

This report is available at no cost from the National Renewable Energy Laboratory (NREL) at www.nrel.gov/publications. 


\begin{tabular}{|c|c|c|c|c|c|}
\hline \multicolumn{6}{|c|}{8 D x 12 D Phase 1 (500 MW each) } \\
\hline Wake losses (\%) & 5.2 & 6.2 & 5.1 & 4.9 & N/A \\
\hline Gross CF after wake losses (\%) & 48.1 & 47.8 & 48.5 & 49 & N/A \\
\hline Potential capacity (MW) & 500 & 500 & 500 & 500 & N/A \\
\hline Phase 1 depth range $(\mathrm{m})$ & $33.0-47.0$ & $36.0-45.0$ & $37.2-46.0$ & $37.2-46.0$ & N/A \\
\hline Annual energy production (GWh) & $2,109.7$ & $2,093.8$ & $2,127.9$ & 2,148 & N/A \\
\hline \multicolumn{6}{|c|}{$8 \mathrm{D} \times 12 \mathrm{D}$ Phase 1 and 2 (1,000 MW each) } \\
\hline Wake losses (\%) & 6.7 & 8 & 6.8 & 5.7 & 6.3 \\
\hline Gross CF after wake losses (\%) & 47.3 & 46.6 & 47.5 & 48.5 & 47.2 \\
\hline Potential capacity (MW) & 1,000 & 1,000 & 1,000 & 1,000 & 1,000 \\
\hline Phase 2 depth range $(\mathrm{m})$ & $46.0-53.0$ & $46.0-53.3$ & $48.0-54.0$ & $47.0-59.0$ & $51.0-60.0$ \\
\hline Annual energy production (GWh) & $4,143.3$ & $4,086.1$ & $4,166.7$ & $4,252.1$ & $4,134.3$ \\
\hline \multicolumn{6}{|c|}{$8 \mathrm{D} \times 15$ D Phase 1 (500 MW each) } \\
\hline Wake losses (\%) & 5 & 5.8 & 4.9 & 4.5 & N/A \\
\hline Gross CF after wake losses (\%) & 48.3 & 47.9 & 48.6 & 49.2 & N/A \\
\hline Potential capacity (MW) & 500 & 500 & 500 & 500 & $\mathrm{~N} / \mathrm{A}$ \\
\hline Phase 1 depth range $(\mathrm{m})$ & $34.0-48.0$ & $37.0-47.8$ & $37.2-47.3$ & $32.9-46.0$ & N/A \\
\hline Annual energy production (GWh) & $2,115.7$ & $2,101.3$ & $2,130.6$ & 2,156 & N/A \\
\hline \multicolumn{6}{|c|}{$8 \mathrm{D} \times 15 \mathrm{D}$ Phase 1 and $2(1,000 \mathrm{MW}$ each) } \\
\hline Wake losses (\%) & 6.4 & 7.1 & 6.6 & 5.4 & 5.6 \\
\hline Gross CF after wake losses (\%) & 47.4 & 47.1 & 47.6 & 48.6 & 47.5 \\
\hline Potential capacity (MW) & 1,000 & 790 & 1,000 & 955 & 1,000 \\
\hline Phase 2 depth range $(\mathrm{m})$ & $47.0-54.0$ & $46.0-53.0$ & $48.0-54.0$ & $49.0-62.2$ & $50.0-60.0$ \\
\hline Annual energy production (GWh) & $4,154.3$ & $3,263.8$ & $4,169.3$ & $4,067.7$ & $4,164.6$ \\
\hline
\end{tabular}

The data shown in Table ES2, Table ES3, and Table ES4 summarize the analyses that were performed for all three alternatives and turbine spacing scenarios of $8 \mathrm{D}$ x $8 \mathrm{D}, 8 \mathrm{D} \times 12 \mathrm{D}$, and 8 $\mathrm{D} \times 15 \mathrm{D}$. However, the figures and graphs in this report do not always include all cases analyzed because of space limitations. In general, a turbine spacing of $8 \mathrm{D}$ x $12 \mathrm{D}$ was used by NREL for the MA WEA as a baseline case to illustrate all cases. This compares to $8 \mathrm{D} \times 8 \mathrm{D}$ spacing for the Rhode Island/Massachusetts area of mutual interest and Maryland WEA (Musial et al. 2013a, Musial et al. 2013b), and 10 D x 12 D spacing used in the New Jersey WEA (Musial et al. 2013c), and what is commonly used in European wind facilities (see Table 3). NREL believes that bathymetry, wake effects, access to export cable routes, and wind direction are the most important variables in the MA WEA. Other siting issues, such as environmental and competing use factors, may also influence array density as site development progresses.

As shown in Figure ES2, all of the leasing areas except for the deep water only leasing area in Alternate 3 have roughly the same shallow water area (less than $50 \mathrm{~m}$ ), although the area in deeper water (above 50 meters) varies considerably. This size variation in the leasing areas was allowed to preserve the straight diagonal delineations and allow the lessees to control the wind fetch in the prevailing direction. 
The wake losses for the full development scenario, using $8 \mathrm{D} \times 12 \mathrm{D}$ spacing, range from $8.3 \%$ to $10.0 \%$ in Alternative $1,7.9 \%$ to $9.9 \%$ in Alternative 2, and $7.5 \%$ to $10.0 \%$ in Alternative 3 . Over Alternatives 2 and 3, the five leasing area options' maximum nameplate development potential ranged from 1,220 $\mathrm{MW}$ to 2,295 MW. For the four leasing area option, the maximum nameplate development potential ranged from 1,695 MW to 2,955 MW; however, neither of these full development capacity assessments reflect realistic development scenarios and should only be used to compare leasing areas and understand trends. A more realistic, phased development strategy was recommended by NREL. In Section 5, NREL assessed each leasing area and assumed that two 500-MW wind facilities would be built over a time frame of 6 to 16 years. This would result in a total maximum capacity of the entire WEA of 5,000 MW. Phase 1 assumed that one 500-MW project was installed in 6 to 8 years in shallower water, and phase 2 installed another 500-MW project in 10 to 16 years in each leasing area in deeper water. The development time periods were derived from review of the Call nominations. The 500-MW phase 1 projects were analyzed first (in the absence of phase 2 projects), and then both phase 1 and 2 were assessed together in all leasing areas.

The results of these analyses are given in Table ES2, Table ES3, and Table ES4 and are further summarized in Table ES5. Table ES5 gives the array efficiencies for all of the OpenWind wake analyses conducted by NREL. The array efficiency values that are presented in Table ES3 provide a measure of how well the array is performing as a whole than how it would be expected to perform if each turbine were operating with perfect exposure to the freestream wind with no obstructions from other wind turbines.

Table ES5. MA WEA Array Efficiency Analysis for Three Leasing Area Alternatives and Three Turbine Grid Spacing Geometries (Source: NREL)

\begin{tabular}{|c|c|c|c|c|c|c|}
\hline \multicolumn{7}{|c|}{ Array Efficiency (\%) } \\
\hline Full Development & \multicolumn{2}{|c|}{ Alternative 1 } & \multicolumn{2}{c|}{ Alternative 2 } & \multicolumn{2}{c|}{ Alternative 3 } \\
\hline 8 D x 8 D & \multicolumn{2}{|c|}{88.6} & \multicolumn{2}{c|}{88.7} & \multicolumn{2}{c|}{89.0} \\
\hline 8 D x 12 D & \multicolumn{2}{|c|}{90.9} & \multicolumn{2}{c|}{91.1} & 91.2 \\
\hline 8 D x 15 D & \multicolumn{2}{|c|}{92.0} & \multicolumn{2}{c|}{92.2} \\
\hline Phased Development & Phase 1 & Phase 2 & Phase 1 & Phase 2 & Phase1 & Phase 2 \\
& $500 \mathrm{MW}$ & $1,000 \mathrm{MW}$ & $500 \mathrm{MW}$ & $1,000 \mathrm{MW}$ & $500 \mathrm{MW}$ & $1,000 \mathrm{MW}$ \\
\hline 8 D x 8 D & 94.0 & 93.0 & 93.3 & 92.3 & 94.0 & 92.9 \\
\hline 8 D x 12 D & 94.7 & 93.7 & 94.1 & 93.2 & 94.7 & 93.3 \\
\hline 8 D x 15 D & 95.0 & 94.0 & 94.6 & 92.3 & 95.0 & 93.8 \\
\hline
\end{tabular}




\section{Key Findings}

Below are the key findings of NREL's assessment of the MA WEA, which provide considerations for BOEM, policy makers, and stakeholders involved in the Massachusetts offshore wind energy development process.

- Massachusetts is the largest BOEM WEA under consideration at this time $\left(3,006.7 \mathrm{~km}^{2}\right)$ and can feasibly accommodate at least ten 500-MW wind projects $(5,000 \mathrm{MW})$ under a phased development scenario using up to five leasing areas.

- The biggest challenge for offshore wind developers in the MA WEA will be water depths that range between 35 and $65 \mathrm{~m}$.

- The MA WEA can be delineated into four to five leasing areas with equitable divisions of shallower water (less than $50 \mathrm{~m}$ ), wind resource potential, and exposure to unobstructed free stream prevailing wind (Alternative 3 is an exception, with leasing area 5 presenting a potential upwind obstruction).

- The leasing areas in the western part of the MA WEA may have a greater advantage if export cable interconnection points off Cape Cod and the islands are favored. It may be prudent for state or federal regulators to consider options for coordinating cable routing strategies and possible easements among the leasing areas. Within the MA WEA, interconnect access could be a strong driver in appraising leasing area value.

- The maximum nameplate development capacity for Alternatives 2 and 3, the five leasing area options, ranged from 1,220 MW to 2,295 MW. For Alternative 1, the four leasing area option, the maximum nameplate development potential ranged from 1,695 MW to 2,955 MW. This represents a large overall disparity in total area per lease area, even though the shallower water (less than $50 \mathrm{~m}$ ) is balanced to within $5 \%$ for each alternative.

- Diagonal delineations (45 degrees to the BOEM leasing grid) appear to offer the most efficient delineation strategy to create equitable divisions of water by depth, and to minimize inter-array conflicts caused by wake effects.

- The average annual wind speed for the MA WEA ranged from $9.2 \mathrm{~m} / \mathrm{s}$ to $9.4 \mathrm{~m} / \mathrm{s}$, with the highest wind speeds in the eastern areas and the lowest wind speeds in the western areas. For each alternative, this corresponds to a typical range of capacity factors between $45 \%$ and $47 \%$ across the WEA after wake losses are subtracted using $8 \mathrm{D} \times 12 \mathrm{D}$ spacing for a full development scenario.

- Total wake losses from projects developed at $8 \mathrm{D}$ x $12 \mathrm{D}$ spacing in all leasing areas of the MA WEA were computed to range between 6\% and 8\% when 1,000 MW in two 500-MW phases were installed in each leasing area. Wake losses in the MA WEA appear to be lower than other areas studied in the mid-Atlantic because of higher average wind speeds and a distribution of more unidirectional prevailing winds (Musial et al. 2013b and Musial et al. 2013c).

- The grid orientation angle was found to have a negligible impact on array efficiency $(<0.1 \%)$ using the OpenWind model with $8 \mathrm{D}$ x $12 \mathrm{D}$ spacing and $10 \%$ turbulence intensity. The best grid orientation angle was 60 degrees for the $8 \mathrm{D} \times 12 \mathrm{D}$ array, but the true impacts of 
variable turbulence intensity are not effectively captured in OpenWind. A more rigorous array analysis approach is recommended for developers in this area.

- Wake losses increased with decreased turbine spacing, as expected. For the full development scenarios in each alternative, wake losses averaged $7.8 \%$ for the $8 \mathrm{D} \times 15 \mathrm{D}$ spacing and $11.2 \%$ for the $8 \mathrm{D}$ x $8 \mathrm{D}$ spacing. Most of this impact can be accounted for by lower array power density with the wider spacing.

- Additional turbine spacing may have diminishing benefits when multiple large arrays are sited near each other - this is because the benefits of turbine spacing are offset by reductions in the buffers that separate neighboring wind plants.

- Additional development cost will be introduced with wider spacing as the result of longer cable length, greater water depths, and farther distances from shore. These costs should be carefully weighed against the added energy from higher array efficiency.

\section{Recommendations}

NREL's recommendations for the MA WEA are as follows.

- Of the three alternatives, NREL prefers Alternative 2 because it is believed that the development potential of the WEA would be maximized while minimizing the effects of neighboring projects on adjacent wind plants. With the five leasing area option, each area could support at least two 500-MW projects, and some could support three, depending on the spacing.

- Any of the alternatives assessed in this report would be feasible and may be preferable to Alternative 2 for a given set of objectives.

- NREL recommends that BOEM consider methods to discount the deepest aliquots to address the probable time lag in development caused by added cost and complexity of building turbines in deeper water.

The analysis in this report is coarse by industry standards, therefore it is recommended that prospective lessees conduct more rigorous analysis on wake losses before judging the values of these leasing areas. This enhanced analysis should consider diurnal, seasonal, and annual variations as well as a full cost assessment to examine the additional cost of added cable length. In addition, NREL recommends conducting further analysis on wake losses with respect to atmospheric stability conditions. 


\section{Table of Contents}

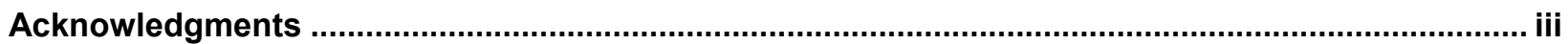

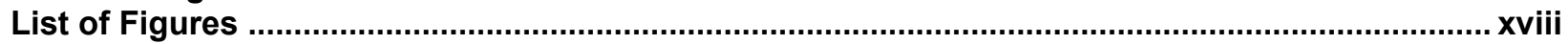

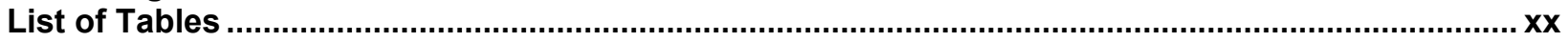

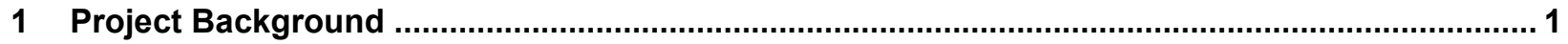

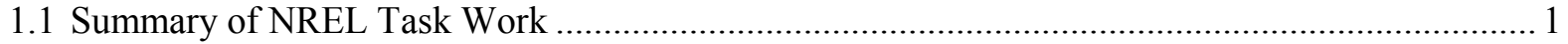

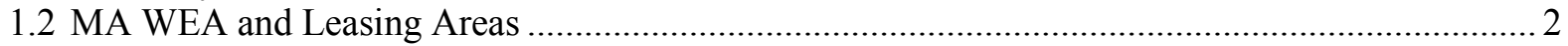

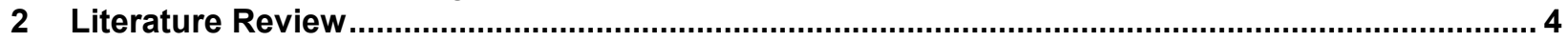

2.1 NREL Review of the Massachusetts RFI and Call ................................................................ 4

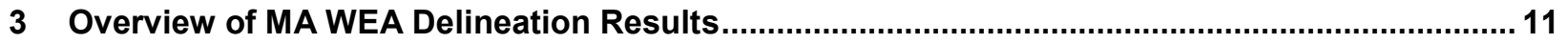

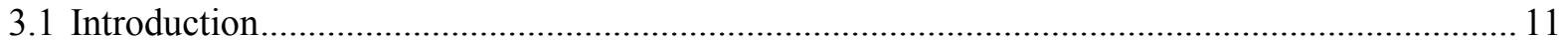

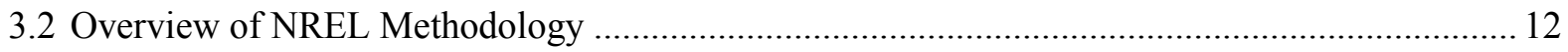

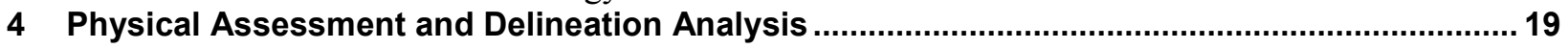

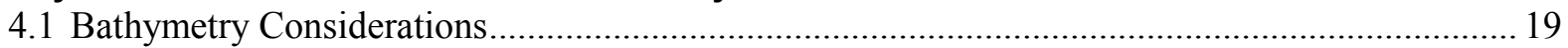

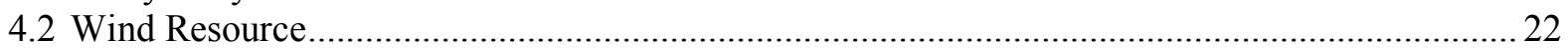

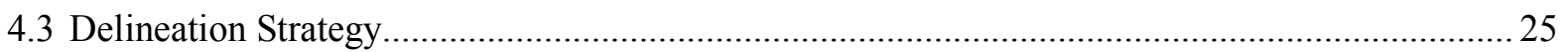

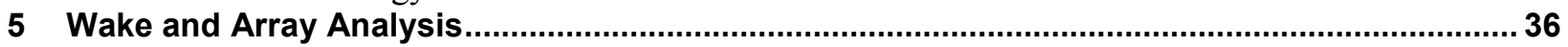

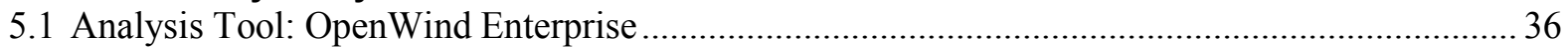

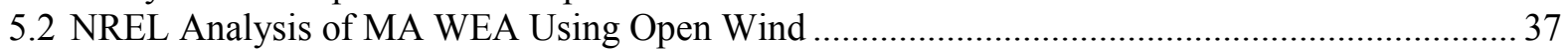

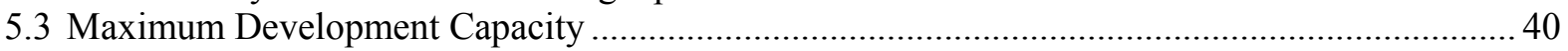

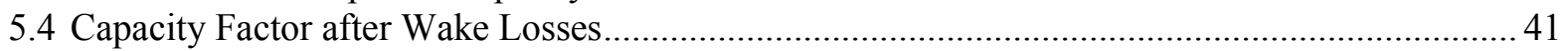

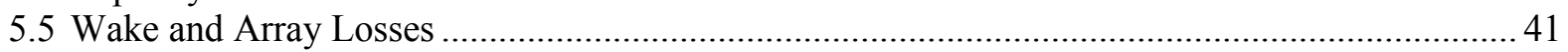

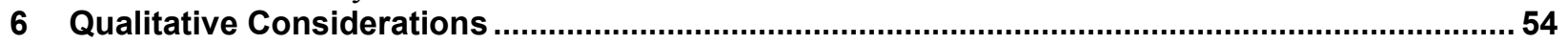

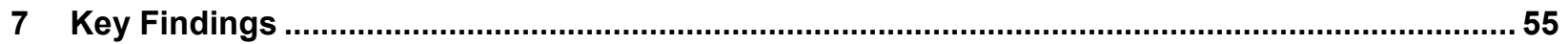

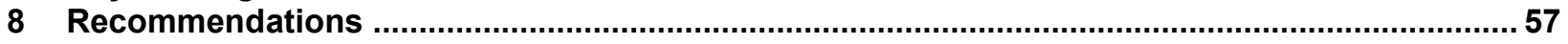

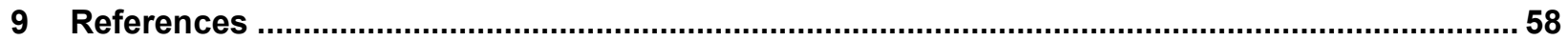

\section{List of Figures}

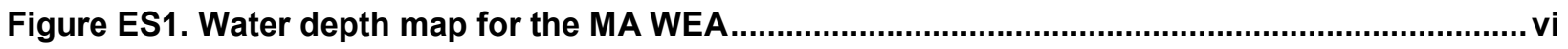

Figure ES2. The three leasing area delineation options that NREL analyzed include: Alternative 1, four diagonal leasing areas; Alternative 2, five diagonal leasing areas; Alternative 3, five leasing areas with one deep area. The lighter green color indicates water depths below $50 \mathrm{~m}$ and the darker green color indicates water depth above $50 \mathrm{~m}$. The MA WEA wind rose is shown at the top right.

Figure 1. Massachusetts (MA) Wind Energy Area (WEA) as defined in February 2012 .................... 3

Figure 2. Evolution of the MA WEA boundaries from February 2011 to the present.

Figure 3. Average turbine array density for 18 European offshore wind power projects. Red lines indicate the array density for the spacing scenarios used in the MA WEA assessment.

Figure 4. Three delineation options used in the MA WEA assessment. Alternative 1: Four leasing areas with diagonal delineation; Alternative 2: Five leasing areas with diagonal delineations;

Alternative 3: Five leasing areas with deep water carve out ..........................................................13

Figure 5. Water depth map for the MA WEA

Figure 6. Current offshore wind projects in Europe: installed, under construction, contracted, and approved as a function of expected commercial operation date..

Figure 7. Histogram of water depths for the MA WEA showing water depths ranging from $30 \mathrm{~m}$ to $65 \mathrm{~m}$ for the total WEA using May 2012 boundaries $\left(3,006.7 \mathrm{~km}^{2}\right)$

This report is available at no cost from the National Renewable Energy Laboratory (NREL) xviii at www.nrel.gov/publications. 
Figure 8. (top) MA WEA showing the annual average wind speed in $0.10 \mathrm{~m} / \mathrm{s}$ increments and (bottom) the wind frequency rose with prevailing winds from the southwest direction

Figure 9. Alternative 1: Four leasing areas with approximately equal shallow water area less than $50 \mathrm{~m}$

Figure 10. Alternative 1: Distribution of area among four leasing areas showing approximately equal shallow water less than $50 \mathrm{~m}$ (maximum variation of shallow water area $=\mathbf{5 \%}$ ).

Figure 11. Alternative 1: Plot showing depth distribution for each leasing area over the entire MA WEA. Shaded area indicates depths that are greater than $50 \mathrm{~m}$.

Figure 12. Alternative 2: Five leasing areas with approximately equal division of shallow water area less than $\mathbf{5 0 ~} \mathrm{m}$

Figure 13. Alternative 2: Distribution of area among five leasing areas showing approximately equal shallow water less than 50 meters (Maximum 1.58\% variation)

Figure 14. Alternative 2: Plot showing depth distribution for each leasing area over the entire depth range. Shaded area indicates depths that are greater than $50 \mathrm{~m}$.

Figure 15. Alternative 3: Five leasing areas with four approximately equal shallow areas and one area containing only deep water

Figure 16. Alternative 3: Distribution of area among five leasing areas showing approximately equal shallow water less than $50 \mathrm{~m}$ in leasing areas 1-4 with a maximum variation of $5 \%$.

Figure 17. Alternative 3: Depth distribution for five leasing areas with four approximately equal shallow areas and one area containing only deep water. Shaded area indicates water depth greater than $50 \mathrm{~m}$.

Figure 18. MA WEA layout map for the $8 \mathrm{D} \times 12 \mathrm{D}$ full build (development) scenario using the Alternative 3 delineation scenario showing the maximum nameplate capacity, wake losses, and expected annual energy production for each of the five leasing areas

Figure 19. Horns Rev I wind farm

Figure 20. OpenWind uses the BOEM leasing grid as a reference frame for the grid orientation angle of the turbine array. The example shown is for $8 \mathrm{D} \times 8 \mathrm{D}$ spacing with a 75-degree grid angle. The MA WEA grid angles were found to be 60 degrees for minimum wake losses.

Figure 21. Comparison of OpenWind array efficiency results for the two five leasing area delineation alternatives of the MA WEA using $8 \mathrm{D} \times 12 \mathrm{D}$ turbine spacing under a full development scenario

Figure 22. Alternative 2 delineation layouts for phase 1 and phase 2 development building two 500-MW projects per leasing area. Projects are shown with 8 D x 8 D, 8 D x 12 D, and 8 D x 15 D spacing.

Figure 23. Alternative 3 delineation layouts for phase 1 and phase 2 development building two 500-MW projects per leasing area. Projects are shown with 8 D x 8 D, 8 D x 12 D, and 8 D x 15 D spacing.

Figure 24. MA WEA for Alternative 2 leasing area delineation showing the effect of turbine spacing and buffers on array efficiencies with two 500-MW projects in each leasing area: (A) 8 D x 8 D spacing; (B) 8 D x 12 D spacing; and (C) 8 D x 15 D spacing. .51

Figure 25. MA WEA for Alternative 3 leasing area delineation showing the effect of turbine spacing and buffers on array efficiencies with two 500-MW projects in each leasing area: (A) 8 D $\times 8$ D spacing; (B) 8 D x 12 D spacing; (C) 8 D x 15 D spacing 


\section{List of Tables}

Table ES1. Evaluation Criteria Used to Assess the Massachusetts (MA) WEA ............................... vi

Table ES2. MA WEA Delineation Analysis for Alternative 1 ......................................................... ix

Table ES3. MA WEA Delineation Analysis for Alternative 2 ...............................................................

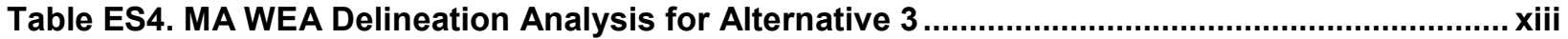

Table ES5. MA WEA Array Efficiency Analysis for Three Leasing Area Alternatives and Three Turbine Grid Spacing Geometries ........................................................................................

Table 1. Summary of RFI Statistics from the Eight Massachusetts (MA) Wind Energy Area (WEA) Responses.

Table 2. Summary of Call Statistics from 10 MA WEA Responses................................................ 7

Table 3. List of 18 of the Largest Offshore Wind Power Projects (>200 MW Capacity) and Average Turbine Density Used By Each Project ............................................................................... 10

Table 4. Evaluation Criteria Used by NREL to Assess the MA WEA .............................................11

Table 5. MA WEA Delineation Analysis for Alternative 1 ........................................................ 14

Table 6. MA WEA Delineation Analysis for Alternative 2 .......................................................... 16

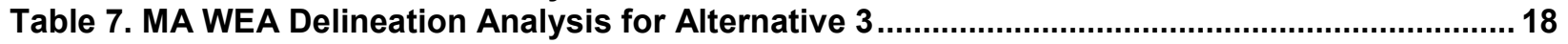

Table 8. Alternative 1: Four Leasing Area Delineation for the MA WEA ......................................... 27

Table 9. Alternative 2: Five Leasing Area Diagonal Delineation for the MA WEA ........................... 30

Table 10. Alternative 3: Five Leasing Area Alternative with Separate Deep Water Site Delineation

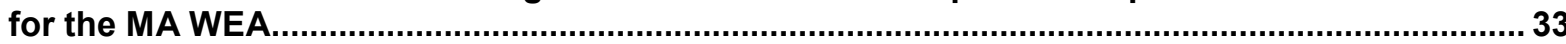

Table 11. Summary of Array Spacing Analysis Conducted to Assess Wake Losses and Energy

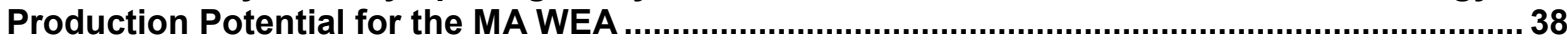

Table 12. MA WEA Array Efficiency Analysis for Three Leasing Area Alternatives and Three Turbine Grid Spacing Geometries 


\section{Project Background}

Since 2009, the U.S. Department of the Interior's Bureau of Ocean Energy Management (BOEM) has been working with intergovernmental task forces to identify the most appropriate areas for commercial wind energy leasing on the Outer Continental Shelf (OCS) off the Atlantic Coast. To date, BOEM has identified six Wind Energy Areas (WEAs) on the OCS that are considered appropriate for commercial offshore wind energy development, with a goal of minimizing conflicts with existing uses and the environment. BOEM is currently considering issuing leases for five WEAs through a competitive process: 1) Virginia, 2) Rhode Island/Massachusetts, 3) New Jersey, 4) Maryland, and 5) Massachusetts. On July 31, 2013, BOEM held the first of these competitive lease auctions for the Rhode Island/Massachusetts WEA (U.S. Department of the Interior 2013). The second auction was held for the Virginia WEA on September 4, 2013. The WEAs that have multiple leasing areas within their boundaries (all but Virginia) require further analysis using engineering tools and site-specific WEA data to ensure that the leasing areas are appropriately divided.

\subsection{Summary of NREL Task Work}

The U.S. Department of Energy's (DOE) National Renewable Energy Laboratory (NREL), under an interagency agreement between DOE and BOEM, is providing technical assistance to identify and delineate offshore leasing areas for wind energy development within the Atlantic Coast WEAs.

The overarching objectives of the interagency agreement are as follows:

1. Develop a logical process by which WEAs can be subdivided into non-overlapping leasing areas for BOEM's use in developing auction processes in a renewable energy lease sale

2. Identify the appropriate number of leasing areas recommended for lease within each WEA

3. Delineate the boundaries of the leasing areas within each WEA

4. Document the methodology (i.e., variables and assumptions) by which the leasing areas are identified and delineated for each state.

The work being performed by NREL for each WEA is based on a predetermined scope of work and uses physical site-specific data and characteristics obtained by NREL and general information and leasing parameters provided by BOEM. For Massachusetts, the interagency agreement work scope comprises several tasks to assist BOEM in making the final determination for delineating the Massachusetts (MA) WEA into leasing areas that are each capable of supporting a commercially viable project. The expectation is that the proposed delineations will provide sufficient area for modifications to the facility layout based on the results of geophysical, geological, and biological surveys that will be conducted by the developer. 
First, NREL was asked to conduct a review of information submitted in response to relevant BOEM Federal Register notices. NREL researchers, based on their expertise, were asked to determine the relevance of the information provided to the leasing area identification and delineation methodology and incorporate the information as appropriate.

Second, NREL was asked to propose a methodology for delineation of the leasing areas and the factors used to identify the number of leasing areas and the proposed delineation boundaries. On May 15, 2013, NREL made a presentation to the Massachusetts Renewable Energy Task Force to fulfill this portion of the Massachusetts work tasks (Musial 2013). The presentation described the proposed method for identifying and evaluating multiple potential leasing areas within the MA WEA and performing an independent analysis on the different delineation options. As a result of discussions at the Massachusetts Renewable Energy Task Force webinar on May 15, 2013, and follow-up conference calls that included representatives of the Massachusetts Clean Energy Center and Massachusetts Office of Coastal Zone Management, NREL obtained feedback that was used in developing the final methodology and delineation options for the MA WEA analysis.

The updated methodology included:

- Development of delineation alternatives for a four leasing area (Alternative 1) and a five leasing area scenario (Alternative 2) with equal division of shallower water [less than 50 meters $(\mathrm{m})]$ in each leasing area

- Development of a third delineation option (Alternative 3) for a five leasing area scenario consisting of four leasing areas with equal division of shallower water less than $50 \mathrm{~m}$ and one leasing area with all deeper water (greater than $50 \mathrm{~m}$ )

- Evaluation and comparison of the full development nameplate capacity potential (based on area) of the leasing areas in all delineation alternatives [in rotor diameters (D)] using $8 \mathrm{D} \times 8$ $\mathrm{D}, 8 \mathrm{D} \times 12 \mathrm{D}$, and $8 \mathrm{D} \times 15 \mathrm{D}$ turbine spacing

- Evaluation and comparison of phased developments of two 500-MW projects in each leasing area (one built earlier in 6-8 years in shallower water and one built later in 10-16 years in deeper water) and the effect of different turbine spacing configurations (8 D x $8 \mathrm{D}, 8 \mathrm{D} \times 12$ $\mathrm{D}$, and $8 \mathrm{D}$ x $15 \mathrm{D}$ ) on wake losses, energy production, and development challenges.

NREL researchers used the input from BOEM and other collaborators to help guide the analysis and subsequently worked with BOEM to integrate the findings into this report.

Finally, NREL researchers will present the findings to the BOEM Massachusetts Renewable Energy Task Force in late 2013.

\subsection{MA WEA and Leasing Areas}

BOEM has been working with the BOEM Massachusetts Renewable Energy Task Force to identify the most appropriate area for leasing offshore Massachusetts since 2009. In December 2010, BOEM published a request for interest (RFI) in the Federal Register to gauge specific interest in obtaining commercial wind leases in an area on the OCS offshore Massachusetts. BOEM received eight expressions of interest from companies potentially seeking a commercial 
lease for offshore wind energy. Working with the task force, BOEM refined the area and published a Call for Information and Nominations (referred to in this document as the "Call") in the Federal Register in February 2012. BOEM received 10 nominations of interest from companies potentially seeking a commercial lease for offshore wind energy in response to the Call. BOEM refined the area further and announced the identification of the MA WEA in May 2012. The MA WEA (area analyzed in this report) comprises 742,974 acres, or 3,006.7 square kilometers $\left(\mathrm{km}^{2}\right)$, and is shown in Figure 1. It is intended to provide for the protection of ecologically sensitive areas and minimize user conflicts while making an appropriate area available for commercial offshore wind energy development. BOEM is proposing to hold a lease sale to auction the MA WEA and issue leases that correspond to the entire identified WEA.

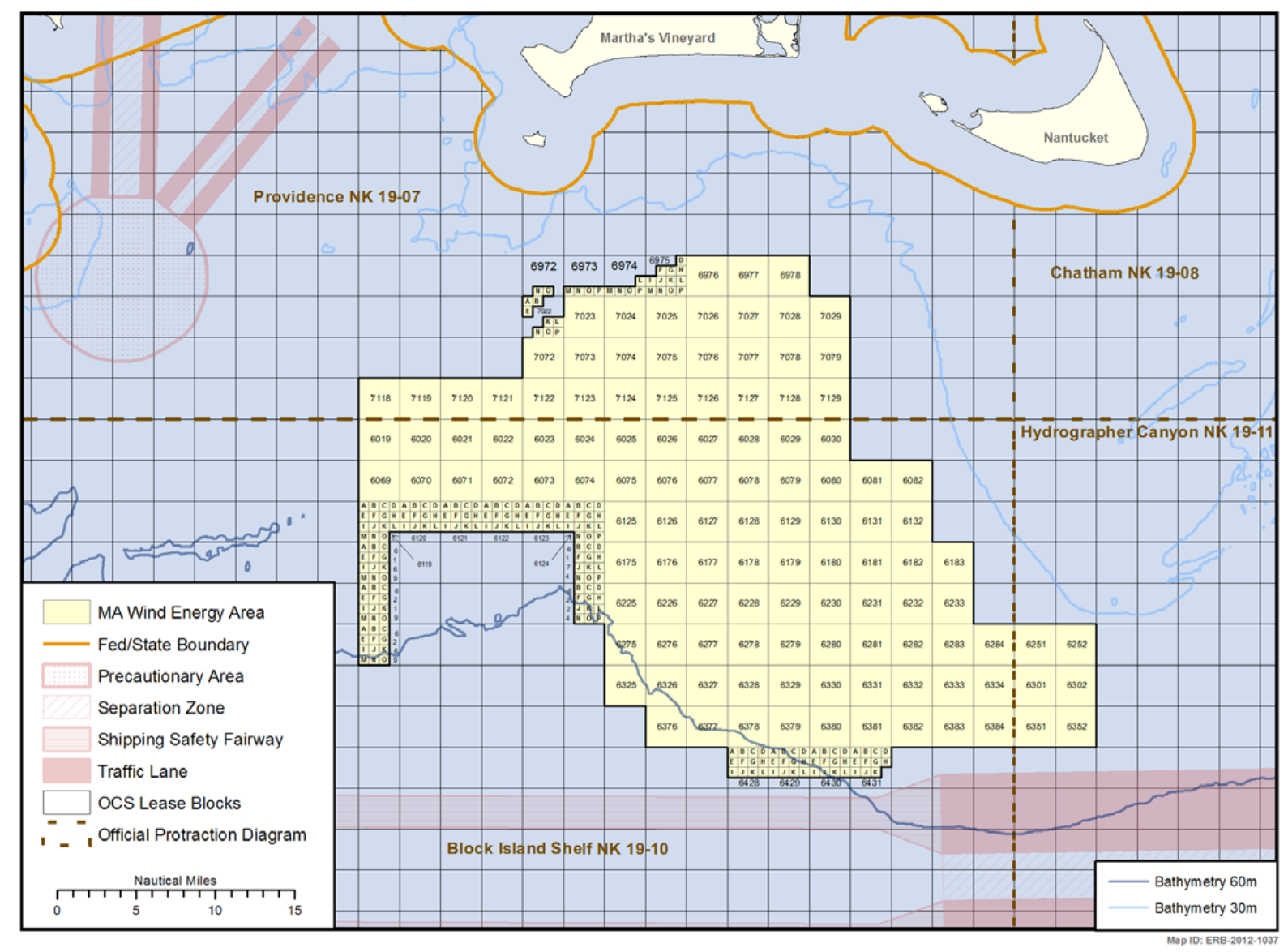

Figure 1. Massachusetts (MA) Wind Energy Area (WEA) as defined in May 2012 (Source: BOEM)

BOEM provided NREL with the MA WEA coordinates for evaluation and recommended that NREL assess multiple potential offshore wind development leasing areas within the WEA. NREL's evaluation of the proposed leasing area delineations focused on relevant technical criteria included total energy production capacity, wake losses, project size, array density, and water depth, as well as several qualitative criteria listed in Table 3. 


\section{Literature Review}

In addition to the references cited in Section 9 of this report, NREL researchers reviewed the following documents and communications:

- The RFI published by BOEM in the Federal Register in December 2010 for offshore Massachusetts and eight responses to the RFI

- The Call published by BOEM in the Federal Register in February 2012 and 10 responses to the Call

- The final MA WEA coordinates developed by BOEM and announced in May 2012

- Presentations delivered at the Massachusetts Renewable Energy Task Force webinar held on May 15, 2013

- Verbal input received from the Massachusetts Clean Energy Center and Massachusetts Office of Coastal Zone Management on May 20, 2013, and follow-up discussions.

\subsection{NREL Review of the Massachusetts RFI and Call}

NREL was granted confidential access to the eight responses to the 2010 RFI that were submitted in February 2011, and 10 responses to the 2011 Call that were submitted in March 2012. These nominations provided insight into the commercial sector considerations for offshore development and wind energy leasing area delineation in the MA WEA. The number of responses generally demonstrated that there is interest in the MA WEA and revealed aspects about broad-scale development project size, turbine size placement, and to some degree, the type of technology that might be used.

A major caveat in the interpretation of data extracted or derived from the MA developers' responses is that the three areas: 1) the RFI area, 2) the Call area, and 3) the May 2012 WEA, which is analyzed in this report, all differ in size and characteristics. Figure 2 shows how the MA WEA boundaries evolved from the time that the RFI was released in December 2010 (far left) to the present area of analysis (May 2012 far right). For this report, NREL assumed developers would not necessarily have anticipated these changes to the WEA, and that they probably believed their projects could be adapted relatively easily to unforeseen modifications within similar boundaries. 


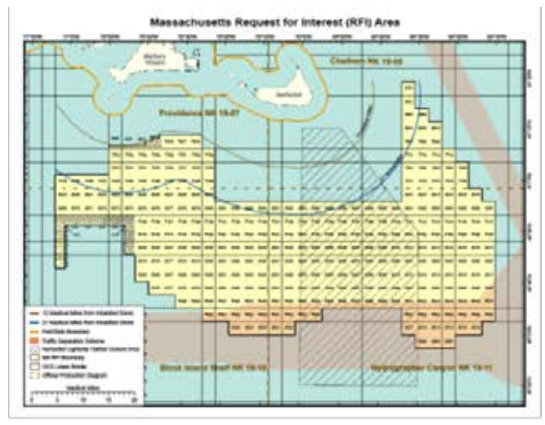

Request for Interest Area (RFI)

8 responses

February 2011

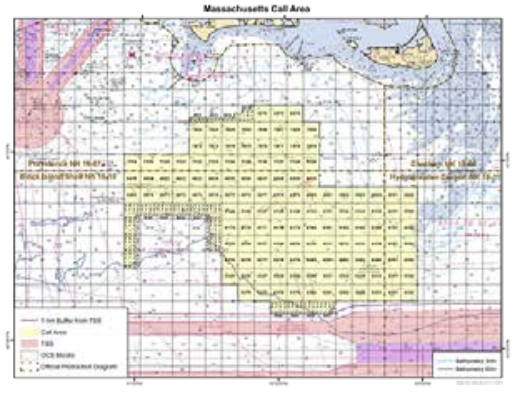

Call for Nominations Area

10 responses

March 2012

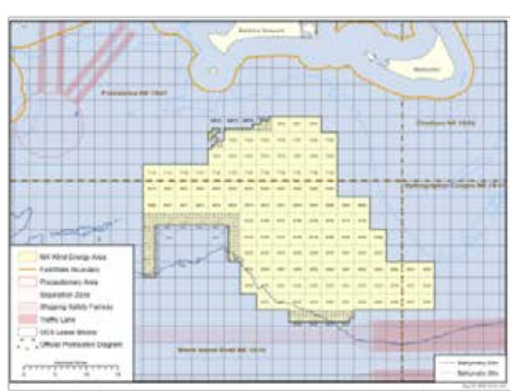

Current Wind Energy Area

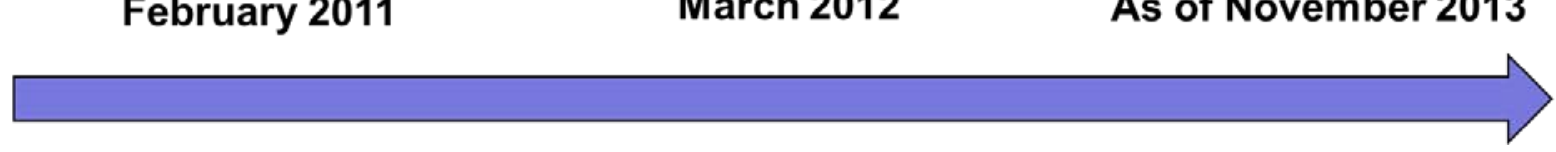

Figure 2. Evolution of the MA WEA boundaries from February 2011 to November 2013

(Source: BOEM)

Aside from the large reduction in the size of the WEA from the RFI boundaries, one significant change that occurred during the MA WEA modifications was that all of the areas with water depths below $30 \mathrm{~m}$ were excluded. Most of the RFI and Call responses referred to projects that were intended to be located in these shallower water lease blocks using conventional foundation and substructure technology. However, with these shallow lease blocks removed in the present WEA (May 2012), it is uncertain how these projects would be adapted. It is also important to note that the RFI and Call responses were based on the undelineated WEA without knowledge of how neighboring wind projects might encroach upon their facility. Developer interests might differ significantly from the responses to the RFI and Call under an auction process when constrained by specific leasing area boundaries. As a result, extrapolations based on these responses may not accurately predict all the current MA WEA development scenarios.

Nevertheless, NREL found the evaluations of the RFI and Call nominations to be informative. Although, the information provided varied significantly and typically did not contain a high level of detail about the technology or expected turbine performance, the responses were useful in highlighting trends related to siting constraints, turbine size, support structure technology (e.g., fixed bottom or floating), project capacity, development schedule, array density, and interconnection points. NREL researchers also considered other factors, such as meteorological information and distance from shore; however, researchers did not consider potential competing use conflicts with organizations like the U.S. Department of Defense and U.S. Coast Guard, or with fisheries or other existing stakeholders that have the potential to introduce further unforeseen use restrictions that could be imposed at a later date and affect the potential value of the lease areas. 
A summary of the RFI and Call data statistics is shown in Table 1 and Table 2. Because of confidentiality requirements, the project data from the individual industry responses were reduced to statistical averages and maximum and minimum values. The latter indicate a wide variety of specifications for the proposed projects. The statistical averages were compared to the nominal values used in the NREL analysis. In many cases, the individual responses did not contain all of the information reported in Tables 1 and 2, or the data could not be found. Therefore, only the responses that contained these data are represented in the table.

Table 1. Summary of RFI Statistics from the Eight Massachusetts (MA) Wind Energy Area (WEA) Responses (Source: NREL)

\begin{tabular}{|c|c|c|c|c|}
\hline & Average & Maximum & Minimum & $\begin{array}{l}\text { NREL } \\
\text { Values }\end{array}$ \\
\hline $\begin{array}{l}\text { Project nameplate capacity in megawatts } \\
\text { (MW) }\end{array}$ & 1,503 & 3,000 & 507 & 5,000 \\
\hline Turbine nameplate capacity (MW) & 4.9 & 6.0 & 3.6 & 5.0 \\
\hline Wind speed $(\mathrm{m} / \mathrm{s})$ at hub height & 9.34 & 9.75 & 8.9 & 9.35 \\
\hline Net capacity factor (\%) & 41 & 43 & 40 & $45-48$ \\
\hline Project area $\left(\mathrm{km}^{2}\right)$ & 1,112 & 2,004 & 240 & $3,006.7$ \\
\hline Array power density (MW/ $\left.\mathrm{km}^{2}\right)$ & 2.36 & 5.34 & 0.6 & 1.66 \\
\hline Turbine array spacing & $\begin{array}{l}8.5 x \\
10.5\end{array}$ & $8 \times 12$ & $9 \times 9$ & $\begin{array}{c}8 \times 8 ; 8 \times \\
12 ; 8 \times 15\end{array}$ \\
\hline Project development time (years) & 8.4 & 12 & 6 & NA \\
\hline \multicolumn{5}{|c|}{$\begin{array}{l}\text { Notes: } \\
\text { - NREL values represent Alternative } 2 \text { and } 3 \text { only, the five leasing area delineations } \\
\text { - The net capacity factor reported in the NREL values is the gross capacity factor after } \\
\text { subtracting wake losses only (e.g., electrical losses not included) } \\
\text { - NREL used the whole wind energy area }\end{array}$} \\
\hline
\end{tabular}


Table 2. Summary of Call Statistics from 10 MA WEA Responses

(Source: NREL)

\begin{tabular}{|c|c|c|c|c|}
\hline & Average & Maximum & Minimum & $\begin{array}{l}\text { NREL } \\
\text { Values }\end{array}$ \\
\hline Project nameplate capacity (MW) & 1,524 & 3,000 & 1,000 & 5,000 \\
\hline Turbine nameplate capacity (MW) & 5.63 & 7.0 & 5.0 & 5.0 \\
\hline Wind speed $(\mathrm{m} / \mathrm{s})$ at hub height & 9.3 & 9.75 & 8.8 & 9.35 \\
\hline Net capacity factor (\%) & 40 & 40 & 40 & $45-48$ \\
\hline Project area $\left(\mathrm{km}^{2}\right)$ & 1,026 & 2,004 & 240 & $3,006.7$ \\
\hline Array power density $\left(\mathrm{MW} / \mathrm{km}^{2}\right)$ & 2.27 & 4.33 & 0.54 & 1.66 \\
\hline Turbine array spacing & $8.5 \times 10.5$ & $8 \times 12$ & $9 \times 9$ & $\begin{array}{c}8 \times 8 ; 8 \times \\
12 ; 8 \times 15\end{array}$ \\
\hline Project development time (years) & 9.1 & 16 & 7 & NA \\
\hline \multicolumn{5}{|c|}{$\begin{array}{l}\text { Notes: } \\
\text { - NREL values represent Alternatives } 2 \text { and } 3 \text { only, the five leasing area delineations } \\
\text { - The net capacity factor reported in the NREL values is the gross capacity factor after } \\
\text { subtracting wake losses only (e.g., electrical losses not included) } \\
\text { - NREL used the whole wind energy area }\end{array}$} \\
\hline
\end{tabular}

Note that project sizes in the responses tended to be large, with a range from 1,000 megawatts (MW) to 3,000 MW for individual developers. These data indicate a desire for developers to build large multi-phased facilities rather than clusters of small projects as was seen in the early years of offshore wind in Europe.

Development time is another parameter that researchers evaluated from the RFI and Call responses. Development times ranged from 6 to 16 years for all of the RFI and Call nominations reviewed. Since most developers assumed that they would have access to shallower water, it is likely that these times could increase because deeper water can impose additional challenges to development. The NREL analysis assumes that development times will be shorter for shallower projects and longer for deeper projects as the costs are currently higher and the technology is less mature for deep sites.

Although not given in Table 1 and Table 2, the vast majority of the developers' responses indicated a preference for fixed-bottom substructure technology even in the deeper waters. The absence of floating wind turbine technology proposals, which would be less depth-dependent, would indicate that even a multiphased project approach would tend to favor the more shallow regions of a given leasing area. We elaborate on this assumption later when it is used in developing the phased development of the 500-MW arrays and the siting scenarios used to calculate wake losses. 
In Table 1 and Table 2, the "NREL Values" are based on a standard set of assumptions that have been used in the previous delineation analyses and reports NREL conducted for BOEM, except for some unique parameters that were introduced specifically for Massachusetts. Specifically, the base-case turbine array spacing was chosen to be $8 \mathrm{D} \times 12 \mathrm{D}$ for Massachusetts, which is wider spacing than the typical $8 \mathrm{D} \times 8 \mathrm{D}$ spacing used for the gross resource estimations carried out in 2010 (Schwartz et al. 2010) and which was used as the base case in the Rhode

Island/Massachusetts and Maryland wind energy areas (Musial et al. 2013a, Musial et al. 2013b). For the New Jersey analyses, a wider base-case array spacing of $10 \mathrm{D} \times 12 \mathrm{D}$ was used at the request of the New Jersey Renewable Energy Task Force (Musial et al. 2013c). Both the 8 D x 8 $\mathrm{D}$ spacing and the $8 \mathrm{D} \times 12 \mathrm{D}$ spacing are comparable to the turbine array spacing that is typical for many European offshore wind facilities as shown in Figure 3.

The RFI and Call notices did not specifically ask for the responses to quantify array spacing. Therefore, very few responses included this information, making it difficult to establish a clear trend in commercial project array spacing for Massachusetts. However, Figure 3 shows that when examining actual data from existing European projects, a preferred trend in array spacing is not apparent. In 17 European offshore wind projects and including Cape Wind (Cape Wind 2013), ranging in size from 160 to $630 \mathrm{MW}$, the average wind turbine density ranges from 3.5 to $8.8 \mathrm{MW} / \mathrm{km}^{2}$ (Figure 3 and Table 3 ) based on turbine array spacing only. These 18 projects represent all of the existing offshore wind plants over $200 \mathrm{MW}$ in nameplate capacity for which turbine array spacing data were available. The mean turbine density for all 18 projects is 6.1 $\mathrm{MW} / \mathrm{km}^{2}$. By comparison, the turbine density used in the MA WEA assessment is $5 \mathrm{MW} / \mathrm{km}^{2}$ for $8 \mathrm{D} \times 8 \mathrm{D}$ spacing, $3.3 \mathrm{MW} / \mathrm{km}^{2}$ for $8 \mathrm{D} \times 12 \mathrm{D}$ spacing, and $2.6 \mathrm{MW} / \mathrm{km}^{2}$ for $8 \mathrm{D} \times 15 \mathrm{D}$ spacing. Specifically, the $8 \mathrm{D} \times 12 \mathrm{D}$ baseline spacing adopted by NREL for the MA WEA assessment results in lower wake losses and provides a more conservative (lower) estimate of potential development capacity than the $8 \mathrm{D}$ x $8 \mathrm{D}$ spacing used by NREL in other similar studies.

A better metric for comparison of array density may be total array power density (APD) as provided in Table 1 and Table 2. These data were available for all proposed projects in the RFI and Call responses as each developer specified the project nameplate capacity they are planning and the footprint it would occupy within the Call area. In many cases, individual developers specified the nameplate capacity in multiple phases. For this analysis, the APD values were derived simply from the total project nameplate capacity in megawatts divided by the total project area proposed for each project in kilometers squared. APD comprises both the array spacing and any additional buffer zones that the developer included. As such, these values indicate a lower density than the turbine array density, which just includes the spacing in between turbines. Wake loss findings shown in Section 5 indicate that losses are mitigated through a combined use of array spacing and buffers between projects. For the MA WEA Call responses in Table 2, the APD was computed by NREL to range between $0.54 \mathrm{MW} / \mathrm{km}^{2}$ and 4.33 $\mathrm{MW} / \mathrm{km}^{2}$, with an average of $2.2 \mathrm{MW} / \mathrm{km}^{2}$. This compares to NREL's analysis of the MA WEA, which has an average overall APD of $1.66 \mathrm{MW} / \mathrm{km}^{2}$. 


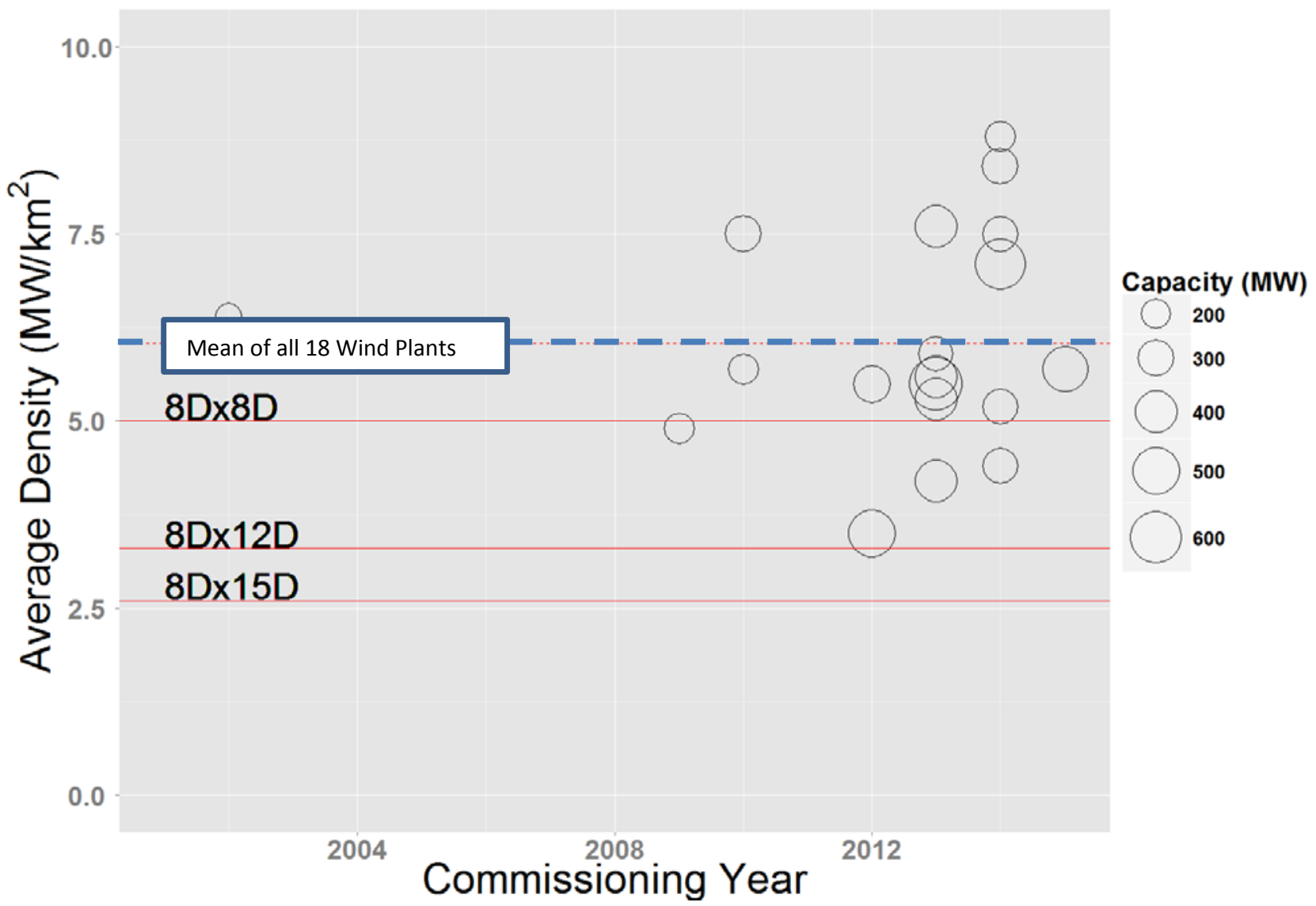

Figure 3. Average turbine array density for 18 European offshore wind power projects and Cape Wind. Red lines indicate the array density for the spacing scenarios used in the MA WEA assessment

(Source: NREL) 
Table 3. List of 18 of the Largest Offshore Wind Power Projects (>200 MW Capacity) and Average Turbine Density Used By Each Project

(Source: NREL)

\begin{tabular}{|c|c|c|c|c|c|}
\hline Country & Name of Wind Farm & $\begin{array}{l}\text { Installed } \\
\text { Capacity } \\
\text { (MW) }\end{array}$ & $\begin{array}{l}\text { Area of } \\
\text { Wind } \\
\text { Farm } \\
\left(\mathrm{km}^{2}\right)\end{array}$ & $\begin{array}{l}\text { Average } \\
\text { Turbine } \\
\text { Density } \\
\left(\mathrm{MW} / \mathrm{km}^{2}\right)\end{array}$ & $\begin{array}{l}\text { Commissioning } \\
\text { Date (year) }\end{array}$ \\
\hline $\begin{array}{l}\text { United } \\
\text { Kingdom }\end{array}$ & London Array 1 & 630 & 100 & 5.5 & 2013 \\
\hline $\begin{array}{l}\text { United } \\
\text { Kingdom }\end{array}$ & Gwynt y Mor & 576 & 79 & 7.1 & 2014 \\
\hline $\begin{array}{l}\text { United } \\
\text { Kingdom }\end{array}$ & Greater Gabbard & 504 & 147 & 3.5 & 2012 \\
\hline United States & Cape Wind & 468 & 62 & 5.7 & 2015 \\
\hline Germany & Bard & 400 & 59 & 5.3 & 2013 \\
\hline Germany & Borkum West 2 & 400 & 56 & 5.6 & 2013 \\
\hline Germany & Global Tech 1 & 400 & 41 & 7.6 & 2013 \\
\hline Denmark & Anholt & 399.6 & 88 & 4.2 & 2013 \\
\hline $\begin{array}{l}\text { United } \\
\text { Kingdom }\end{array}$ & Sheringham Shoal & 316.8 & 35 & 5.5 & 2012 \\
\hline $\begin{array}{l}\text { United } \\
\text { Kingdom }\end{array}$ & Thanet & 300 & 35 & 7.5 & 2010 \\
\hline Germany & Nordsee Ost & 295.2 & 24 & 8.4 & 2014 \\
\hline Germany & Baltic 2 & 288 & 30 & 7.5 & 2014 \\
\hline Germany & Dantysk & 288 & 66 & 4.4 & 2014 \\
\hline Germany & $\begin{array}{l}\text { Meerwind Sud und } \\
\text { Ost }\end{array}$ & 288 & 42 & 5.2 & 2014 \\
\hline $\begin{array}{l}\text { United } \\
\text { Kingdom }\end{array}$ & Lincs & 270 & 35 & 5.9 & 2013 \\
\hline Belgium & Northwind & 216 & 14.5 & 8.8 & 2014 \\
\hline Denmark & Horns Rev 2 & 209.3 & 33 & 4.9 & 2009 \\
\hline Denmark & Rodsand 2 & 207 & 34 & 5.7 & 2010 \\
\hline
\end{tabular}




\section{Overview of MA WEA Delineation Results}

\subsection{Introduction}

The primary objectives of the NREL interagency agreement were to:

- Develop a technical methodology and approach to delineate leasing areas within the MA WEA, such that the leasing areas — when aggregated — are equal to the total area within the WEA

- Evaluate different delineation options, which includes considering the various internal and external physical factors of the defined leasing areas, and identify the advantages and disadvantages of each option.

As explained in Section 1, NREL obtained feedback that was used in developing the final methodology and delineation options for the analysis of the MA WEA following feedback from BOEM, the Massachusetts Renewable Energy Task Force, and Massachusetts state agencies of NREL's proposed methodology.

For each of the delineation alternatives, several quantitative and qualitative evaluation criteria were examined. These criteria are listed in Table 4. Some of these criteria relate to the physical characteristics of the MA WEA and are discussed in Section 4 while other criteria relate primarily to specific wake losses and array spacing assumptions and are covered in Section 5.

Table 4. Evaluation Criteria Used by NREL to Assess the MA WEA (Source: NREL)

\begin{tabular}{|ll|}
\hline \multicolumn{1}{|c|}{ Quantitative Evaluation Criteria } & \multicolumn{1}{c|}{ Qualitative Evaluation Criteria } \\
\hline Total area $\left(\mathrm{km}^{2}\right.$ and acres) & Distance from shore \\
\hline Maximum nameplate capacity (MW) & Technology challenges \\
\hline Bathymetry $(\mathrm{m})$ & Development cost \\
\hline $\begin{array}{l}\text { Annual average wind speed and direction [meters per } \\
\text { second ( } \mathrm{m} / \mathrm{s}) \text { ] }\end{array}$ & Interconnection logistics \\
\hline 500-MW phased developments & Development timing \\
\hline Wake losses (\%) and array efficiency & \\
\hline Array orientation angle (degrees) & \\
\hline Turbine spacing within array (D) & \\
\hline Capacity factor after wake losses (\%) & \\
\hline Annual energy production [gigawatt-hours (GWh)] & \\
\hline
\end{tabular}


For each leasing area option, NREL evaluated and compared the full development potential using $8 \mathrm{D} \times 8 \mathrm{D}, 8 \mathrm{D} \times 12 \mathrm{D}$, and $8 \mathrm{D} \times 15 \mathrm{D}$ turbine spacing. The full development of the entire WEA (without including internal buffers) was not considered a reasonable assumption for actual development, and NREL felt that decisions based solely on maximum development potential of the WEA could be misleading. Therefore, NREL also evaluated and compared phased developments of two 500-MW projects per leasing area (one in the 6-8 year time frame in shallower water and one later, in the 10-16 year time frame in deeper water). This additional analysis, described in Section 5, was added by NREL as a way to assess projects of a reasonable scale based on experience and data collected from European wind facilities. It should be noted that the MA WEA is larger than other WEAs assessed and its development potential is not limited exclusively by area. Bathymetry and wake effects caused by array density are important variables in the MA WEA. Other siting issues, such as environmental and competing use factors, may also influence array density as site development progresses.

\subsection{Overview of NREL Methodology}

The MA WEA has a total area of $3,006.7 \mathrm{~km}^{2}$, which is capable of supporting at least four to five separate leasing areas. NREL conducted analysis using specific criteria to examine delineation scenarios for the MA WEA.

NREL's technical assessment included a comparison of key parameters, such as maximum development capacity, wind speed, bathymetry impacts, capacity factor (after wake losses), wind direction, wake losses, and energy production. To model these parameters, researchers created spatial maps using the WEA geographic information system (GIS) coordinates provided by BOEM and evaluated the delineation options using area, wind speed, wind direction, and bathymetry as the primary input source data. Three delineation options were developed having four to five leasing areas each. The initial delineations were reviewed and refined through collaboration with BOEM and an unpublished interim report was submitted to BOEM describing the final options. Gridded layouts were created using in the OpenWind Enterprise tool developed by AWS Truepower (AWS Truepower 2010). The layouts were then applied to the three delineation alternatives for evaluation and comparison. Researchers used the OpenWind tool to evaluate array effects, energy production capacity, and capacity factor.

$\underline{\text { Table } 5}$, Table 6 , and Table 7 provide comparisons of the quantitative results of offshore wind facility performance analysis for the three leasing area delineation options assessed by NREL as shown in Figure 4. Each option was assessed for a baseline turbine array spacing of $8 \mathrm{D} \times 12 \mathrm{D}$ with full development. In addition, much of the analysis was focused on phased development, in which two 500-MW projects were placed in each of the five leasing area options. For the phased array analysis, $8 \mathrm{D} \times 8 \mathrm{D}, 8 \mathrm{D} \times 12 \mathrm{D}$, and $8 \mathrm{D} \times 15 \mathrm{D}$ turbine array spacing were evaluated for turbine placement wake losses versus water depth impact.

Under NREL's phased development analysis, phase 1 assumes that one 500-MW project will be installed in each leasing area in the shallowest areas below $50 \mathrm{~m}$. Phase 2 is assumed to be a second 500-MW project in each leasing area that is added at some future date. Phase 2 is assumed to have a 50-D internal buffer away from the phase 1 project and is built in the next shallowest sites in the same leasing area. In most cases, phase 2 is upwind from the phase 1 projects and is in deeper water. It is assumed that both phases use fixed-bottom foundation 
technology but that the deeper waters of phase 2 will be more difficult and time-consuming to develop. The array spacing is varied to assess the impact on water depth of spreading the turbines further apart to reduce wake losses.

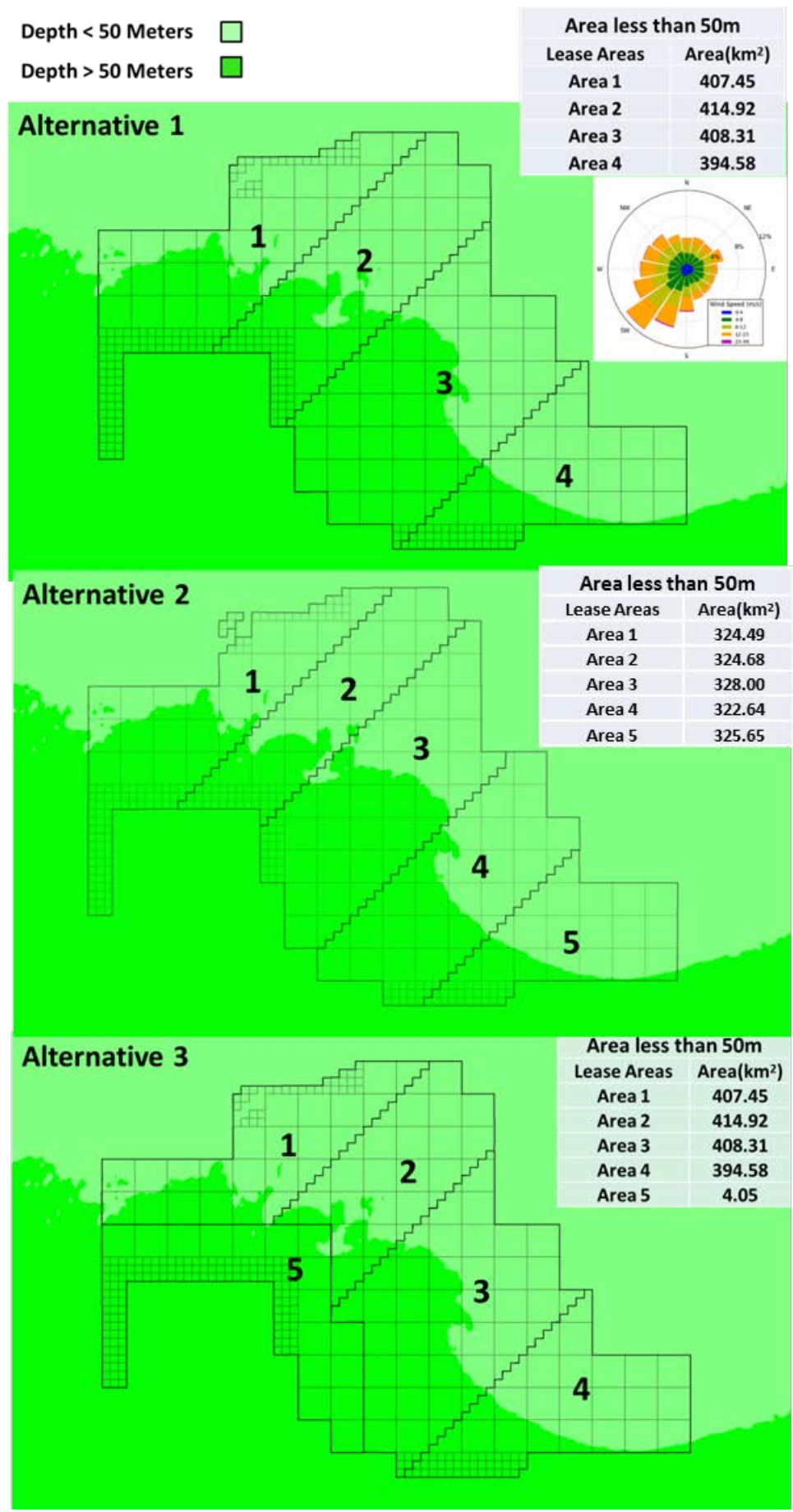

Figure 4. Three delineation options used in the MA WEA assessment. Alternative 1: Four leasing areas with diagonal delineation; Alternative 2: Five leasing areas with diagonal delineations;

Alternative 3: Five leasing areas with deep water carve out

(Source: NREL)

This report is available at no cost from the National Renewable Energy Laboratory (NREL) 
Table 5. MA WEA Delineation Analysis for Alternative 1

(Source: NREL)

\begin{tabular}{|c|c|c|c|c|}
\hline \multirow[b]{2}{*}{ Parameter } & \multicolumn{4}{|c|}{ Delineation Alternative 1} \\
\hline & $\begin{array}{l}\text { Leasing } \\
\text { Area } 1\end{array}$ & $\begin{array}{l}\text { Leasing } \\
\text { Area } 2\end{array}$ & $\begin{array}{l}\text { Leasing } \\
\text { Area } 3\end{array}$ & $\begin{array}{l}\text { Leasing } \\
\text { Area } 4\end{array}$ \\
\hline Total area $\left(\mathrm{km}^{2}\right)$ & 759 & 676 & 1,004 & 569 \\
\hline Total area $(<50 \mathrm{~m})$ & 407 & 415 & 408 & 395 \\
\hline Ave. depth (m) & 47.6 & 51.8 & 47.9 & 49.8 \\
\hline Bathymetry - depth range $(\mathrm{m})$ & $36.0-61.0$ & $37.6-63.0$ & $34.0-62.0$ & $33.0-61.4$ \\
\hline Ave wind speed at $90 \mathrm{~m}(\mathrm{~m} / \mathrm{s})$ & 9.3 & 9.3 & 9.4 & 9.2 \\
\hline \multicolumn{5}{|c|}{8 D x 8 D Full Development } \\
\hline Wake losses (\%) & 10.6 & 12.3 & 12.4 & 10.5 \\
\hline $\begin{array}{c}\text { Gross capacity factor (CF) after wake } \\
\text { losses (\%) }\end{array}$ & 45.2 & 44.4 & 44.4 & 46 \\
\hline Potential capacity (MW) & 3,430 & 2,715 & 4,450 & 2,505 \\
\hline Annual energy production (GWh) & 13,590 & $10,557.6$ & $17,331.8$ & $10,094.9$ \\
\hline \multicolumn{5}{|c|}{8 D x 12 D Full Development } \\
\hline Wake losses (\%) & 8.3 & 9.9 & 10 & 8.3 \\
\hline Gross CF after wake losses (\%) & 46.4 & 45.6 & 45.7 & 47.2 \\
\hline Potential capacity (MW) & 2,305 & 1,855 & 2,955 & 1,695 \\
\hline Annual energy production (GWh) & 9,366 & $7,411.7$ & $11,836.3$ & $7,006.1$ \\
\hline \multicolumn{5}{|c|}{8 D x 15 D Full Development } \\
\hline Wake losses (\%) & 7.2 & 8.7 & 8.8 & 7.3 \\
\hline Gross CF after wake losses (\%) & 46.9 & 46.2 & 46.3 & 47.7 \\
\hline Potential capacity (MW) & 1,850 & 1,455 & 2,360 & 1,360 \\
\hline Annual energy production (GWh) & 7,601.6 & $5,891.5$ & $9,574.3$ & $5,684.2$ \\
\hline \multicolumn{5}{|c|}{8 D x 8 D Phase 1 (500 MW each) } \\
\hline Wake losses (\%) & 6 & 6.9 & 5.7 & 5.4 \\
\hline Gross CF after wake losses (\%) & 47.7 & 47.4 & 48.2 & 48.8 \\
\hline Potential capacity (MW) & 500 & 500 & 500 & 500 \\
\hline Phase 1 depth range $(\mathrm{m})$ & $33.0-45.0$ & $36.0-42.0$ & $37.6-45.0$ & $34.0-44.0$ \\
\hline Annual energy production (GWh) & 2,091 & $2,078.3$ & $2,114.3$ & $2,138.3$ \\
\hline \multicolumn{5}{|c|}{$8 \mathrm{D} \times 8 \mathrm{D}$ Phase 1 and $2(1,000 \mathrm{MW}$ each) } \\
\hline Wake losses (\%) & 6.3 & 8.3 & 7 & 6.3 \\
\hline Gross CF after wake losses (\%) & 47.5 & 46.6 & 47.4 & 48.2 \\
\hline Potential capacity (MW) & 1,000 & 1,000 & 1,000 & 1,000 \\
\hline Phase 2 depth range $(\mathrm{m})$ & $44.7-51.0$ & $43.0-50.0$ & $45.0-51.0$ & $46.0-50.0$ \\
\hline Annual energy production (GWh) & $4,162.3$ & $4,083.9$ & $4,159.2$ & $4,229.1$ \\
\hline
\end{tabular}

This report is available at no cost from the National Renewable Energy Laboratory (NREL) at www.nrel.gov/publications. 


\begin{tabular}{|c|c|c|c|c|}
\hline \multicolumn{5}{|c|}{8 D x 12 D Phase 1 (500 MW each) } \\
\hline Wake losses (\%) & 5.2 & 6.2 & 5.1 & 4.9 \\
\hline Gross CF after wake losses (\%) & 48.1 & 47.8 & 48.5 & 49 \\
\hline Potential capacity (MW) & 500 & 500 & 500 & 500 \\
\hline Phase 1 depth range $(\mathrm{m})$ & $33.0-47.0$ & $36.0-45.0$ & $37.2-46.0$ & $34.6-46.0$ \\
\hline Annual energy production (GWh) & $2,109.7$ & $2,093.8$ & $2,127.9$ & 2,148 \\
\hline \multicolumn{5}{|c|}{$8 \mathrm{D} \times 12$ D Phase 1 and 2 (1,000 MW each) } \\
\hline Wake losses (\%) & 5.9 & 7.3 & 6.4 & 5.7 \\
\hline Gross CF after wake losses (\%) & 47.7 & 47 & 47.7 & 48.5 \\
\hline Potential capacity (MW) & 1,000 & 1,000 & 1,000 & 1,000 \\
\hline Phase 2 depth range $(\mathrm{m})$ & $46.0-53.0$ & $46.0-53.3$ & $48.0-54.0$ & $47.0-59.0$ \\
\hline Annual energy production (GWh) & $4,179.6$ & $4,119.6$ & $4,180.4$ & $4,253.5$ \\
\hline \multicolumn{5}{|c|}{$8 \mathrm{D} \times 15$ D Phase 1 (500 MW each) } \\
\hline Wake losses (\%) & 5 & 5.8 & 4.9 & 4.5 \\
\hline Gross CF after wake losses (\%) & 48.3 & 47.9 & 48.6 & 49.2 \\
\hline Potential capacity (MW) & 500 & 500 & 500 & 500 \\
\hline Phase 1 depth range $(\mathrm{m})$ & $34.0-48.0$ & $37.0-47.8$ & $37.2-47.3$ & $32.9-46.0$ \\
\hline Annual energy production (GWh) & $2,115.7$ & $2,101.3$ & $2,130.6$ & 2,156 \\
\hline \multicolumn{5}{|c|}{$8 \mathrm{D} \times 15 \mathrm{D}$ Phase 1 and $2(1,000 \mathrm{MW}$ each) } \\
\hline Wake losses (\%) & 5.7 & 6.8 & 6.3 & 5.4 \\
\hline Gross CF after wake losses (\%) & 45.6 & 45.7 & 47.2 & 46.4 \\
\hline Potential capacity (MW) & 1,855 & 2,955 & 1,695 & 2,305 \\
\hline Phase 2 depth range $(\mathrm{m})$ & $47.0-54.0$ & $46.0-56.0$ & $48.0-54.0$ & $49.0-62.2$ \\
\hline Annual energy production (GWh) & $7,411.7$ & $11,836.3$ & $7,006.1$ & 9,366 \\
\hline
\end{tabular}

This report is available at no cost from the National Renewable Energy Laboratory (NREL) at www.nrel.gov/publications. 
Table 6. MA WEA Delineation Analysis for Alternative 2

(Source: NREL)

\begin{tabular}{|c|c|c|c|c|c|}
\hline \multirow[b]{2}{*}{ Parameter } & \multicolumn{5}{|c|}{ Delineation Alternative 2} \\
\hline & $\begin{array}{l}\text { Leasing } \\
\text { Area } 1\end{array}$ & $\begin{array}{l}\text { Leasing } \\
\text { Area } 2\end{array}$ & $\begin{array}{l}\text { Leasing } \\
\text { Area } 3\end{array}$ & $\begin{array}{l}\text { Leasing } \\
\text { Area } 4\end{array}$ & $\begin{array}{c}\text { Leasing Area } \\
5\end{array}$ \\
\hline Total area $\left(\mathrm{km}^{2}\right)$ & 642 & 484 & 792 & 644 & 445 \\
\hline Total area $(<50 \mathrm{~m})$ & 324 & 325 & 328 & 323 & 326 \\
\hline Ave depth (m) & 50 & 47 & 51 & 51 & 48 \\
\hline Bathymetry - depth range $(\mathrm{m})$ & $33.0-61.0$ & $36.1-55.6$ & $37.0-62.0$ & $37.0-63.2$ & $34.0-61.5$ \\
\hline Ave wind speed at $90 \mathrm{~m}(\mathrm{~m} / \mathrm{s})$ & 9.3 & 9.3 & 9.3 & 9.4 & 9.4 \\
\hline \multicolumn{6}{|c|}{8 D x 8 D Full Development } \\
\hline Wake losses (\%) & 10 & 11.9 & 12.4 & 11.8 & 10.2 \\
\hline Gross CF after wake losses (\%) & 45.5 & 44.6 & 44.3 & 44.9 & 46.2 \\
\hline Potential capacity (MW) & 2,755 & 1,830 & 3,375 & 2,675 & 2,015 \\
\hline Annual energy production (GWh) & $10,985.9$ & $7,151.3$ & $13,109.5$ & 10,536 & $8,162.4$ \\
\hline \multicolumn{6}{|c|}{8 D x 12 D Full Development } \\
\hline Wake losses (\%) & 7.9 & 9.4 & 9.9 & 9.3 & 7.9 \\
\hline Gross CF after wake losses (\%) & 46.7 & 45.9 & 45.7 & 46.3 & 47.5 \\
\hline Potential capacity (MW) & 1,910 & 1,220 & 2,240 & 1,795 & 1,315 \\
\hline Annual energy production (GWh) & $7,812.2$ & $4,908.4$ & $8,966.3$ & $7,279.8$ & 5,470 \\
\hline \multicolumn{6}{|c|}{8 D x 15 D Full Development } \\
\hline Wake losses (\%) & 6.9 & 8.2 & 8.8 & 8.2 & 6.9 \\
\hline Gross CF after wake losses (\%) & 47.1 & 46.4 & 46.2 & 46.7 & 47.9 \\
\hline Potential capacity (MW) & 1,530 & 965 & 1,790 & 1,430 & 1,050 \\
\hline Annual energy production (GWh) & $6,312.4$ & $3,925.7$ & $7,244.8$ & $5,860.3$ & $4,406.9$ \\
\hline \multicolumn{6}{|c|}{8 D x 8 D Phase 1 (500 MW each) } \\
\hline Wake losses (\%) & 6.1 & 7.8 & 7.1 & 6.5 & 5.8 \\
\hline Gross CF after wake losses (\%) & 47.7 & 46.9 & 47.4 & 47.9 & 48.6 \\
\hline Potential capacity (MW) & 500 & 500 & 500 & 500 & 500 \\
\hline Phase 1 depth range $(\mathrm{m})$ & $34.0-46.0$ & $37.0-47.0$ & $37.0-44.0$ & $36.1-45.7$ & $33.0-46.0$ \\
\hline Annual energy production (GWh) & $2,089.3$ & 2,054 & $2,076.9$ & $2,100.8$ & $2,130.2$ \\
\hline \multicolumn{6}{|c|}{8 D x 8 D Phase 1 and 2 (1,000 MW each) } \\
\hline Wake losses (\%) & 6.5 & 8.8 & 8.4 & 7.8 & 6.9 \\
\hline Gross CF after wake losses (\%) & 47.3 & 46.2 & 46.6 & 47.1 & 48 \\
\hline Potential capacity (MW) & 1,000 & 1,000 & 1,000 & 1,000 & 1,000 \\
\hline Phase 2 depth range $(\mathrm{m})$ & $47.0-51.0$ & $45.0-55.0$ & $47.0-53.0$ & $48.0-52.0$ & $45.0-51.0$ \\
\hline Annual energy production (GWh) & $4,150.3$ & $4,049.9$ & $4,081.5$ & $4,132.5$ & $4,206.6$ \\
\hline
\end{tabular}

This report is available at no cost from the 


\begin{tabular}{|c|c|c|c|c|c|}
\hline \multicolumn{7}{|c|}{ 8 D x 12 D Phase 1 (500 MW each) } \\
\hline Wake losses (\%) & 5.6 & 6.7 & 6.3 & 5.8 & 5.3 \\
\hline Gross CF after wake losses (\%) & 48 & 47.4 & 47.8 & 48.3 & 48.8 \\
\hline Potential capacity (MW) & 500 & 500 & 500 & 500 & 500 \\
\hline Phase 1 depth range (m) & $34.0-46.0$ & $37.0-48.0$ & $36.4-48.0$ & $36.0-48.4$ & $33.0-48.6$ \\
\hline Annual energy production (GWh) & $2,102.7$ & $2,075.9$ & 2,096 & $2,114.8$ & $2,140.3$ \\
\hline
\end{tabular}

$8 \mathrm{D} \times 12 \mathrm{D}$ Phase 1 and 2 (1,000 MW each)

\begin{tabular}{|c|c|c|c|c|c|}
\hline Wake losses (\%) & 6.3 & 7.3 & 7.5 & 7.1 & 6 \\
\hline Gross CF after wake losses (\%) & 47.5 & 46.9 & 47 & 47.4 & 48.4 \\
\hline Potential capacity (MW) & 1,000 & 960 & 1,000 & 1,000 & 900 \\
\hline Phase 2 depth range (m) & $46.0-54.0$ & $47.5-55.0$ & $48.0-54.0$ & $49.0-58.0$ & $48.0-62.0$ \\
\hline Annual energy production (GWh) & $4,160.5$ & $3,944.3$ & $4,118.5$ & $4,157.8$ & $3,817.7$ \\
\hline
\end{tabular}

8 D x 15 D Phase 1 (500 MW each)

\begin{tabular}{|c|c|c|c|c|c|}
\hline Wake losses (\%) & 4.7 & 6.1 & 6 & 5.4 & 4.8 \\
\hline Gross CF after wake losses (\%) & 48.4 & 47.6 & 47.9 & 48.4 & 49.2 \\
\hline Potential capacity (MW) & 500 & 500 & 500 & 500 & 500 \\
\hline Phase 1 depth range (m) & $34.0-50.0$ & $36.1-48.2$ & $37.0-48.0$ & $38.0-49.0$ & $35.0-50.0$ \\
\hline Annual energy production (GWh) & $2,120.4$ & $2,087.4$ & $2,101.2$ & $2,123.1$ & 2,155 \\
\hline
\end{tabular}

\section{$8 \mathrm{D} \times 15 \mathrm{D}$ Phase 1 and 2 (1,000 MW each)}

\begin{tabular}{|c|c|c|c|c|c|}
\hline Wake losses (\%) & 5.7 & 6.8 & 7 & 6.6 & 5.563291 \\
\hline Gross CF after wake losses (\%) & 47.7 & 47.2 & 47.1 & 47.6 & 48.58987 \\
\hline Potential capacity (MW) & 1,000 & 790 & 1,000 & 1,000 & 790 \\
\hline Phase 2 depth range (m) & $50.0-59.0$ & $49.0-55.0$ & $50.0-56.0$ & $50.0-62.0$ & $48.0-61.0$ \\
\hline Annual energy production (GWh) & 4,180 & $3,266.3$ & $4,132.9$ & $4,175.3$ & $3,366.4$ \\
\hline
\end{tabular}

This report is available at no cost from the National Renewable Energy Laboratory (NREL) at www.nrel.gov/publications. 
Table 7. MA WEA Delineation Analysis for Alternative 3

(Source: NREL)

\begin{tabular}{|c|c|c|c|c|c|}
\hline \multirow[b]{2}{*}{ Parameter } & \multicolumn{5}{|c|}{ Delineation Alternative 3} \\
\hline & $\begin{array}{l}\text { Leasing } \\
\text { Area } 1\end{array}$ & $\begin{array}{l}\text { Leasing } \\
\text { Area } 2\end{array}$ & $\begin{array}{l}\text { Leasing } \\
\text { Area } 3\end{array}$ & $\begin{array}{c}\text { Leasing } \\
\text { Area } 4\end{array}$ & $\begin{array}{l}\text { Leasing } \\
\text { Area } 5\end{array}$ \\
\hline Total area $\left(\mathrm{km}^{2}\right)$ & 531 & 496 & 844 & 569 & 567 \\
\hline Total area $(<50 \mathrm{~m})$ & 407 & 411 & 408 & 395 & 4 \\
\hline Ave depth $(m)$ & 47 & 45 & 50 & 48 & 56 \\
\hline Bathymetry - depth range $(\mathrm{m})$ & $33.0-54.0$ & $36.0-54.0$ & $37.6-62.0$ & $34.0-62.0$ & $50.0-62.0$ \\
\hline Ave wind speed at $90 \mathrm{~m}(\mathrm{~m} / \mathrm{s})$ & 9.3 & 9.3 & 9.3 & 9.4 & 9.3 \\
\hline \multicolumn{6}{|c|}{8 D x 8 D Full Development } \\
\hline Wake losses (\%) & 10.8 & 12.1 & 12.5 & 10.3 & 9.5 \\
\hline Gross CF after wake losses (\%) & 45.2 & 44.6 & 44.5 & 46.1 & 45.5 \\
\hline Potential capacity (MW) & 2,255 & 1,845 & 3,430 & 2,425 & 2,265 \\
\hline Annual energy production (GWh) & $8,927.4$ & $7,206.7$ & $13,378.9$ & $9,798.7$ & $9,042.1$ \\
\hline \multicolumn{6}{|c|}{8 D x 12 D Full Development } \\
\hline Wake losses (\%) & 8.5 & 9.6 & 10 & 8.2 & 7.5 \\
\hline Gross CF after wake losses (\%) & 46.4 & 45.8 & 45.7 & 47.2 & 46.6 \\
\hline Potential capacity (MW) & 1,470 & 1,220 & 2,295 & 1,660 & 1,585 \\
\hline Annual energy production (GWh) & 5,975 & $4,900.6$ & $9,201.9$ & $6,869.9$ & $6,472.2$ \\
\hline \multicolumn{6}{|c|}{8 D x 15 D Full Development } \\
\hline Wake losses (\%) & 7.4 & 8.4 & 8.9 & 7.1 & 6.5 \\
\hline Gross CF after wake losses (\%) & 46.9 & 46.4 & 46.3 & 47.7 & 47.1 \\
\hline Potential capacity (MW) & 1,170 & 970 & 1,840 & 1,330 & 1,250 \\
\hline Annual energy production (GWh) & $4,812.2$ & $3,946.8$ & $7,473.2$ & $5,566.9$ & $5,158.5$ \\
\hline \multicolumn{6}{|c|}{8 D x 8 D Phase 1 (500 MW each) } \\
\hline Wake losses (\%) & 6 & 6.9 & 5.7 & 5.4 & $\mathrm{~N} / \mathrm{A}$ \\
\hline Gross CF after wake losses (\%) & 47.7 & 47.4 & 48.2 & 48.8 & N/A \\
\hline Potential capacity (MW) & 500 & 500 & 500 & 500 & N/A \\
\hline Phase 1 depth range $(\mathrm{m})$ & $33.0-45.0$ & $36.0-42.0$ & $37.6-45.0$ & $34.0-44.0$ & N/A \\
\hline Annual energy production (GWh) & 2,091 & $2,078.3$ & $2,114.3$ & $2,138.3$ & N/A \\
\hline \multicolumn{6}{|c|}{$8 \mathrm{D} \times 8 \mathrm{D}$ Phase 1 and $2(1,000 \mathrm{MW}$ each) } \\
\hline Wake losses (\%) & 6.9 & 8.7 & 7.3 & 6.3 & 6.4 \\
\hline Gross CF after wake losses (\%) & 47.2 & 46.4 & 47.3 & 48.2 & 47.1 \\
\hline Potential capacity (MW) & 1,000 & 1,000 & 1,000 & 1,000 & 1,000 \\
\hline Phase 2 depth range $(\mathrm{m})$ & $44.7-51.0$ & $43.0-50.0$ & $45.0-51.0$ & $46.0-50.0$ & $46.0-50.0$ \\
\hline Annual energy production (GWh) & $4,133.6$ & $4,064.2$ & $4,146.3$ & 4,228 & $4,129.3$ \\
\hline
\end{tabular}

This report is available at no cost from the 
8 D x 12 D Phase 1 (500 MW each)

\begin{tabular}{|c|c|c|c|c|c|}
\hline \multicolumn{6}{|c|}{8 D x 12 D Phase 1 (500 MW each) } \\
\hline Wake losses (\%) & 5.2 & 6.2 & 5.1 & 4.9 & $\mathrm{~N} / \mathrm{A}$ \\
\hline Gross CF after wake losses (\%) & 48.1 & 47.8 & 48.5 & 49 & N/A \\
\hline Potential capacity (MW) & 500 & 500 & 500 & 500 & $\mathrm{~N} / \mathrm{A}$ \\
\hline Phase 1 depth range $(\mathrm{m})$ & $33.0-47.0$ & $36.0-45.0$ & $37.2-46.0$ & $37.2-46.0$ & N/A \\
\hline Annual energy production (GWh) & $2,109.7$ & $2,093.8$ & $2,127.9$ & 2,148 & N/A \\
\hline \multicolumn{6}{|c|}{$8 \mathrm{D} \times 12$ D Phase 1 and $2(1,000 \mathrm{MW}$ each) } \\
\hline Wake losses (\%) & 6.7 & 8 & 6.8 & 5.7 & 6.3 \\
\hline Gross CF after wake losses (\%) & 47.3 & 46.6 & 47.5 & 48.5 & 47.2 \\
\hline Potential capacity (MW) & 1,000 & 1,000 & 1,000 & 1,000 & 1,000 \\
\hline Phase 2 depth range $(\mathrm{m})$ & $46.0-53.0$ & $46.0-53.3$ & $48.0-54.0$ & $47.0-59.0$ & $51.0-60.0$ \\
\hline Annual energy production (GWh) & $4,143.3$ & $4,086.1$ & $4,166.7$ & $4,252.1$ & $4,134.3$ \\
\hline \multicolumn{6}{|c|}{8 D x 15 D Phase 1 (500 MW each) } \\
\hline Wake losses (\%) & 5 & 5.8 & 4.9 & 4.5 & N/A \\
\hline Gross CF after wake losses (\%) & 48.3 & 47.9 & 48.6 & 49.2 & $\mathrm{~N} / \mathrm{A}$ \\
\hline Potential capacity (MW) & 500 & 500 & 500 & 500 & N/A \\
\hline Phase 1 depth range $(\mathrm{m})$ & $34.0-48.0$ & $37.0-47.8$ & $37.2-47.3$ & $32.9-46.0$ & $\mathrm{~N} / \mathrm{A}$ \\
\hline Annual energy production (GWh) & $2,115.7$ & $2,101.3$ & $2,130.6$ & 2,156 & N/A \\
\hline \multicolumn{6}{|c|}{$8 \mathrm{D} \times 15$ D Phase 1 and $2(1,000 \mathrm{MW}$ each) } \\
\hline Wake losses (\%) & 6.4 & 7.1 & 6.6 & 5.4 & 5.6 \\
\hline Gross CF after wake losses (\%) & 47.4 & 47.1 & 47.6 & 48.6 & 47.5 \\
\hline Potential capacity (MW) & 1,000 & 790 & 1,000 & 955 & 1,000 \\
\hline Phase 2 depth range $(\mathrm{m})$ & $47.0-54.0$ & $46.0-53.0$ & $48.0-54.0$ & $49.0-62.2$ & $50.0-60.0$ \\
\hline Annual energy production (GWh) & $4,154.3$ & $3,263.8$ & $4,169.3$ & $4,067.7$ & $4,164.6$ \\
\hline
\end{tabular}

\section{Physical Assessment and Delineation Analysis}

\subsection{Bathymetry Considerations}

The water depth, or bathymetry, was considered a major variable in assessing the wind development potential of the MA WEA leasing area. Figure 5 shows a bathymetry map of the MA WEA. Data plotted in the figure were derived from the National Oceanic and Atmospheric Administration's (NOAA's) Coastal Relief Model (CRM) for New England. The native data are in a geographic coordinate system, and were reprojected to the wind resource projection (UTM zone 18) using a bilinear resampling method resulting in a $100-\mathrm{m}$ spatial resolution.

NOAA's CRM is a nationally comprehensive dataset, available at a relatively high spatial resolution (3 arc-seconds) for the coastal waters of the contiguous United States and Hawaii. NOAA has integrated data from the U.S. National Ocean Service Hydrographic Database, U.S. Geological Survey, Monterey Bay Aquarium Research Institute, U.S. Army Corps of Engineers, International Bathymetric Chart of the Caribbean Sea and the Gulf of Mexico, and various other academic institutions. Freely available to the public, NREL is able to distribute the data used in our analysis to our partners and stakeholders. The data is downloadable from NOAA's National Geophysical Data Center at 
http://www.ngdc.noaa.gov/mgg/coastal/crm.html, which provides scientific stewardship for sea floor and lakebed geophysical data including bathymetry (NOAA 2013).

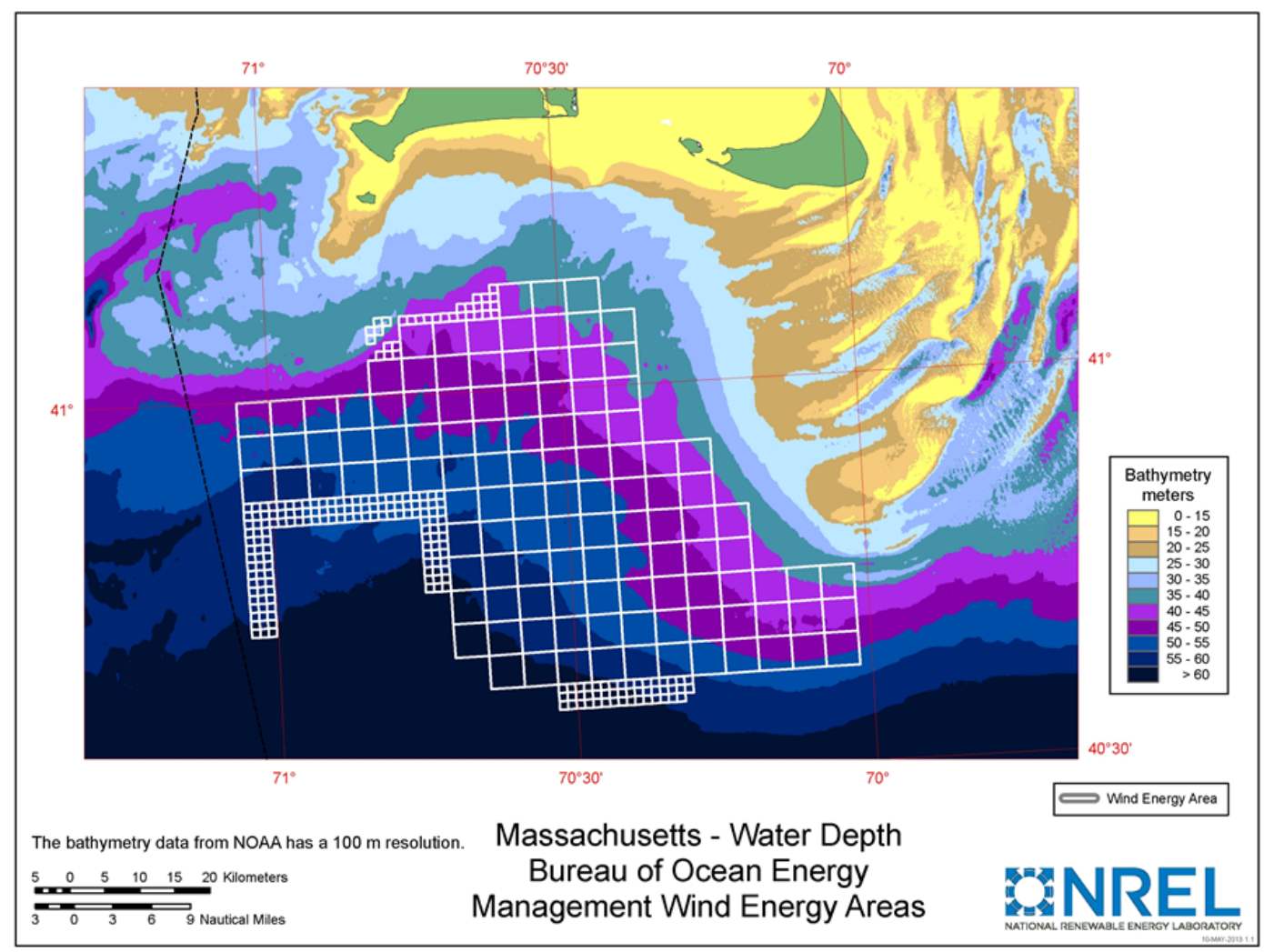

Figure 5. Water depth map for the MA WEA (Source: NREL)

Depth considerations are important with respect to project risk, cost, and expected development timing. Figure 6 shows a plot of the current projects installed, under construction, contracted, and approved in Europe as a function of the expected commercial commissioning date as of the end of 2012. The figure shows that the majority of the operating projects are installed in waters less than $30 \mathrm{~m}$ deep, with only a few of the newer projects pushing into depths of $35 \mathrm{~m}$ or greater [e.g., Alpha Ventus/Germany (average depth of $30 \mathrm{~m}$ ) and Talisman Energy/Scotland (average depth of $45 \mathrm{~m}$ )]. Until now, European projects have remained in shallow water because shallow waters are more abundant in the North and Baltic Seas than in U.S. waters, and it was necessary for the industry to gain experience in shallower waters to gain confidence in the technology. European offshore wind developers are now beginning to venture into deeper waters and future projects are being planned and constructed in depths of up to $50 \mathrm{~m}$, but these are not yet commissioned. 


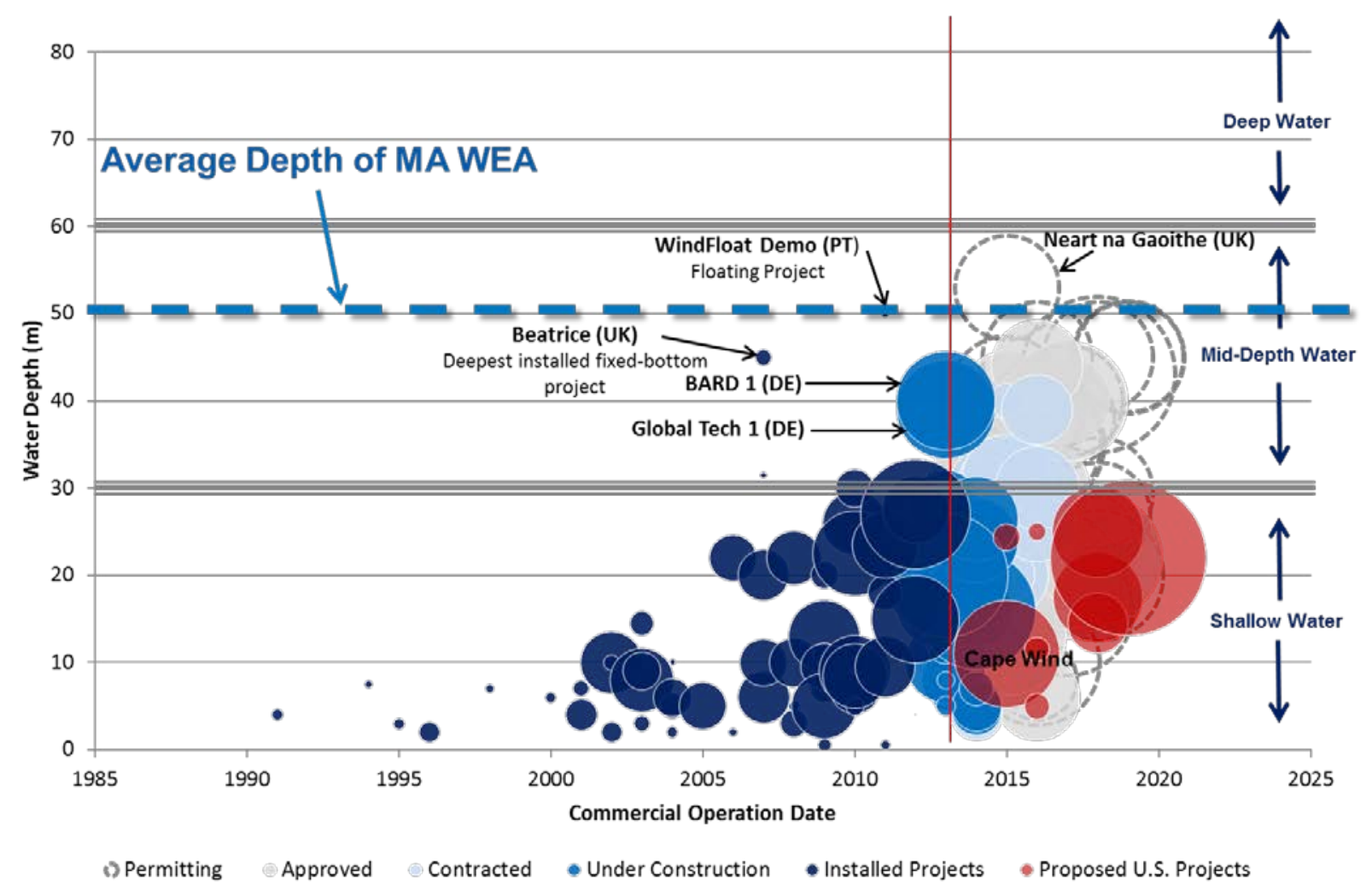

Figure 6. Current offshore wind projects in Europe: installed, under construction, contracted, and approved as a function of expected commercial operation date

(Source: NREL)

The analysis found that the MA WEA has a range of water depths between $35 \mathrm{~m}$ and $65 \mathrm{~m}$, with an average depth of about $50 \mathrm{~m}$. Figure 7 shows the distribution of depths across the MA WEA in a histogram. For the assessment, NREL assumed that there would be two development phases corresponding to water depth with the assumption that shallow water would be developed first and then deeper water at a later phase. Based on the data shown in Figure 6 and from the RFI and Call responses (Table 1 and Table 2 showing 6-16 year development time frames), the development time frame for phase 1 projects $(<50 \mathrm{~m})$ was assumed to be $6-8$ years and 10-16 years for phase 2 projects. This assumption was applied in Section 5, in which project capacity and wake effects were studied for 500-MW phased development scenarios with each leasing area consisting of one 500-MW project initially and then a second project at a later date. 


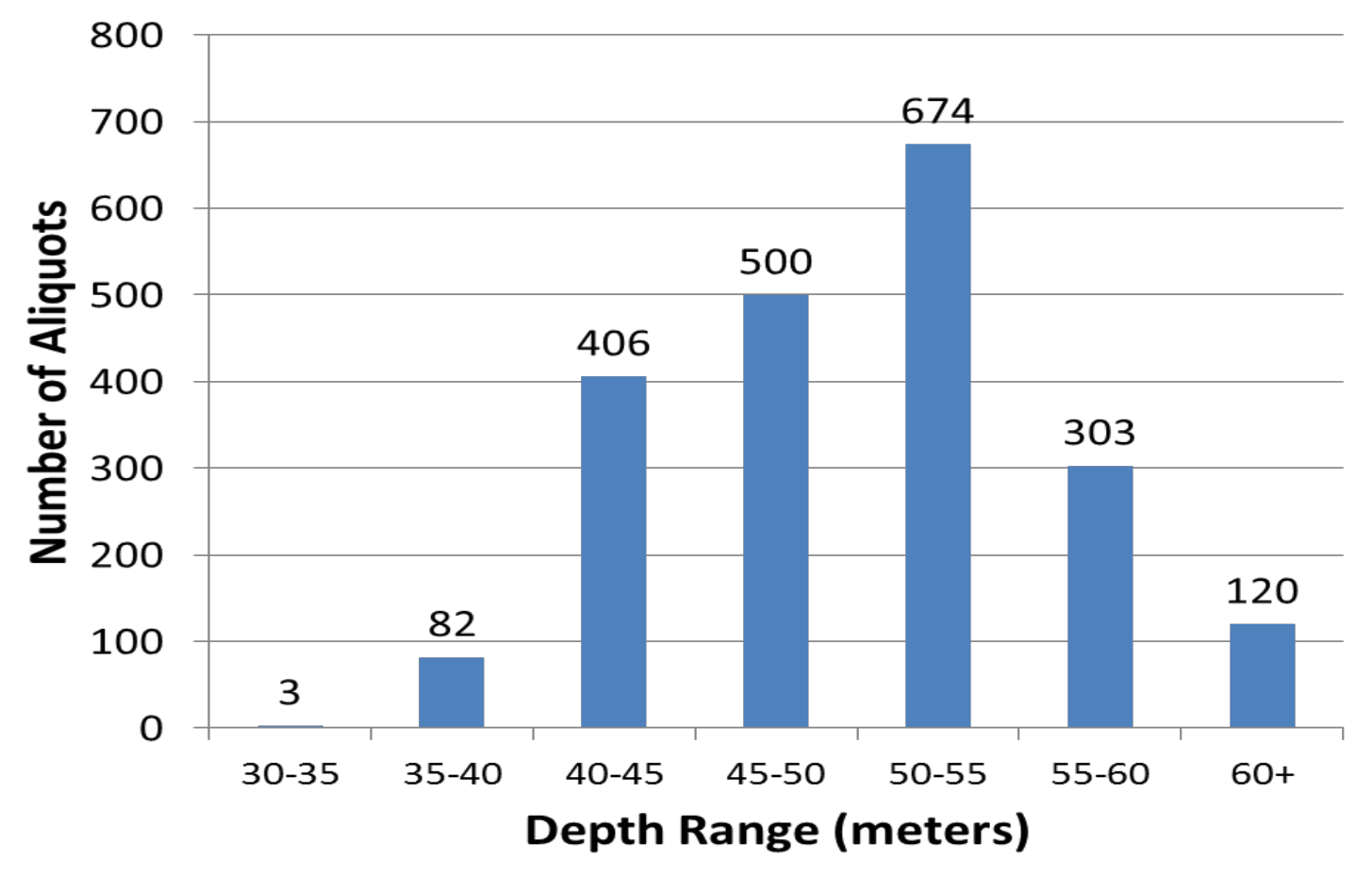

Figure 7. Histogram of water depths for the MA WEA showing water depths ranging from $30 \mathrm{~m}$ to $65 \mathrm{~m}$ for the total WEA using May 2012 boundaries $\left(3,006.7 \mathrm{~km}^{2}\right)$

(Source: NREL)

\subsection{Wind Resource}

\subsubsection{Wind Source Data}

For this investigation, NREL surveyed a variety of data sources to find a high-quality dataset that embodies best industry practices. Ultimately, the wind resource data used for the MA WEA was a high-resolution, long-term record obtained from AWS Truepower that correlated well with local empirical observations.

The mesoscale model, Mesoscale Atmospheric Simulations System, was used to simulate the atmosphere with a coarse, horizontal grid spacing of $20 \mathrm{~km}$ over the United States and immediately offshore (Manobianco et al. 1996). The Mesoscale Atmospheric Simulations System is a numerical weather model that has been developed over the past 20 years by MESO, Inc., in partnership with AWS Truepower. The mesoscale simulations were processed to produce a long-term time series of weather information called windTrends. The windTrends dataset is available from 1997 to the present and contains hourly approximations of several meteorological fields, including wind speed and direction. This data set was used to produce an annual average wind speed map at a resolution of $20,000 \mathrm{~m}(20 \mathrm{~km})$ and a set of statistical files containing information about the wind resource. This information was then used as input to the microscale model, WindMap (Brower 1999), which interpolates the coarse 20-km grid data to a highresolution grid spacing of $200 \mathrm{~m}$ to simulate more localized effects. The outputs of WindMap are 200-m mean annual wind speed maps and wind resource grid (WRG/B) files containing the wind speed, wind direction, and frequency distribution of the wind speed, at a hub height of $90 \mathrm{~m}$. 
NREL researchers input these WRG/B files into the OpenWind model, where the wind speed gradients and directional distributions across the WEA were determined.

As with any analytically based modeling process, significant uncertainties are embodied in the model data. Therefore, validation with empirical measurements is needed to gain sufficient confidence in the modeled results. We compared the 200-m high-resolution WindMap data to the well-established Modern-Era Retrospective Analysis (MERRA) data set produced by the National Aeronautics and Space Administration (NASA 2013). MERRA integrates a variety of observing systems with numerical models to produce a temporally and spatially consistent synthesis of observations and analyses of variables that are not easily observed. MERRA data confirmed the general wind speed and direction characteristics of the WRG/B data but it could not be used exclusively to accomplish the objectives of this study because it does not have the needed resolution. In addition, NREL usually compares modeled offshore data to measured data from buoys, but the MA WEA is not near any offshore buoys that could provide reliable validation points. We compared the MERRA data to measurements from two buoys belonging to the National Data Buoy Center: 44017, which is located approximately $100 \mathrm{~km}$ west of the MA WEA, and 44008, which is about $90 \mathrm{~km}$ to the southeast of the MA WEA. Both buoys confirmed the general pattern seen in MERRA and in the WRG of a southwesterly peak with lesser peaks from the northwest and northeast, although the distance to the WEA is too large for an accurate comparison (NOAA 2013). Given the lack of measurements available offshore and the coarse resolution of other modeled data sets, the WRG/B data files used for this study provided the best current wind climate information for the MA WEA.

\subsubsection{Wind Resource Evaluation of the MA WEA}

The annual average wind speed determined from the AWS Truepower WRG/B data described in Section 3.2 is shown in the map in Figure 9 for the MA WEA. The figure shows that the wind speed varies from approximately $9.2 \mathrm{~m} / \mathrm{s}$ to $9.5 \mathrm{~m} / \mathrm{s}$ at $90 \mathrm{~m}$, with highest wind speeds in the east and lowest speeds in the west. This wind speed gradient of about $0.3 \mathrm{~m} / \mathrm{s}$ across the MA WEA could be significant in terms of energy production and capacity factor but is on the same scale as the typical uncertainty of about $+/-0.35 \mathrm{~m} / \mathrm{s}$ that is often associated with modeled wind resource data for many areas of the United States (AWS Truepower 2012).

The prevailing winds, indicated by the wind rose also shown in Figure 9, come largely from the southwest directions. Having a high percentage of the winds from a single prevailing direction sector simplifies the siting and layout optimization as opposed to more bimodal wind direction distributions seen in the mid-Atlantic, where projects may experience relatively higher wake losses and more difficultly in optimizing array layouts for power production. For the MA WEA, array layouts used in the analysis found that a grid orientation angle of 60 degrees provided the lowest wake losses. 

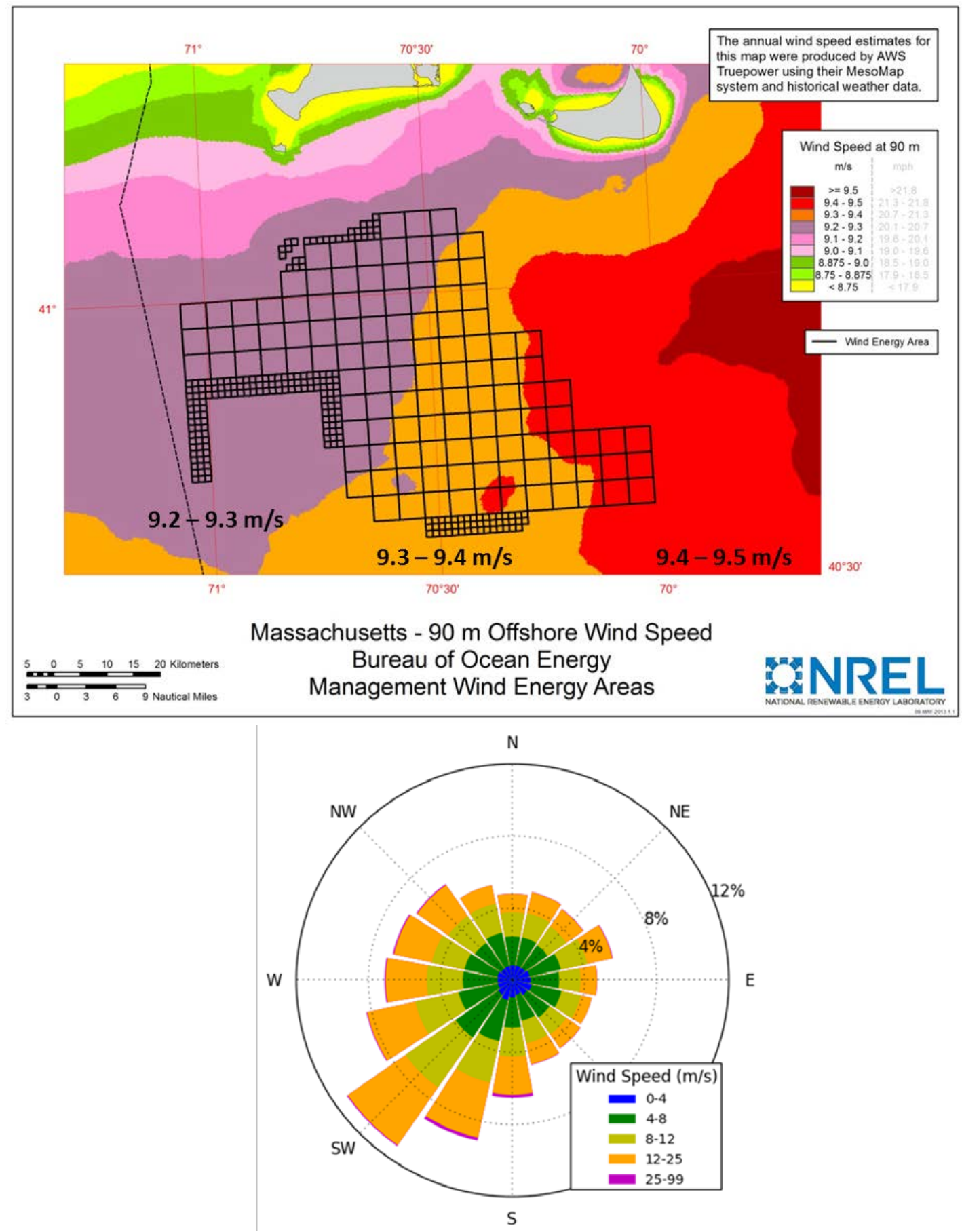

Figure 8. (top) MA WEA showing the annual average wind speed in $0.10 \mathrm{~m} / \mathrm{s}$ increments and (bottom) the wind frequency rose with prevailing winds from the southwest direction (Source: NREL) 


\subsection{Delineation Strategy}

BOEM, NREL, and the Commonwealth of Massachusetts have been discussing various strategies for delineating the MA WEA to create offshore leasing areas that can be auctioned in a future sale. This section provides the analysis used to assess possible strategies for delineating the MA WEA, which was presented to BOEM in an unpublished interim report on November 3, 2013.

The following three delineation alternatives were assessed (in no order of preference):

- Alternative 1. Four leasing areas with diagonal delineation lines and approximately equal shallow area

- Alternative 2. Five leasing areas with diagonal delineation lines and approximately equal shallow area

- Alternative 3. Five leasing areas with four areas having approximately equal shallow area and one comprising mostly deep water greater than $50-\mathrm{m}$.

These alternatives were discussed and agreed upon with BOEM over several iterations and are shown in Figure 4.

The criteria for selecting these delineations were based on the following assumptions and constraints:

- Number of leasing areas. The leasing process was to be limited to a maximum of five nonoverlapping leasing areas that would together make up the total area of the MA WEA. With $3,006.7 \mathrm{~km}^{2}$, the MA WEA is a relatively large area than other BOEM WEAs as of this writing. This constraint ensured that the leasing areas would also be relatively large $\left(445 \mathrm{~km}^{2}\right.$ to $1,004 \mathrm{~km}^{2}$ ), with an area that is ample enough to mitigate wake losses and adapt to the most anticipated siting irregularities within their own boundaries.

- Equalizing the shallow water resource. NREL found that the depth of the MA WEA ranged from $35 \mathrm{~m}$ to $65 \mathrm{~m}$ with the average depth at about $50 \mathrm{~m}$. Researchers assumed that the shallower depths would be less costly and easier to develop and would therefore be more valuable. The delineations attempted to equalize the amount of shallow water below $50 \mathrm{~m}$ in each of the leasing areas. Cognizant that the areas cannot be perfectly equal, given the inherent nature of soundings data and the fact that BOEM would prefer not to sub-divide aliquots, BOEM asked that the range between the maximum and minimum shallow areas among leasing areas be kept to a minimal difference (i.e., $5 \%$ ).

- Minimizing external wake effects. Delineation lines were drawn at approximately a 45 degree southwest-to-northeast diagonal to be approximately parallel to the prevailing southwest wind direction shown in Figure 8. This strategy was developed to minimize potential conflicts between neighboring wind projects and to give the lessees the maximum control over their own area. The inefficiencies associated with drawing zigzag diagonal delineation lines along the north-south aliquot grid (which were important to avoid in areas such as Maryland) were relatively inconsequential in Massachusetts due to relatively large leasing areas (Musial et al. 2013). 
- Wind resource. Researchers considered average wind speed across the MA WEA and found that it varied between $9.2 \mathrm{~m} / \mathrm{s}$ and $9.4 \mathrm{~m} / \mathrm{s}$, which is very low variability. As a result, average wind speed did not play a major role in delineation boundary decisions because the energy capture potential between areas was not impacted significantly by wind speed variations. Note that for the small wind speed gradient that does exist, the variations are generally from west to east. Therefore, variations of annual average wind speed only occur between leasing areas but not within leasing areas.

Section 4.3 includes details on each of the alternatives with the pros and cons included in this section. For each alternative, there is a set of figures and tables that include:

- A summary table that provides the water depths, areas, average wind speed, and generating capacity estimates. Water depths were estimated from the NOAA CRM model, which were reprojected to $100 \mathrm{~m}$ x $100 \mathrm{~m}$ cells in UTM zone 18 with bilinear resampling. Capacity estimates were based on assumed 8 D x 12 D turbine spacing using the NREL 5-MW, 126-m diameter rotor wind turbine.

- A map showing the WEA with the proposed delineation boundaries (also see Figure 4). These figures all contain the wind rose from Figure 8 for the MA WEA to illustrate how the delineation boundaries are drawn parallel to the prevailing southwest wind direction. Each figure also shows two levels of water depth (bathymetry). The darker/brighter green color indicates depths greater than $50 \mathrm{~m}$ and the lighter green indicates depths less than $50 \mathrm{~m}$.

- A bar chart comparing the amount of shallow water (less than $50 \mathrm{~m}$ ) and the total area of each leasing area within each alternative.

- A line graph comparing the water depths in 5-m increments for each leasing area. These charts provide better resolution for identifying specific differences among the areas that might be important to developers.

\subsubsection{Alternative 1}

Alternative 1 divides the MA WEA along diagonal lines parallel to the prevailing wind direction and orthogonal to the isobaths using four leasing areas as shown in Figure 9. As indicated in Table 5, the four leasing areas range in total area between $569 \mathrm{~km}^{2}$ and $1,004 \mathrm{~km}^{2}$ but have very similar areas sizes for water below $50 \mathrm{~m}$ ranging between $395 \mathrm{~km}^{2}$ and $415 \mathrm{~km}^{2}$. Using this alternative, each leasing area would be able to support at least one large near-term wind project using fixed-bottom technology in the areas less than $50 \mathrm{~m}$ deep. Table 5 shows that gross capacity is estimated between 1,294 MW and 1,361 MW for the area with water depths below 50 m using an $8 \mathrm{D} \times 12 \mathrm{D}$ layout. The primary advantage of Alternative 1 is that the average depth of projects would be shallower and therefore easier to build at a lower cost (about the same as Alternative 3 in leasing areas 1-4). Compared to Alternative 2, the shallow region is larger in Alternative 1, which gives developers some additional flexibility to select the more optimal siting options. The upwind fetch for each leasing area in the prevailing direction would be controlled mostly by each respective lessee so inter-array wake effects would be minimized. The same assumptions would apply for Alternative 3 except the deeper water in leasing areas 1, 2, and 3 of Alternative 1 is carved off into a fifth deep water site in Alternative 3.

Note that in Alternative 1, the total area varies significantly between leasing areas, which is due almost entirely to the area over the deeper aliquots as shown in Figure 10. The deeper regions 
may also be able to support an additional wind project in some of the leasing areas but the technology and cost to develop these regions may limit their commercially viability in the near term.

Figure 11 shows the distribution of bathymetry over all of the Alternative 1 leasing areas. From this plot it can be seen that leasing area 2 has the best distribution of shallow water with more area concentrated in the shallower $35 \mathrm{~m}-40 \mathrm{~m}$ bin.

Table 8. Alternative 1: Four Leasing Area Delineation for the MA WEA (Source: NREL)

\begin{tabular}{|c|c|c|c|c|c|}
\hline \multicolumn{6}{|c|}{ Alternative 1} \\
\hline & $\begin{array}{l}\text { Leasing } \\
\text { Area } 1\end{array}$ & $\begin{array}{l}\text { Leasing } \\
\text { Area } 2\end{array}$ & $\begin{array}{l}\text { Leasing } \\
\text { Area } 3\end{array}$ & $\begin{array}{l}\text { Leasing } \\
\text { Area } 4\end{array}$ & $\begin{array}{l}\text { All } \\
\text { Areas }\end{array}$ \\
\hline Total area $\left(\mathrm{km}^{2}\right)$ & 759 & 676 & 1,004 & 569 & 3,008 \\
\hline Total area $<50 \mathrm{~m}\left(\mathrm{~km}^{2}\right)$ & 407 & 415 & 408 & 395 & 1,625 \\
\hline $\begin{array}{l}\text { Estimated total gross } \\
\text { capacity (MW)* }\end{array}$ & 2,490 & 2,216 & 3,294 & 1,867 & 9,868 \\
\hline $\begin{array}{l}\text { Estimated gross capacity } \\
\text { less than } 50 \mathrm{~m}(\mathrm{MW})^{*}\end{array}$ & 1,337 & 1,361 & 1,340 & 1,294 & 5,332 \\
\hline Ave depth (m) & 50 & 48 & 52 & 48 & 50 \\
\hline Ave depth $<50 \mathrm{~m}(\mathrm{~m})$ & 46 & 44 & 46 & 45 & 45 \\
\hline Depth range (m) & \multicolumn{5}{|c|}{ Area at depth $\left(\mathrm{km}^{2}\right)$} \\
\hline$>60$ & 4 & 3 & 64 & 19 & 90 \\
\hline $55-60$ & 110 & 54 & 225 & 70 & 459 \\
\hline $50-55$ & 237 & 204 & 307 & 86 & 834 \\
\hline 45-50 & 226 & 174 & 218 & 167 & 785 \\
\hline $40-45$ & 143 & 140 & 166 & 189 & 638 \\
\hline $35-40$ & 32 & 101 & 24 & 36 & 193 \\
\hline$<35$ & 7 & 0 & 0 & 3 & 9 \\
\hline Average wind speed $(\mathrm{m} / \mathrm{s})$ & 9.2 & 9.2 & 9.3 & 9.3 & 9.25 \\
\hline
\end{tabular}




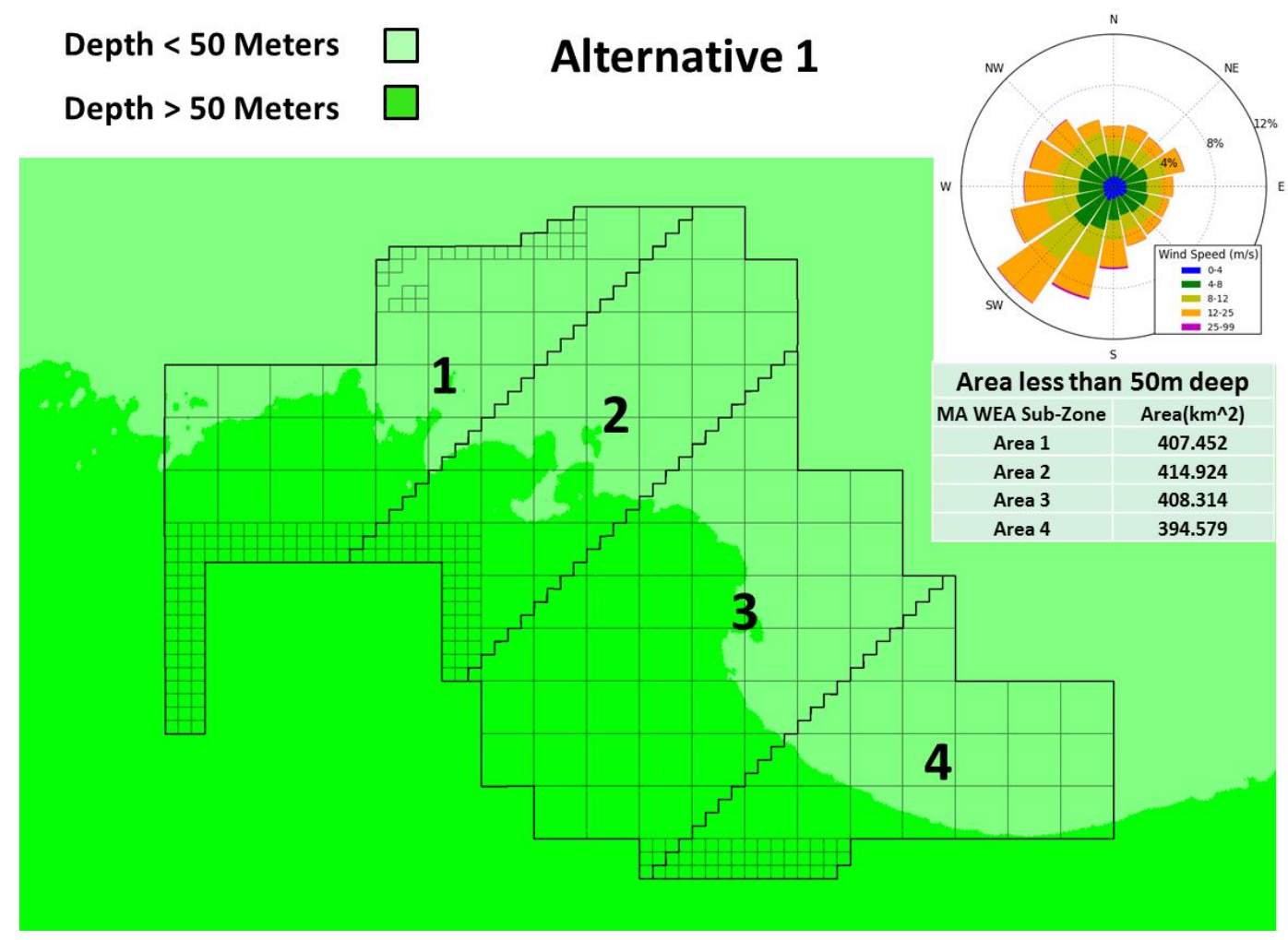

Figure 9. Alternative 1: Four leasing areas with approximately equal shallow water area less than $50 \mathrm{~m}$

(Source: NREL)

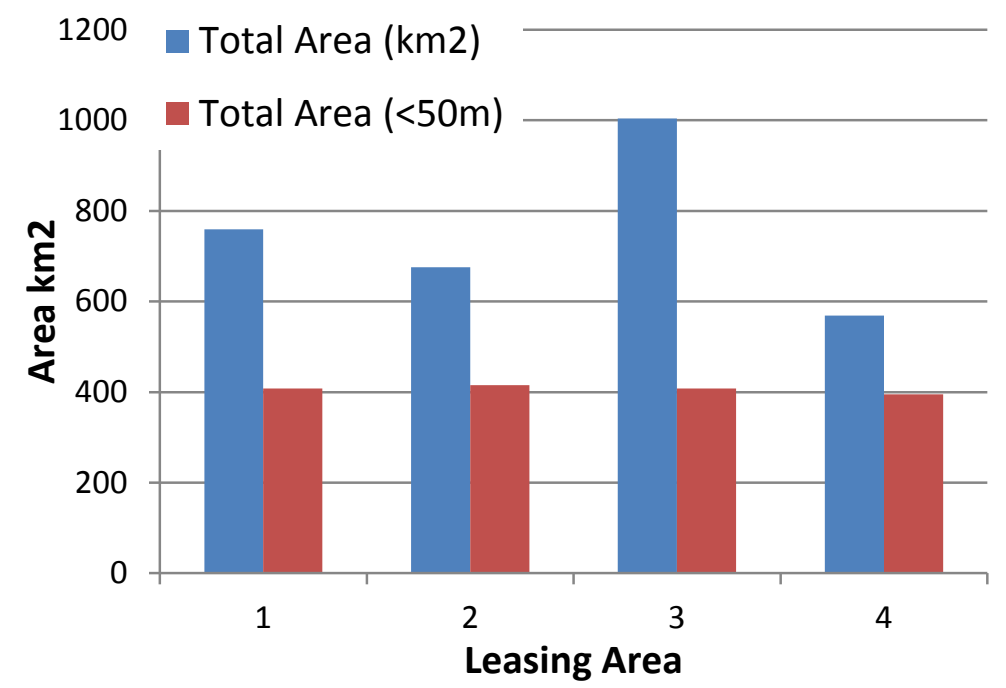

Figure 10. Alternative 1: Distribution of area among four leasing areas showing approximately equal shallow water less than $50 \mathrm{~m}$ (maximum variation of shallow water area $=\mathbf{5 \%}$ )

(Source: NREL) 


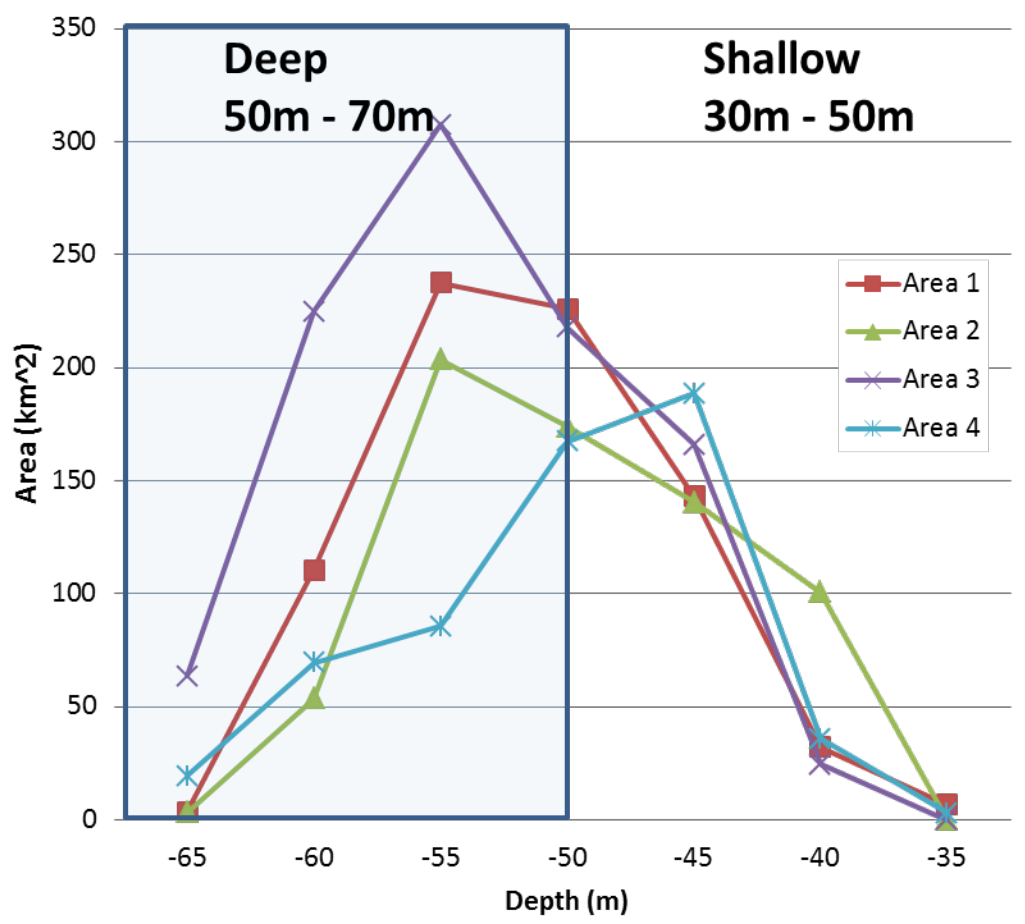

Figure 11. Alternative 1: Plot showing depth distribution for each leasing area over the entire MA WEA. Shaded area indicates depths that are greater than $50 \mathrm{~m}$.

(Source: NREL)

\subsubsection{Alternative 2}

Alternative 2 divides the MA WEA along diagonal southwest-to-northeast lines parallel to the prevailing wind direction and orthogonal to the isobaths using five leasing areas as shown in Figure 12. Similar to Alternative 1, each area has approximately the same total shallow water area in depths less than $50 \mathrm{~m}$. In Table 6, the total areas range from $445 \mathrm{~km}^{2}$ to $792 \mathrm{~km}^{2}$ for all five leasing areas, with the shallow area below $50 \mathrm{~m}$ ranging from $323 \mathrm{~km}^{2}$ to $328 \mathrm{~km}^{2}$. Using this alternative, each leasing area would be able to support at least one large near-term wind project using fixed-bottom technology in the areas less than $50 \mathrm{~m}$ deep. Table 6 shows that gross capacity is estimated between 1,058 MW and 1,075 MW for the WEA for water depths below 50 $\mathrm{m}$ using an $8 \mathrm{D} \times 12 \mathrm{D}$ layout. The primary advantage of Alternative 2 is that the number of auctionable leasing areas would be maximized (five) while providing prospective lessees with principal control over their respective upwind fetches. Compared to Alternative 1, the projects in shallower water would need to be constructed incrementally further out and in deeper water for the same turbine spacing.

Note that in Alternative 2, the total area varies significantly between leasing areas, which is caused by the differences in area over the deeper aliquots as shown in Figure 13. The deeper regions may also be able to support an additional wind project, but technology and cost to develop these regions limit commercial viability in the near term.

Figure 14 shows the distribution of bathymetry over all five leasing areas. From this plot it can be seen that leasing area 2 and 3 have the best distribution of shallow water with more area concentrated in the $35-\mathrm{m}$ to $40-\mathrm{m}$ bin. 
Table 9. Alternative 2: Five Leasing Area Diagonal Delineation for the MA WEA (Source: NREL)

\begin{tabular}{|c|c|c|c|c|c|c|}
\hline \multicolumn{7}{|c|}{ Alternative 2} \\
\hline & $\begin{array}{l}\text { Leasing } \\
\text { Area } 1\end{array}$ & $\begin{array}{l}\text { Leasing } \\
\text { Area } 2\end{array}$ & $\begin{array}{l}\text { Leasing } \\
\text { Area } 3\end{array}$ & $\begin{array}{l}\text { Leasing } \\
\text { Area } 4\end{array}$ & $\begin{array}{l}\text { Leasing } \\
\text { Area } 5\end{array}$ & $\begin{array}{l}\text { All } \\
\text { Areas }\end{array}$ \\
\hline Total area $\left(\mathrm{km}^{2}\right)$ & 642 & 484 & 792 & 644 & 445 & 3,008 \\
\hline Total area $<50 \mathrm{~m}\left(\mathrm{~km}^{2}\right)$ & 324 & 325 & 328 & 323 & 326 & 1,625 \\
\hline $\begin{array}{l}\text { Estimated total gross } \\
\text { capacity (MW)* }\end{array}$ & 2,107 & 1,588 & 2,599 & 2,113 & 1,461 & 9,868 \\
\hline $\begin{array}{l}\text { Estimated gross capacity } \\
\text { less than } 50 \mathrm{~m}(\mathrm{MW})^{*}\end{array}$ & 1,065 & 1,065 & 1,075 & 1,058 & 1,068 & 5,332 \\
\hline Ave depth & 50 & 47 & 51 & 51 & 48 & 50 \\
\hline Ave depth $<50 \mathrm{~m}(\mathrm{~m})$ & 46 & 44 & 45 & 46 & 45 & 45 \\
\hline Depth range $(\mathrm{m})$ & & & Area at $c$ & pth $\left(\mathrm{km}^{2}\right)$ & & \\
\hline$>60$ & 4 & 0 & 29 & 52 & 6 & 90 \\
\hline $55-60$ & 110 & 1 & 172 & 127 & 49 & 459 \\
\hline $50-55$ & 204 & 158 & 264 & 143 & 65 & 834 \\
\hline $45-50$ & 189 & 143 & 139 & 181 & 133 & 785 \\
\hline $40-45$ & 116 & 106 & 135 & 122 & 159 & 638 \\
\hline $35-40$ & 13 & 76 & 54 & 20 & 31 & 193 \\
\hline$<35$ & 7 & 0 & 0 & 0 & 3 & 9 \\
\hline Average wind speed $(\mathrm{m} / \mathrm{s})$ & 9.2 & 9.2 & 9.2 & 9.3 & 9.3 & 9.24 \\
\hline
\end{tabular}




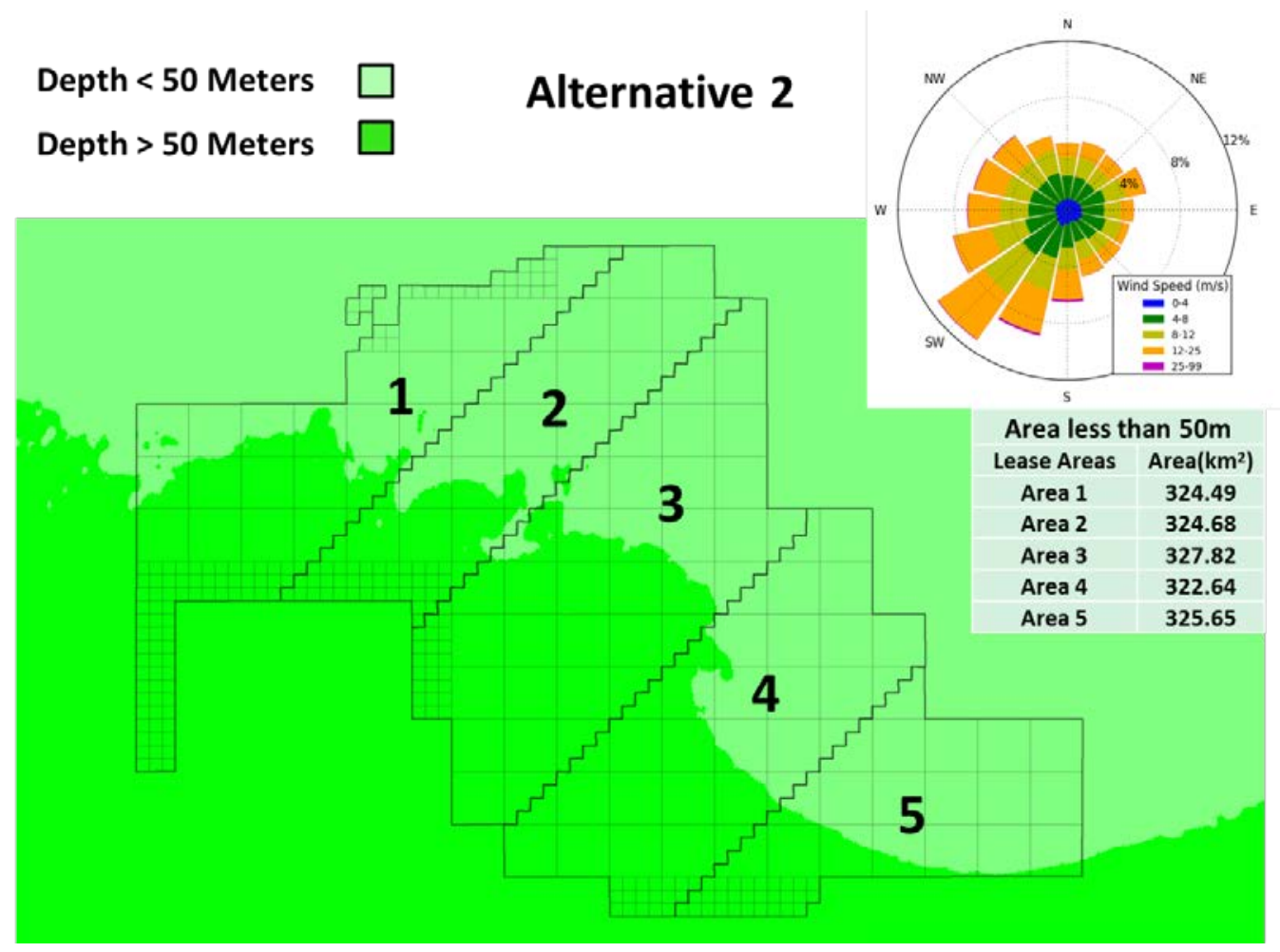

Figure 12. Alternative 2: Five leasing areas with approximately equal division of shallow water area less than $\mathbf{5 0} \mathrm{m}$

(Source: NREL)

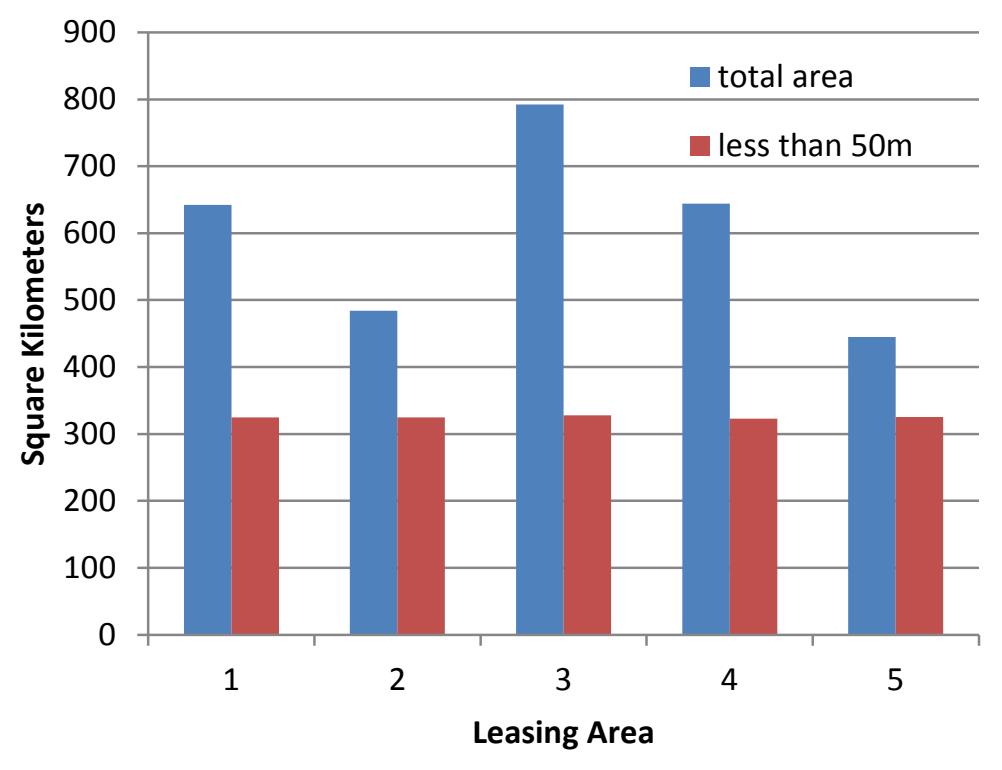

Figure 13. Alternative 2: Distribution of area among five leasing areas showing approximately equal shallow water less than 50 meters (Maximum $1.58 \%$ variation)

(Source: NREL) 


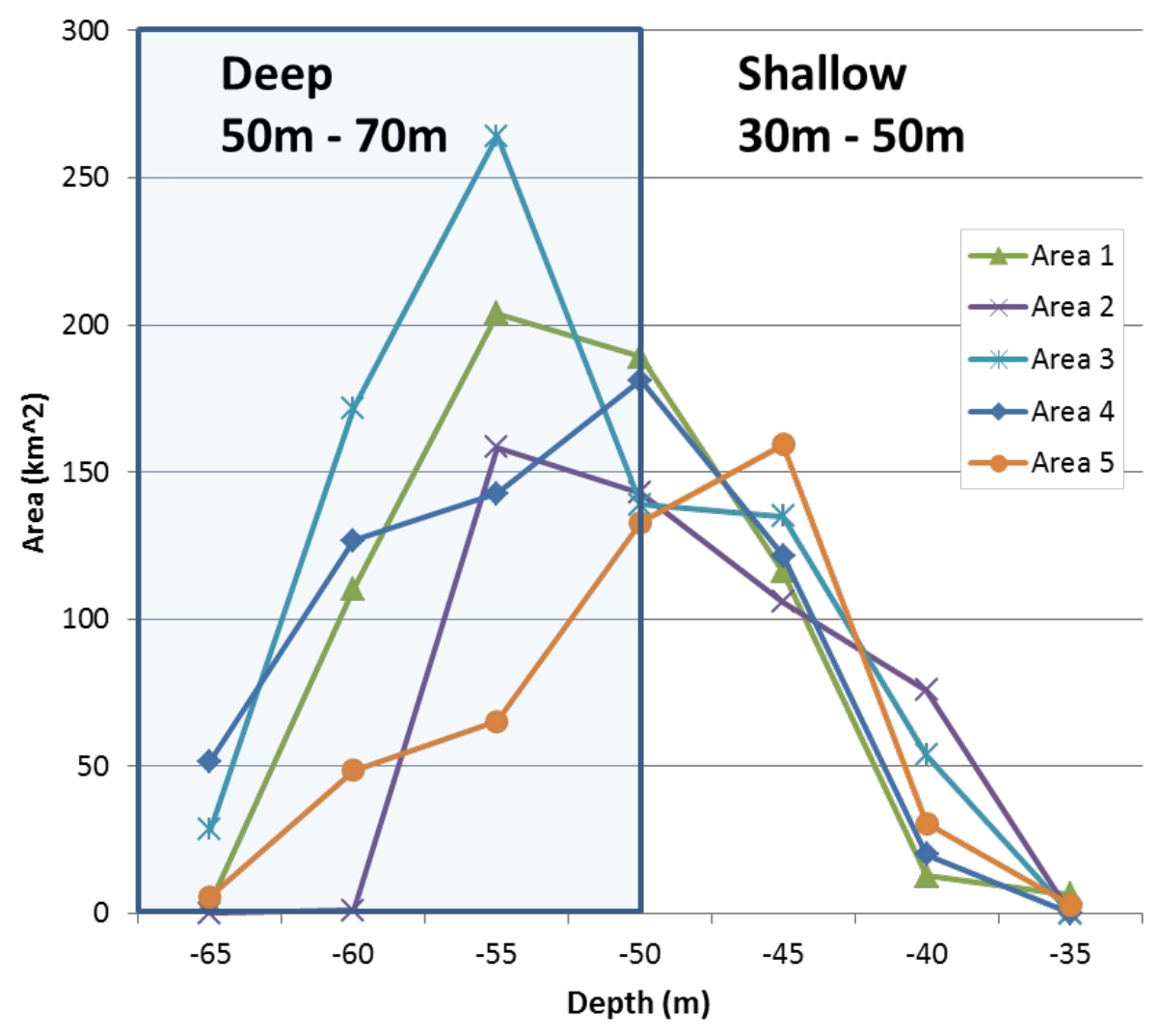

Figure 14. Alternative 2: Plot showing depth distribution for each leasing area over the entire depth range. Shaded area indicates depths that are greater than $50 \mathrm{~m}$.

(Source: NREL)

\subsubsection{Alternative 3}

Alternative 3 divides the MA WEA along diagonal lines parallel to the prevailing wind direction and orthogonal to the isobaths using the four leasing areas described in Alternative 1, but creating a fifth leasing area by carving deeper water areas from leasing areas 1 through 3 as shown in Figure 15. In Table 7, the leasing areas range in total area between $496 \mathrm{~km}^{2}$ and 844 $\mathrm{km}^{2}$. Leasing areas 1 through 4 have very similar areas sizes for water below $50 \mathrm{~m}$ that are nearly identical to the areas in Alternative 1, ranging between $395 \mathrm{~km}^{2}$ and $411 \mathrm{~km}^{2}$ (note that a small amount of shallow water $\left(4 \mathrm{~km}^{2}\right)$ was transferred to leasing area 5 from leasing area 2). Using this alternative, each leasing area 1 through 4 would be able to support at least one large nearterm wind project using fixed-bottom technology in the areas less than $50 \mathrm{~m}$ deep. Table 7 shows that the gross capacity is estimated between 1,294 MW and 1,349 MW for the area with water depths below $50 \mathrm{~m}$ using an $8 \mathrm{D} \times 12 \mathrm{D}$ layout in leasing areas 1 through 4 . The primary advantage of Alternative 3 is that shallow projects would still be easier to build and incrementally lower in cost (about the same as Alternative 1), but developers in leasing areas 1 through 3 would not be burdened with as much deep water, which could add significant cost to hold the lease. Compared to Alternative 2, the shallow region in each leasing area in Alternative 3 is larger, giving developers some flexibility to select the most optimal siting options. The disadvantage of this alternative, however, is that the upwind fetch would not be controlled by the lessees in leasing areas 1 through 3 because a developer in leasing area 5 would eventually install projects upwind. 
In Alternative 3, the total area varies the least of the three alternatives, but differences between leasing areas are still significant, as shown in Figure 16. The presence of leasing area 5 (deep site) may limit the ability of developers in leasing areas 1 through 3 to add a deeper phased development when the technology to develop these regions becomes commercially available (See phased analysis in Section 5).

Figure 17 shows the distribution of bathymetry over all of the leasing areas. From this plot, it can be seen that leasing area 2 still has the best distribution of shallow water with more area concentrated in the $35-\mathrm{m}$ to $40-\mathrm{m}$ bin.

Table 10. Alternative 3: Five Leasing Area Alternative with Separate Deep Water Site Delineation for the MA WEA

(Source: NREL)

\begin{tabular}{|c|c|c|c|c|c|c|}
\hline \multicolumn{7}{|c|}{ Alternative 3} \\
\hline & $\begin{array}{l}\text { Leasing } \\
\text { Area } 1\end{array}$ & $\begin{array}{l}\text { Leasing } \\
\text { Area } 2\end{array}$ & $\begin{array}{l}\text { Leasing } \\
\text { Area } 3\end{array}$ & $\begin{array}{l}\text { Leasing } \\
\text { Area } 4\end{array}$ & $\begin{array}{l}\text { Leasing } \\
\text { Area } 5\end{array}$ & $\begin{array}{l}\text { All } \\
\text { Areas }\end{array}$ \\
\hline Total area $\left(\mathrm{km}^{2}\right)$ & 531 & 496 & 844 & 569 & 567 & 3,008 \\
\hline Total area $<50 \mathrm{~m}\left(\mathrm{~km}^{2}\right)$ & 407 & 411 & 408 & 395 & 4 & 1,625 \\
\hline $\begin{array}{l}\text { Estimated total gross } \\
\text { capacity (MW)* }\end{array}$ & 1,744 & 1,626 & 2,770 & 1,867 & 1,862 & 9,868 \\
\hline $\begin{array}{l}\text { Estimated gross capacity less } \\
\text { than } 50 \mathrm{~m}(\mathrm{MW})^{*}\end{array}$ & 1,336 & 1,349 & 1,340 & 1,294 & 13 & 5,332 \\
\hline Average depth $(\mathrm{m})$ & 47 & 45 & 50 & 48 & 56 & 50 \\
\hline Average depth $<50 \mathrm{~m}(\mathrm{~m})$ & 46 & 44 & 46 & 45 & 50 & 45 \\
\hline Depth range(m) & \multicolumn{6}{|c|}{ Area at depth $\left(\mathrm{km}^{2}\right)$} \\
\hline$>60$ & 0 & 0 & 19 & 19 & 52 & 90 \\
\hline $55-60$ & 0 & 0 & 113 & 70 & 276 & 459 \\
\hline $50-55$ & 124 & 84 & 304 & 86 & 236 & 834 \\
\hline $45-50$ & 226 & 170 & 218 & 167 & 4 & 785 \\
\hline $40-45$ & 143 & 140 & 166 & 189 & 0 & 638 \\
\hline $35-40$ & 32 & 101 & 24 & 36 & 0 & 193 \\
\hline$<35$ & 7 & 0 & 0 & 3 & 0 & 9 \\
\hline Average wind speed $(\mathrm{m} / \mathrm{s})$ & 9.2 & 9.2 & 9.3 & 9.3 & 9.2 & 9.24 \\
\hline
\end{tabular}




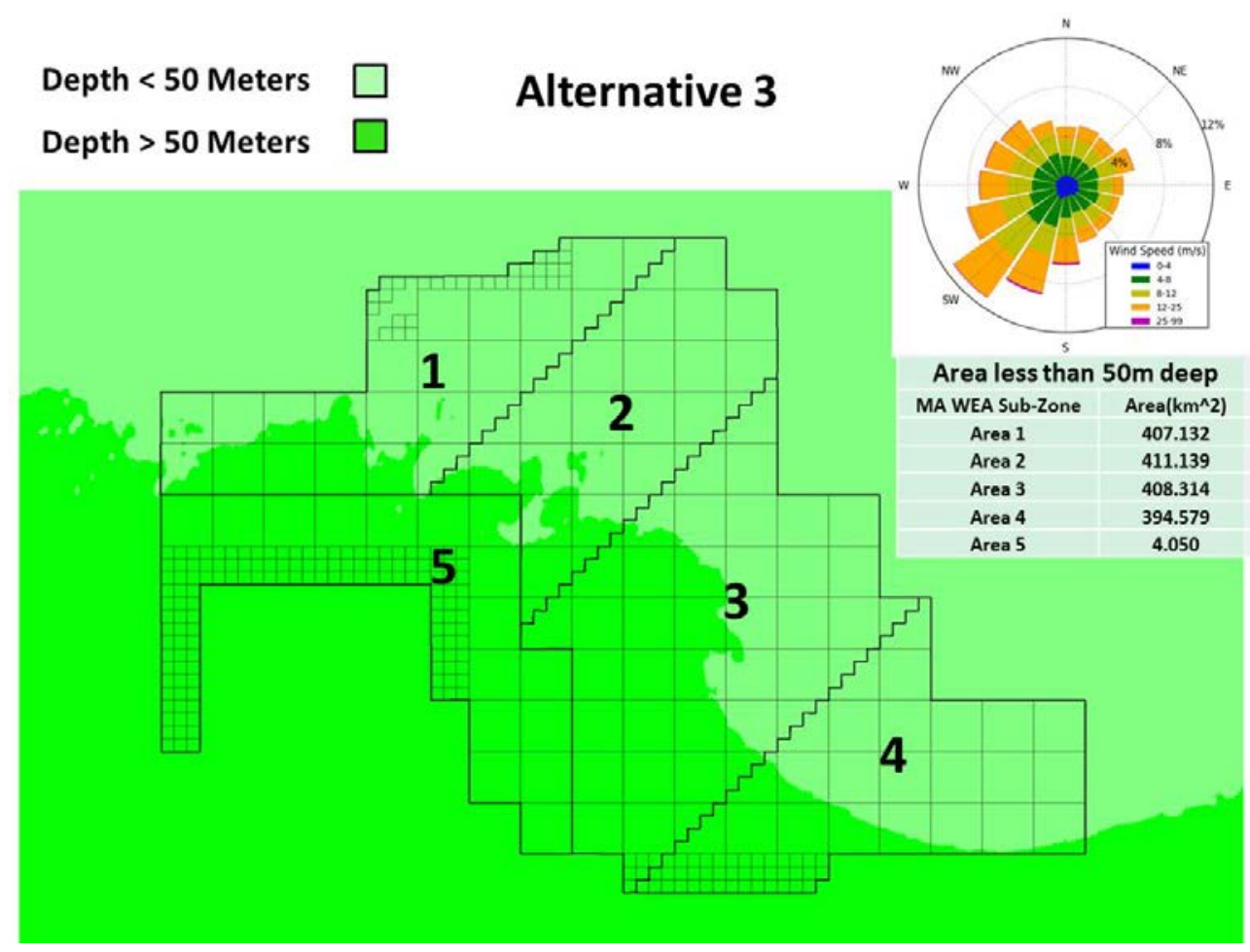

Figure 15. Alternative 3: Five leasing areas with four approximately equal shallow areas and one area containing only deep water

(Source: NREL)

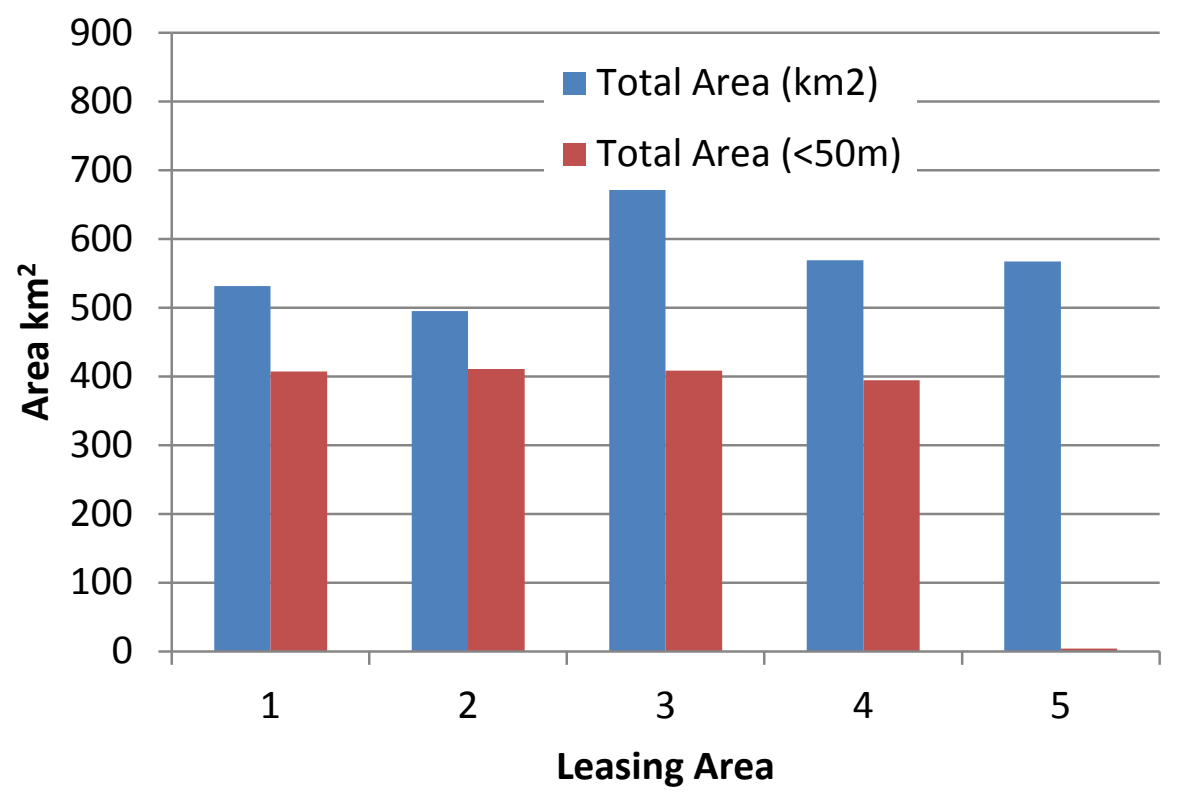

Figure 16. Alternative 3: Distribution of area among five leasing areas showing approximately equal shallow water less than $50 \mathrm{~m}$ in leasing areas 1-4 with a maximum variation of $5 \%$

(Source: NREL) 


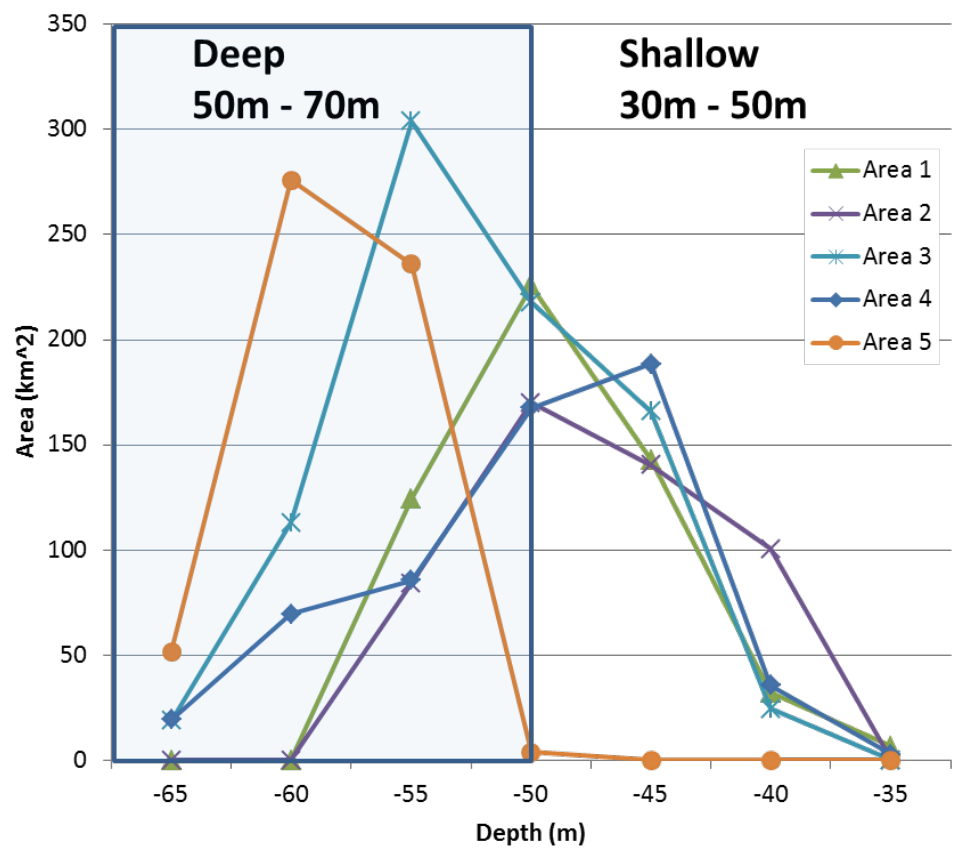

Figure 17. Alternative 3: Depth distribution for five leasing areas with four approximately equal shallow areas and one area containing only deep water. Shaded area indicates water depth greater than $\mathbf{5 0} \mathrm{m}$.

(Source: NREL)

\subsubsection{Delineation Summary}

NREL researchers evaluated the three leasing area alternatives presented in this paper. Each provides a reasonable approach with advantages and disadvantages to delineate the Massachusetts offshore wind energy area into four or five leasing areas. All of the alternatives are feasible and would allow offshore wind developers to install large-scale projects of at least $500 \mathrm{MW}$ with minimal obstruction from adjacent wind projects.

Of the three alternatives, NREL prefers Alternative 2. The primary basis of this preference is because it is believed that it would maximize the development potential of the MA WEA while minimizing the effects of neighboring projects on adjacent wind plants. With the five leasing area option, each area could support at least two 500-MW projects, and some with even more capacity, depending on the spacing (discussed further in Section 5).

The overarching issue for the MA WEA is the greater water depths, compared to most European sites developed as of 2013, which will be a primary factor in driving the economics of this WEA. NREL recommends that BOEM consider methods to discount the deepest aliquots to reduce the burden on the lessees. 


\section{Wake and Array Analysis}

\subsection{Analysis Tool: OpenWind Enterprise}

The OpenWind Enterprise tool is a commercial wind energy facility design tool created by AWS Truepower and licensed to NREL. It has the capability to perform layout design, flow modeling, wake modeling, and energy assessment. OpenWind Enterprise was selected for its interoperability with GIS data as well as its capability to model deep array wake effects. The primary OpenWind components are described as follows.

\subsubsection{WindMap Flow Model}

The WindMap flow model within OpenWind is based on the NOABL code (Phillips 1979) and solves the conservation of mass equation to generate a three-dimensional wind flow map. The model accounts for moderate changes in terrain and surface roughness when used in conjunction with measured time series meteorological data.

\subsubsection{OpenWind Wake Model}

Wake models and scientific approaches for predicting the influence of upstream turbines are evolving rapidly. Generally, the accepted commercially available wake modeling codes have improved over the past decade but still carry a high degree of uncertainty because they do not include accurate physical models for some important phenomena, such as turbulence, atmospheric stability, wake meandering (unsteady transverse displacements of the disturbed flow downstream of the turbine), and fundamentals, such as the correct choice of freestream wind speed profile (Barthelmie et al. 2010). Even the most advanced techniques for wind turbine wake modeling carry a relatively high degree of uncertainty. More computationally intensive research methods are currently under development in research laboratories but are not yet practical for commercial use (e.g., large-eddy simulations) (Churchfield et al. 2012). Even though these methods may produce more accurate results, they are still under development and are computationally too expensive to be used for wind energy evaluations like the one conducted for this report. As a result, it is difficult to make an accurate comparison of the different wake models that are currently available.

The model used to perform the wake loss analysis for this report is the OpenWind Deep Array Fast Eddy-Viscosity Wake Model (DAWM). As of the writing of this report, it is one of the most widely used and accepted tools in the industry. NREL's prior experience (mostly land-based) indicates that the OpenWind DAWM performs better than other models that are currently available. The DAWM module enhances the open-source version of OpenWind and provides additional accuracy in the modeling of the downwind effects of freestream- and turbinegenerated turbulence and predicts the recovery of the freestream wind flow field in the array. DAWM within OpenWind (AWS Truepower 2010) is a combination of the open-source standard Eddy-Viscosity (EV) model and a roughness effect associated with each turbine. 


\subsubsection{OpenWind Layout Design}

The gridded turbine layer function within OpenWind was used to create maximum capacity layouts to fill the WEA leasing areas using the turbine spacing specified by NREL. Square or triangular tiling was used with manually adjusted bearing, obliquity, and offset to obtain the desired number of turbines. Where the layouts are adjacent to the line of delineation between leasing areas, the layouts force a minimum setback of $8 \mathrm{D}$ from the delineation line. This is realistic because developers in the leasing areas do not have control over adjacent layouts and a setback is required to ensure minimum turbine spacing from upwind turbines that may be installed outside their respective leasing areas. This is a practical requirement of layout design to maintain turbine spacing in each leasing area and is not viewed strictly as a buffer, although the setback does act in the same way as a buffer imposed to allow wakes to dissipate. Additional buffers will probably be needed to further reduce wake losses in the development of each leasing area, which could dictate more extensive setbacks. For the MA WEA, NREL assumed that setbacks of $50 \mathrm{D}(6.3 \mathrm{~km})$ were maintained between phased developments within the same leasing areas. The 50-D setback was adopted because it corresponded to less than a $1.0 \%$ increase of wake losses from upstream wind facilities of the same size. The 50-D setback rule was not applied, however, when the upstream project was in an adjacent leasing area, as it was assumed that developers would not necessarily have control over neighboring developments.

Layouts can also be generated within OpenWind by optimizing for energy or cost, rather than using the gridded turbine layer function. This iterated optimization is commonly used for landbased projects in which many development constraints, as well as road and cable layers, can be optimized to produce a layout that evolves organically into the best fit for the situation. For this assessment, NREL used the gridded turbine layer function because it is more applicable to the open offshore environment and allows for a quick comparison of different layout scenarios.

Wind turbine array modeling used the NREL 5-MW reference turbine (Jonkman et al. 2009) in all analysis that has a rotor diameter of $126 \mathrm{~m}$. This turbine is representative in nameplate capacity of the turbines being proposed and is considered conservative with respect to current technology in terms of rotor diameter, power performance, and capacity factor.

\subsubsection{OpenWind Energy Assessment}

The energy capture function in OpenWind sums the energy produced by the turbines using 72 direction sectors and 71 wind speed steps. It calculates and stores the energy yield, capacity factor, and wake losses associated with each turbine. Losses other than those caused by the wake effects can be accounted for by directly entering assumptions or calculating from other layers.

\subsection{NREL Analysis of MA WEA Using OpenWind}

In Section 4, NREL researchers concluded that there are advantages and disadvantages for each of the delineation alternatives and that any of the three options would be feasible for BOEM to implement (depending on specific objectives). Of the three alternatives, NREL prefers Alternative 2. The primary basis for this preference is because it is believed that this layout would maximize the development potential of the WEA while minimizing the effects of neighboring projects on adjacent wind plants. Each area could support at least two 500-MW projects, and some areas could support three depending on the spacing. Five areas could maximize the potential diversity among developers and therefore the potential economic benefits 
for Massachusetts. The overarching issue for the MA WEA is the greater water depths, which will be a primary factor in driving the economics of this WEA.

For the MA WEA, the turbine spacing and the spacing between major project phases (i.e., the buffers) will determine the energy losses caused by turbine wakes, the depth at which turbines are installed, and the cost of the inter-array cables. This section shows how trade-offs can be made among these variables within the three delineation scenarios. Based on a review of historic and future European offshore wind plants and the information contained in the Call nominations, described in Section 2, full development of the MA WEA would not be expected as a full build of all of the available area. Instead, developers are expected to judiciously exploit the shallowest water areas first. To maximize energy output and minimize the consequences of deep array turbulence, developers would be expected to provide internal buffer zones within their leasing area that separate projects in unit phases. However, a study of full development nameplate capacity, in which all available area within the leasing area is assumed to be populated with turbines, does provide a good basis for comparing one area to another. However, it would probably overestimate wake losses. As such, NREL researchers conducted both full development and 500-MW unit project size analyses.

A summary of these analyses is shown in Table 11.

Table 11. Summary of Array Spacing Analysis Conducted to Assess Wake Losses and Energy Production Potential for the MA WEA

(Source: NREL)

$\begin{array}{lll}\text { Analysis Performed } & \text { Alternative 1: } & \text { Alternative 2: } \\ & \text { Four Leasing Area } & \text { Five Leasing Area } \\ & \text { Scenario } & \text { Scenario } \\ & \text { (Diagonal) } & \text { (Diagonal) }\end{array}$

\section{Full Development Analysis}

$8 \mathrm{D} \times 8 \mathrm{D}$ spacing
(max capacity)
$8 \mathrm{D} \times 12 \mathrm{D}$ spacing
(max capacity)
8 D x 15 D spacing
(max capacity)

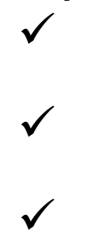

Phased 500-MW Unit Development

$8 \mathrm{D} \times 8 \mathrm{D}$ 500-MW

phased development

$8 \mathrm{D} \times 12 \mathrm{D} 500-\mathrm{MW}$

phased development

$8 \mathrm{D} \times 15 \mathrm{D} 500 \mathrm{MW}$

phased development

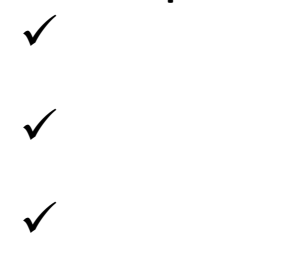

\author{
Alternative 3: \\ Five Leasing Area \\ Scenario (four shallow \\ and one deep leasing \\ area)
}
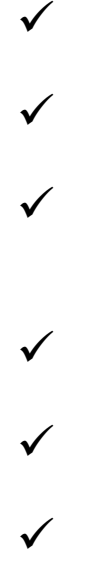
The analysis, summarized in Table 11, includes both full development scenarios and phased development. For all of the analysis cases, NREL researchers used three turbine spacing scenarios: $8 \mathrm{D} \times 8 \mathrm{D}, 8 \mathrm{D} \times 12 \mathrm{D}$, and $8 \mathrm{D} \times 15 \mathrm{D}$. The numerical results of these analyses are shown in Table 5, Table 6 , and Table 7. Some of these analyses are also shown graphically in the following sections to illustrate key points. The base case in most of the graphical illustrations was $8 \mathrm{D} \times 12 \mathrm{D}$ spacing, although all spacing scenarios are represented throughout the report. In the Rhode Island/Massachusetts WEA and the Maryland WEA studies conducted by NREL as part of the WEA analyses conducted for BOEM, a baseline spacing of $8 \mathrm{D}$ x $8 \mathrm{D}$ was used, which is representative of the industry average (Figure 3, Table 3) and the resource assessment studies of the United States (Musial and Ram 2010, Musial 2013a, Musial et al. 2013b). For the New Jersey analysis, NREL used a reference spacing of $10 \mathrm{D}$ x $12 \mathrm{D}$ as requested by New Jersey (Musial et al. 2013c). The $8 \mathrm{D} \times 12 \mathrm{D}$ spacing is conservative in estimating total capacity than the $8.5 \mathrm{D}$ x $10.5 \mathrm{D}$ average spacing proposed by developers in the Massachusetts Call (Table 1 and Table 2).

A 500-MW project size is typical unit capacity for what developers are proposing for offshore wind projects in a single phase, even though Table 1 and Table 2 show the average total nameplate project capacity to be over $1,500 \mathrm{MW}$. This is because most projects are envisioned by the developers to be installed in multiyear phases. The 500-MW scale has also been used as a standard reference for DOE offshore wind project cost modeling (Tegen 2012) and is considered a scale in which offshore wind cost economies of scale could be reached (Maples 2012). Using array densities that are indicative of the Call nominations (see Table 1 and Table 2), NREL researchers determined that each leasing area in Massachusetts could support at least two 500MW wind projects or a total of 5,000 MW for the entire WEA. It was assumed that each leasing area would deploy one 500-MW project in the near term under phase 1 (6-8 year time frame), and a second phase of another 500-MW project would be deployed using deeper water technology (10-16 year time frame). These time frames are consistent with the time frames found in the RFI and Call responses.

The analysis approach assumed that phase 1 projects were deployed first, and the performance and wake loss analysis were conducted without the presence of phase 2 turbines. Then the phase 2 projects were assumed to be deployed $50 \mathrm{D}$ upwind of the phase 1 project, and their relative impacts on the original array were examined. A 50-D setback $(6.3 \mathrm{~km})$ from phase 1 projects was imposed on the phase 2 development based on a general finding that wake losses introduced by the upstream wind project in Phase 2 were limited to about $1 \%$ of annual energy using the OpenWind analysis program. By comparison, a similar analysis showed that $80 \mathrm{D}(10.1 \mathrm{~km})$ resulted in about $0.7 \%$ additional wake losses. The 80 -D setback criterion was not used because it pushed the phase 2 turbines into the deepest waters, which could add significant additional cost. Although the rationale for selecting a 50-D setback was arbitrary, the researchers estimated that a $1 \%$ loss was a reasonable tradeoff, and that additional benefits from further spacing would be marginal. A more rigorous analysis is recommended for establishing actual setback and buffer requirements. 


\subsection{Maximum Development Capacity}

NREL researchers evaluated the development capacity of the total MA WEA for each of the delineation and turbine spacing scenarios using the NREL 5-MW reference turbine (Jonkman et al. 2009) to create full development layouts that maximized the nameplate capacity of installed turbines without imposing further siting constraints for attributes such as water depth. One exception was the assumption that developers would self-impose an internal setback buffer of 8 $\mathrm{D}$ from the delineation line, anticipating that neighboring developers could feasibly place turbines near the delineation boundary. This is consistent with NREL's analysis for the Rhode Island/Massachusetts, Maryland, and New Jersey WEAs (Musial et al. 2013a, Musial et al. 2013b, and Musial et al. 2013c). A layout map with the 8-D setback buffers is shown in Figure 18. In this figure, an $8 \mathrm{D} \times 12 \mathrm{D}$ full build analysis is shown for Alternative 3 ; however, the same data for Alternatives 1 and 2 can be found in Table 5, Table 6, and Table 7. The maximum nameplate capacity for this delineation alternative of the MA WEA determined to be about 8,230 MW for the total WEA. On average, each leasing area can support between 1,220 MW and 2,295 MW. By comparison, the five leasing area diagonal option can support an upper limit of 8,480 MW, with a range between 1,220 MW and 2,240 MW per leasing area. The four leasing area option yielded a maximum nameplate capacity of $8,810 \mathrm{MW}$, with a range per leasing area between 1,695 MW and 2,955 MW. The variability between leasing areas was mostly because of area differences in the deeper water (greater than $50 \mathrm{~m}$ ). This is because equitable distribution of area in shallow water depths (below $50 \mathrm{~m}$ ) was given a much higher weighting than achieving an overall area balance (see Section 4).

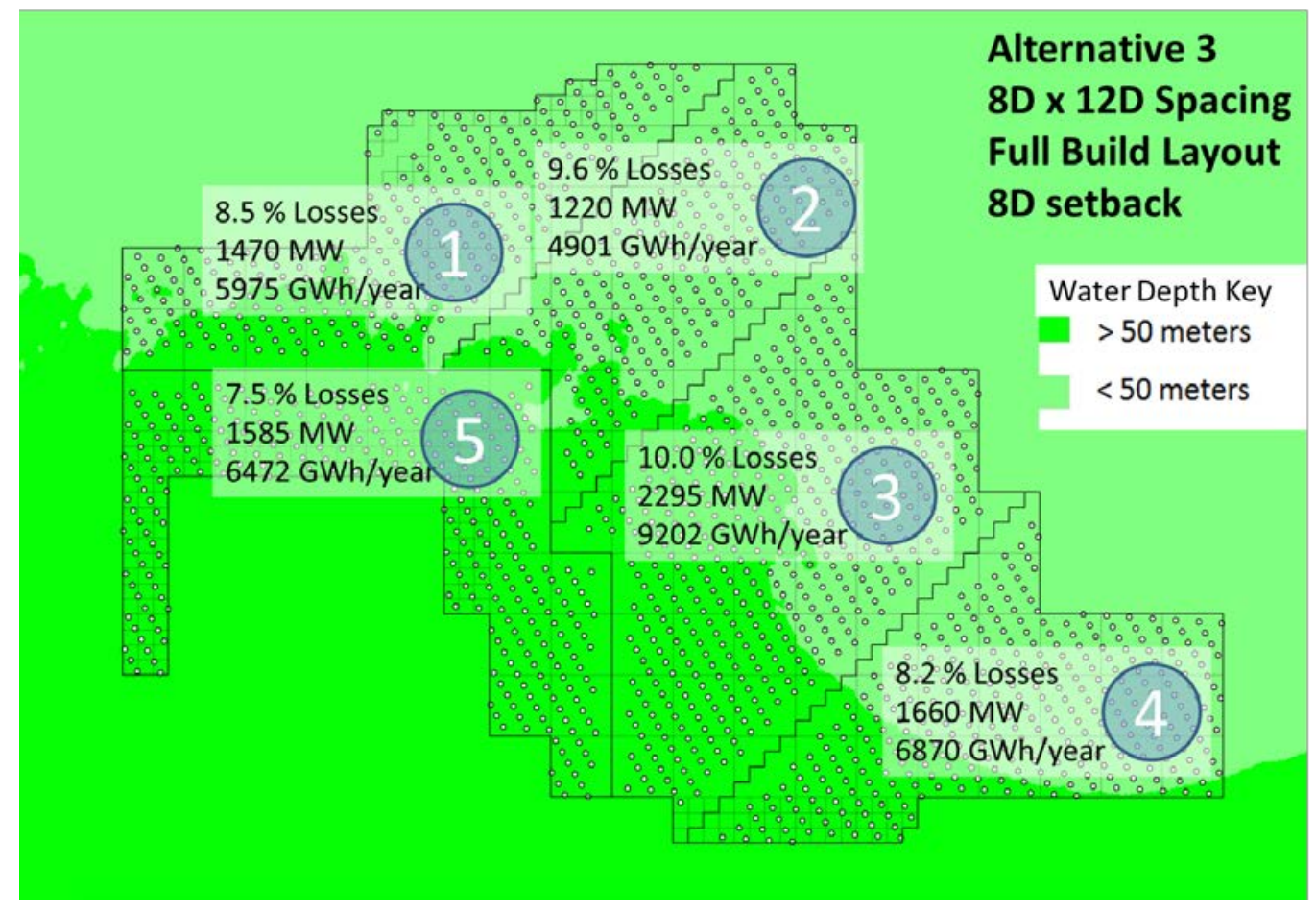

Figure 18. MA WEA layout map for the $8 \mathrm{D} \times 12 \mathrm{D}$ full build (development) scenario using the Alternative 3 delineation scenario showing the maximum nameplate capacity, wake losses, and expected annual energy production for each of the five leasing areas (Source: NREL) 
As mentioned earlier, because development is not expected to follow a maximum capacity scenario, the full development capacities should be considered a theoretical upper bound for the MA WEA under the specific spacing scenarios prescribed.

NREL's comparison of all of the leasing areas analyzed for the MA WEA shows a reasonable balance in terms of potential development challenges and cost among the delineated leasing areas in each alternative, but there are some differing characteristics that could have an impact on developability. One important aspect (although not fully evaluated) is the distance to possible interconnection sites and cable routes that may require easements through neighboring leasing areas. Many developers indicated a preference or need to direct their power off-take cables toward the northwest, either to Buzzards Bay, Narragansett Bay, or points in eastern Connecticut or Long Island power grids, although some developers did indicate that their export cables could land in Cape Cod and the islands. If there is a preference to export power toward the more populated parts of Massachusetts, Rhode Island, and New York, leasing areas on the west side would have an advantage. In any case, it may be prudent to consider options for coordinating cable routing strategies and possible easements. Within the MA WEA this could be a strong driver in appraising leasing area value.

\subsection{Capacity Factor after Wake Losses}

The gross capacity factor is the average energy output (before any losses outside the turbine itself are considered) as a percentage of the maximum possible energy output if the turbines were operating continuously at their rated power output, which is $5 \mathrm{MW}$ per turbine for this analysis. For each delineation option, the gross capacity factor was calculated using the OpenWind analysis tool, and methods and layouts described in Section 5.1 and Section 5.2. Table 5, Table $\underline{6}$, and Table 7 provide the gross capacity factors for all of the leasing areas and delineation options after wake losses are subtracted. These capacity factors after wake losses are estimated to be in the range of $45 \%$ to $49 \%$, depending on the leasing areas and the turbine layout. The capacity factors generally range about $1 \%$ lower in the western leasing areas. Furthermore, the capacity factors reported in this analysis should not be confused with the net capacity factor (NCF), which is based on actual power delivered on shore and would account for such things as electrical losses in transmitting the power to shore, blade soiling, and other operating inefficiencies. NCF values would likely be nearer to $40 \%$ as estimated by some of the RFI and Call nominations shown in Table 1 and Table 2.

\subsection{Wake and Array Losses}

\subsubsection{Introduction}

Wind turbine wakes within an array can result in losses in energy production and increases in structural fatigue loading. The severity of wake conditions is affected by climatic conditions, such as the ambient wind speed, ambient turbulence intensity, atmospheric stability conditions, and prevailing wind directions. Wake characteristics are also strongly influenced by the physical parameters of the wind facility including the number of turbines in operation, their spacing, and the wind plant layout. Further wake losses can also be induced by the presence of neighboring wind plants.

Atmospheric stability is a measure of the wind's tendency to rise and fall vertically as it flows in the horizontal direction. When the atmosphere is stable, the thermal layers of the atmosphere are 
stratified, which means that heavier, cooler air is at the lowest layer and the warmer air is aloft. In this case, the flow generally stays in horizontal layers and has little tendency to mix vertically. If the temperature differential is reversed and the warmer air is below and cooler air is aloft, then the atmosphere is unstable. In this case, the two layers have a tendency to mix, with the cooler air descending and the warmer air rising. This vertical movement results in turbulence in the flow. When this type of unstable condition is present, the turbulent mixing of layers increases the available energy to the wind turbines by dissipating the wakes more rapidly and bringing more kinetic energy into the array. This is a complex condition of the atmosphere that is difficult to model and may not be fully represented by the current wind plant layout tools (including OpenWind).

Figure 19 is a photo of the Horns Rev I offshore wind facility off the west coast of Denmark. The photo was taken on a day when fog was formed because of special atmospheric conditions resulting from a layer of cold humid air moving above a warmer sea surface (Hasager et al. 2013). The vapor trails allow wind flow visualization throughout the array and illustrate the creation of wakes downstream of the turbines. The photo shows that the wind is coming from the lower left corner and blows down the rows of the array. As the wakes propagate downstream they expand, and mix with wakes from turbines deeper in the array. This leads to increased turbulence and lower wind speeds deeper in the array and reduces power output at turbines downstream. Horns Rev I uses a symmetrical gridded array with 7 D x 7 D turbine spacing and a turbine array density of $6.4 \mathrm{MW} / \mathrm{km}^{2}$, compared to $5.0 \mathrm{MW} / \mathrm{km}^{2}$ for the $8 \mathrm{D} \times 8 \mathrm{D}$ spacing, 3.3 $\mathrm{MW} / \mathrm{km}^{2}$ for the $8 \mathrm{D} \times 12 \mathrm{D}$ spacing, and $2.6 \mathrm{MW} / \mathrm{km}^{2}$ for the $8 \mathrm{D} \times 15 \mathrm{D}$ spacing analyzed in this report. 


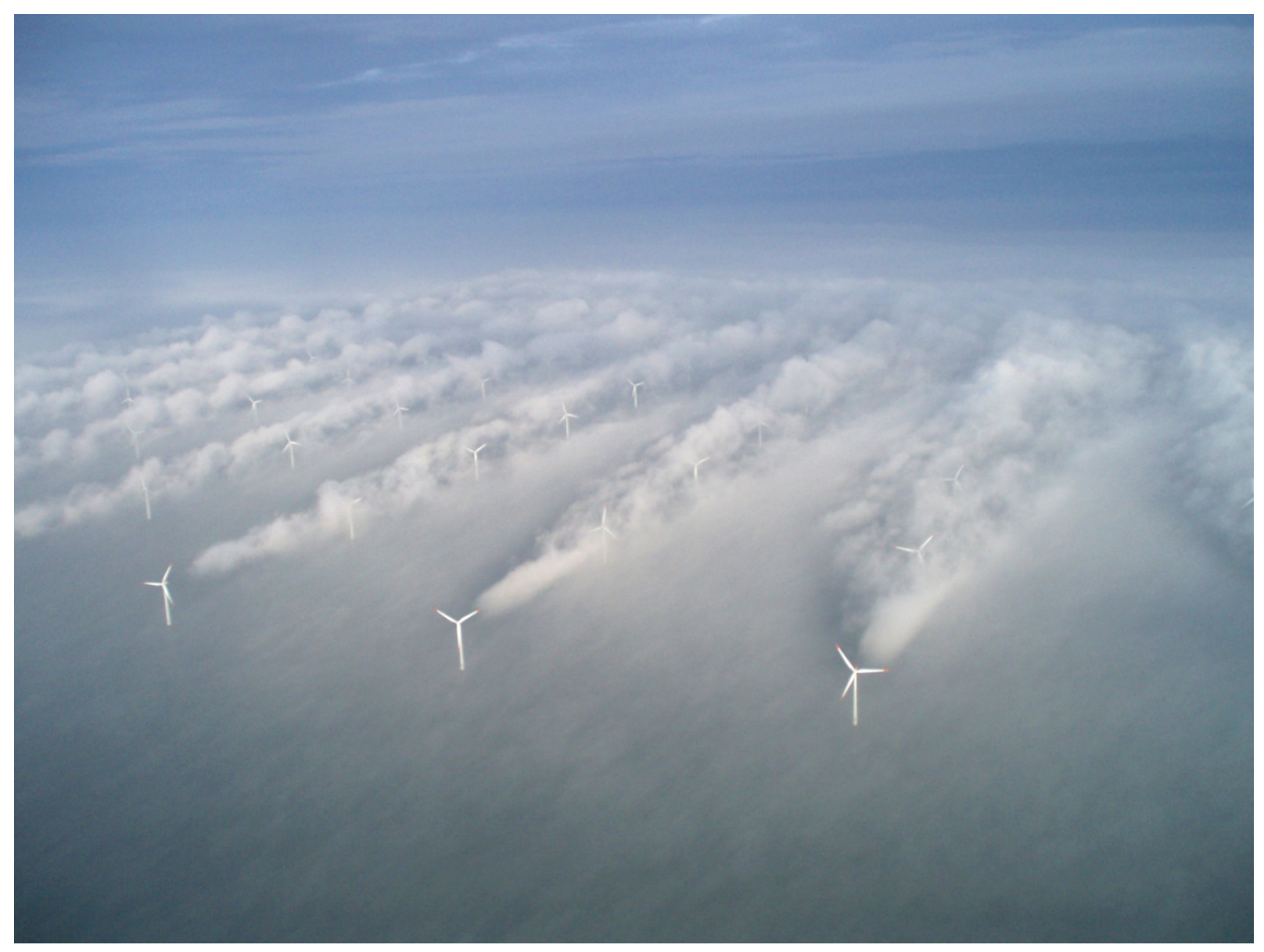

Figure 19. Horns Rev I wind farm

(Source: Vattenfall, Photo by Christian Steiness)

\subsubsection{Effect of Grid Orientation}

Prevailing wind directions must be considered when orienting the turbines to minimize the wake effects. NREL researchers used OpenWind to determine the grid orientation that provided the lowest wake losses for each grid array spacing scenario considered. For a gridded array, the orientation is described in OpenWind by a bearing angle, or a grid orientation angle. The grid orientation angle uses the BOEM leasing area Outer Continental Shelf block grid as a reference frame, as illustrated in Figure 20. 


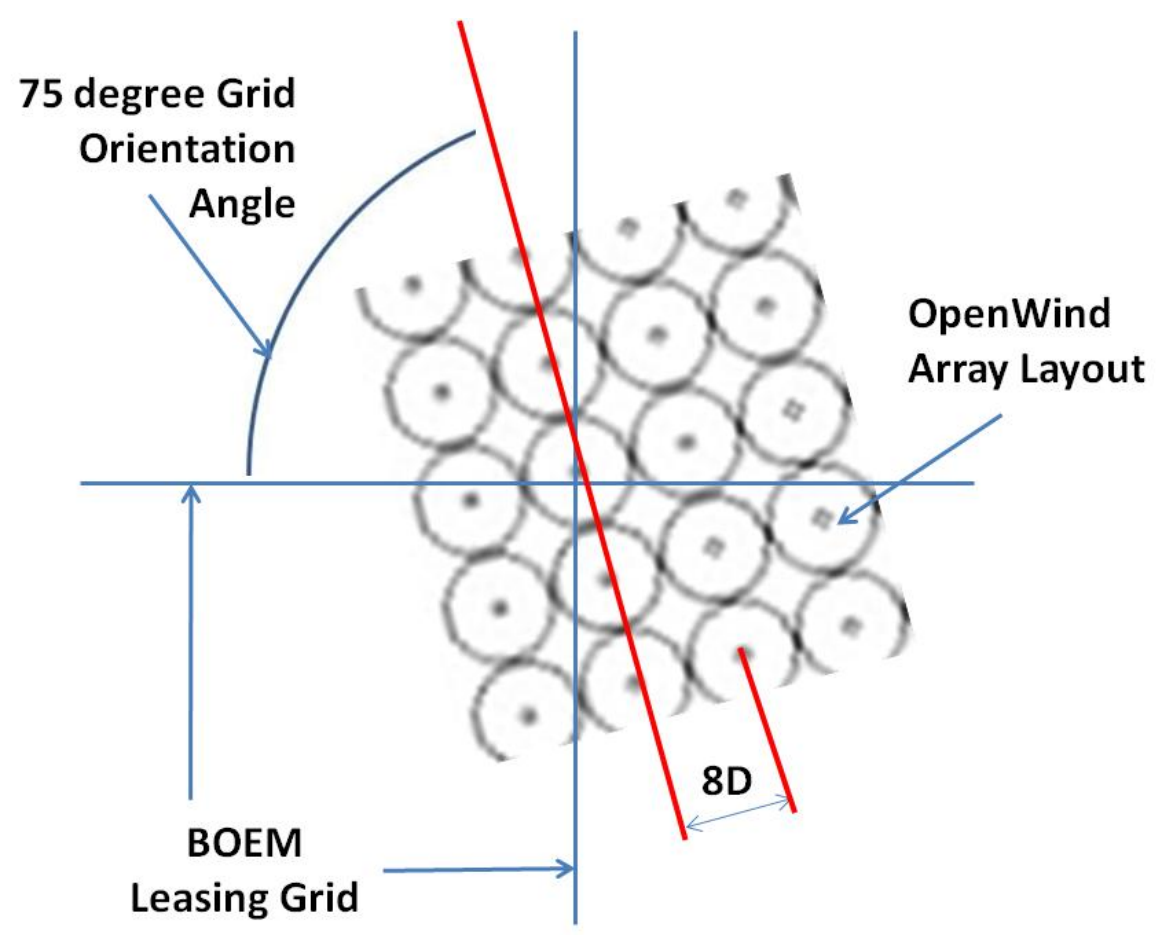

Figure 20. OpenWind uses the BOEM leasing grid as a reference frame for the grid orientation angle of the turbine array. The example shown is for $8 \mathrm{D} \times 8 \mathrm{D}$ spacing with a 75-degree grid angle. The MA WEA grid angles were found to be 60 degrees for minimum wake losses. (Source: NREL)

NREL performed the analysis in OpenWind using the wind rose shown in Figure 8 to rotate the grid orientation at 5-degree increments to find the angle relative to the leasing grid and the prevailing wind with the lowest wake losses. The results revealed that the modeled wake losses, based on capacity factor, varied by only $0.1 \%$ over the full range of grid rotation under a full build scenario. This variation indicated that, for the $8 \mathrm{D} \times 12 \mathrm{D}$ grid array spacing, the grid orientation angle was relatively unimportant in determining the total plant losses.

The grid orientation angle that yielded the lowest wake losses was found to be at 60 degrees for the $8 \mathrm{D} \times 12 \mathrm{D}$ spacing in the MA WEA. This orientation is rotated 15 degrees clockwise from 45-degree diagonals of the leasing area delineation boundaries.

\subsubsection{Wake Loss Summary}

Measurements of annual average wake losses at some offshore wind power plants in European waters have been in the range of $10 \%$ to $20 \%$ (Barthelmie 2013; Hansen et al. 2012) based on available wake measurement data. As part of the MA WEA wake analysis, NREL researchers examined the array efficiency (100\% ideal efficiency - \% wake losses) for the three delineation alternatives in Figure 4. A summary of the analysis results is given in Table 12. 
Table 12. MA WEA Array Efficiency Analysis for Three Leasing Area Alternatives and Three Turbine Grid Spacing Geometries

(Source: NREL)

\begin{tabular}{|c|c|c|c|c|c|c|}
\hline \multicolumn{7}{|c|}{ Array Efficiency (\%) } \\
\hline Full Development & \multicolumn{2}{|c|}{ Alternative 1 } & \multicolumn{2}{c|}{ Alternative 2 } & \multicolumn{2}{c|}{ Alternative 3 } \\
\hline 8 D x 8 D & \multicolumn{2}{|c|}{88.6} & \multicolumn{2}{c|}{88.7} & \multicolumn{2}{c|}{89.0} \\
\hline 8 D x 12 D & \multicolumn{2}{|c|}{90.9} & \multicolumn{2}{c|}{91.1} & \multicolumn{2}{c|}{91.2} \\
\hline 8 D x 15 D & \multicolumn{2}{|c|}{92.0} & 92.3 & Phase 2 \\
\hline Phased Development & Phase 1 & Phase 2 & Phase 1 & Phase 2 & Phase1 & Phase 2 \\
\hline & 500 MW & 1,000 & 500 MW & 1,000 & 500 MW & 1,000 \\
\hline 8 D x 8 D & 94.0 & 93.0 & 93.3 & 92.3 & 94.0 & 92.9 \\
\hline 8 D x 12 D & 94.7 & 93.7 & 94.1 & 93.2 & 94.7 & 93.3 \\
\hline 8 D x 15 D & 95.0 & 94.0 & 94.6 & 92.3 & 95.0 & 93.8 \\
\hline
\end{tabular}

The array efficiency values that are presented in Table 12 give a measure of how well the array is performing as a whole, compared to how it would be expected to perform if each turbine were operating with perfect exposure to the freestream wind with no obstructions from other wind turbines. As expected, the efficiencies for the three full development scenarios are the lowest, because the turbine array density and array power density ${ }^{1}$ is larger (e.g., more turbines per square kilometer). For the phased development cases, the array power densities are essentially held constant because each area builds either $500 \mathrm{MW}$ or 1,000 MW and only the spacing (turbine array density) is varied. Because the size of the leasing area is held constant, the phased development analysis is essentially examining the tradeoff between turbine spacing and intraarray buffer zones; as the spacing increases, the size of the buffers gets smaller. The result is that the impact of array spacing on total losses is tempered. In a remote array, one might expect a trend where wider spacing results in lower losses or conversely greater array efficiencies; however, this trend is not as evident in the presence of multiple wind plants. This result suggests that the benefits of additional spacing may have diminishing returns when multiple large arrays are sited near each other.

Most developers (especially when responding to the RFI and Call) did not consider that their project would be next to another project and could experience diminished capacity as a result of

\footnotetext{
${ }^{1}$ Array power density is defined here as the total area in kilometers squared $\left(\mathrm{km}^{2}\right)$ of the leasing area divided by the nameplate capacity in megawatts. Turbine array density is determined only by the spacing between turbines.
} 
wakes from those adjacent projects. Therefore, in the context of competitive multiproject development, offshore wind developers should consider the balance between array spacing and additional buffer zones (especially when siting within multileasing area WEAs such as Massachusetts) to be a zero-sum tradeoff between turbines array spacing and the area between arrays (buffer zones).

For the MA WEA under 1 and 2 phase development, the difference in overall array efficiency were relatively close, within $1 \%$ of each other. The data in Table 12 verify that the overall variation in array efficiency with turbine spacing is small. As such, other factors like cable length and water depth might play a larger role in the overall economics. However, the authors caution that the absolute quantities predicted by OpenWind should be reassessed with higher definition tools and more rigorous analysis.

\subsubsection{Wake Losses for Full Development}

Array efficiency was estimated using OpenWind to range from $88.6 \%$ with $8 \mathrm{D} \times 8 \mathrm{D}$ spacing to $92 \%$ for $8 \mathrm{D} \times 15 \mathrm{D}$ (see Table 9 ) for the full development scenarios of Alternative 1. For Alternative 2, the range was from $88.7 \%$ to $92.2 \%$, and for Alternative 3, the range was from $89 \%$ to $92.3 \%$. These efficiencies are higher than what has been seen in Europe, but at an expected range considering that the spacing in this analysis is generally wider than most operating European projects currently providing field data.

Figure 21 shows the individual turbine placement in the full development layouts for Alternatives 2 and 3, and the five leasing area alternatives using $8 \mathrm{D}$ x $12 \mathrm{D}$ turbine spacing. (Alternative 1 is not shown). Color coding indicates the efficiency of each turbine while operating in the array, with each turbine represented by a single dot. The colors indicate the magnitude in which the turbine is under-performing in the array as compared to how it would perform in an unobstructed freestream wind. Note how the strong degradation in the wind project interior dominates the chart for delineation scenarios, with the largest degradation occurring in leasing area 3, which has the poorest exposure to freestream prevailing wind because of the presence of adjacent leasing areas on both sides. Although losses for each leasing area were still less than $10 \%$ for all areas under full development with $8 \mathrm{D}$ x $12 \mathrm{D}$ spacing, individual turbines in the deep array are experiencing much higher losses. For large arrays, wake losses appear to be driven mostly by deep array effects and are largely independent of the grid orientation.

Researchers also investigated the variability in the leasing area array efficiencies between Alternative 2 and Alternative 3. One concern was that Alternative 3 could potentially introduce wake losses in leasing areas 1,2 , and 3 as a result of upwind turbines in leasing area 5 . For the 8 D x 12 D full development scenario, the computed wake losses for Alternative 2 were $7.9 \%$, $9.4 \%$, and $9.9 \%$ for leasing areas 1, 2, and 3, respectively. For the same scenario, the computed wake losses for Alternative 3 were $8.5 \%, 9.6 \%$, and $10.0 \%$ for leasing areas 1, 2, and 3 , respectively. These differences do not suggest a strong effect from the upwind leasing area on the downwind projects as might be expected. Although the Alternative 3 delineation would diminish the output of leasing areas 1,2, and 3 after development in leasing area 5 occurs, this potential wake impact is probably mitigated by other effects. One effect is that in Alternative 3, leasing areas 1, 2, and 3 are wider and shorter than in Alternative 2. Therefore, the arrays are less deep in the prevailing wind direction, leading to lower inter-array losses that tend to offset the additional external array losses. 


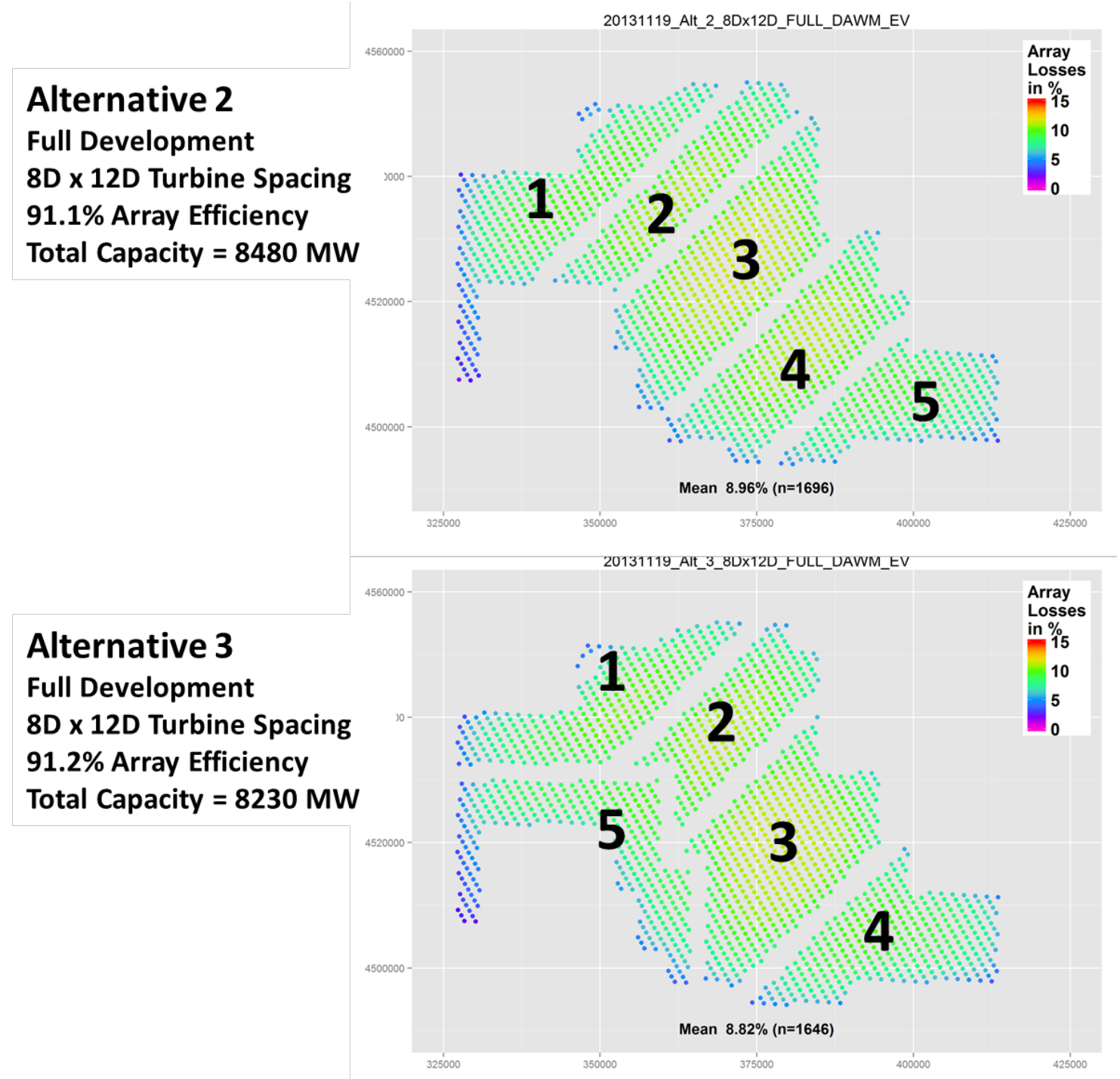

Figure 21. Comparison of OpenWind array efficiency results for the two five leasing area delineation alternatives of the MA WEA using $8 \mathrm{D} \times 12 \mathrm{D}$ turbine spacing under a full development scenario

(Source: NREL)

Although the characteristics of the individual leasing areas vary in terms of the array efficiencies, all of the delineation scenarios appear to be approximately equivalent for overall wake losses. Using the $8 \mathrm{D} \times 12 \mathrm{D}$ spacing scenario, the computed array efficiencies of Alternative 1, 2, and 3 are $90.9 \%, 91.1 \%$, and $91.2 \%$, respectively. This is not significant relative to the other uncertainties associated with the analysis. However, as mentioned earlier, full development scenarios are not the best way to judge overall wake effects because these development scenarios are unlikely. 


\subsubsection{Wake Losses for Phased Development}

For the phased development, NREL analyzed a scenario where ten 500-MW wind projects were built over a 16-year time frame in two time phases by five independent developers. This was a hypothetical case that addresses the reality of how projects are actually planned and executed in discrete units. As mentioned earlier, $500 \mathrm{MW}$ was chosen to represent a typical unit capacity for what developers are expected to deploy on a large scale in the future for a single phase under multiyear, multiphase development scenarios. The 500-MW scale is also used as the standard reference for DOE offshore wind project cost modeling (Tegen 2012) and is considered a scale in which offshore wind cost economies of scale could be reached (Maples 2012).

For simplicity, there are two development time phases, with the assumption that the shallowest water sites would be developed first, and the deeper water would be developed at a later phase with a 50-D buffer between projects. Based on the industry depth trend data shown in Figure 6 (Section 4) and the RFI and Call responses (Table 1 and Table 2 showing 8-16 year development time frames), the development time frame for phase 1 projects (water depths less than $50 \mathrm{~m}$ ) was assumed to be $6-8$ years. Similarly, the phase 2 development time frame was assumed to be $10-16$ years.

Figure 22 and Figure 23 show the array layouts for the ten 500-MW projects after phase 1 and 2 development has occurred for Alternative 2 and 3 delineation layouts. Figure 22 shows the layouts for Alternative 2, the five leasing area diagonal delineation option, and Figure 23 shows the layouts for Alternative 3, the five leasing area configuration with four areas in shallower water and one in all deep water. For both configurations, $8 \mathrm{D} \times 8 \mathrm{D}, 8 \mathrm{D} \times 12 \mathrm{D}$, and $8 \mathrm{D} \times 15 \mathrm{D}$ spacing scenarios are used. Phase 1 development was assumed to deploy the turbines in the shallowest sites available until 100 turbines (500 MW) were installed. Phase 2 developments followed phase 1 starting in the next shallowest sites after a 50-D buffer was implemented.

In Figure 22, there are five projects in both phases; however, in Figure 23, leasing area 5 is in deep water and was assumed to be installed in the phase 2 time frame. Therefore, only phase 1 included four projects under the Alternative 3 delineation scenario. Also, the 50-D setback was not observed between the leasing area 5 projects and the projects downwind in leasing areas 1, 2, and 3 , because developers do not have control over neighboring wind plants. Only the 8-D spacing setback was observed in these cases. 


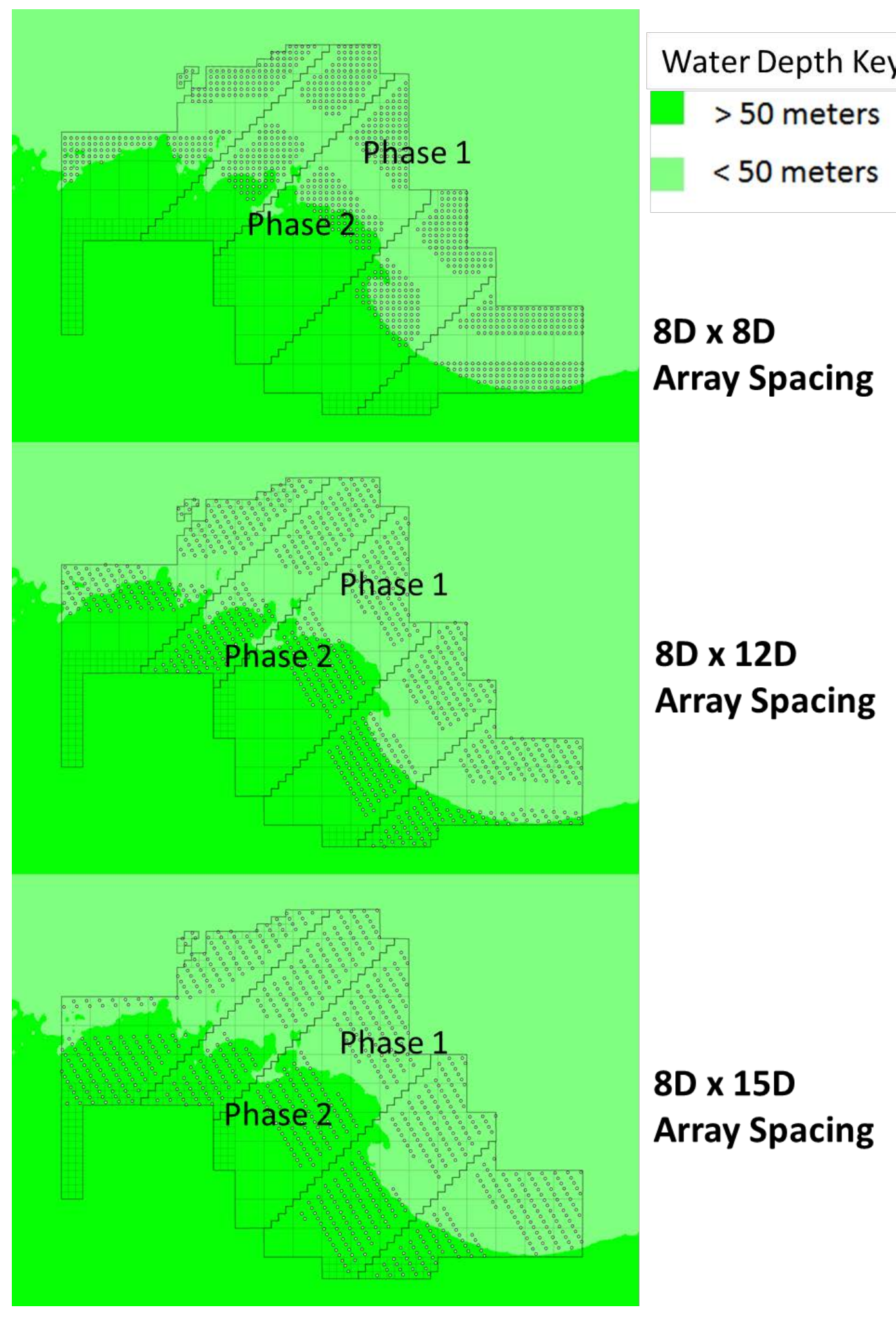

Figure 22. Alternative 2 delineation layouts for phase 1 and phase 2 development building two 500-MW projects per leasing area. Projects are shown with 8 D x 8 D, 8 D x 12 D, and 8 D x 15 D spacing.

(Source: NREL) 


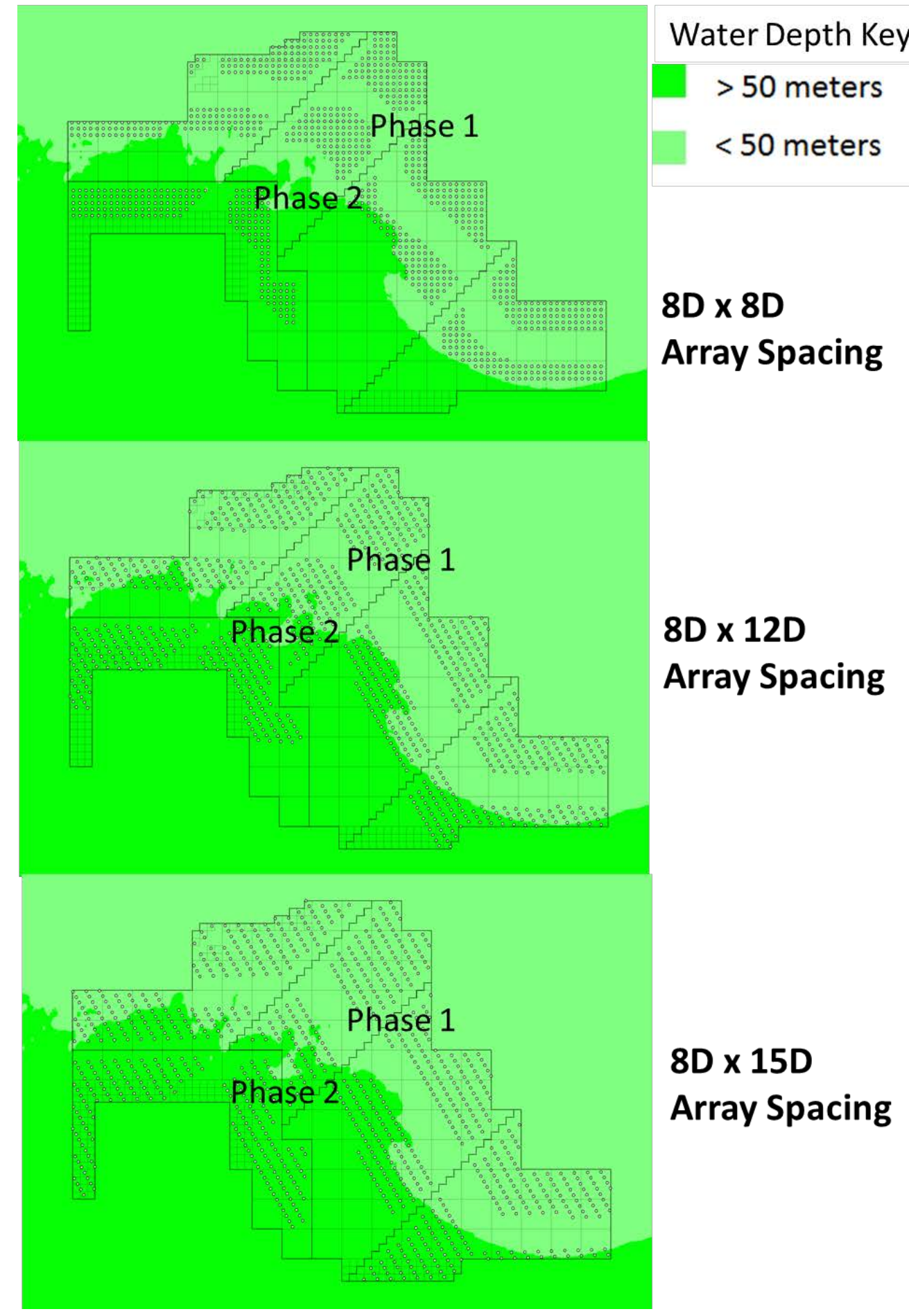

Figure 23. Alternative 3 delineation layouts for phase 1 and phase 2 development building two 500-MW projects per leasing area. Projects are shown with 8 D x 8 D, 8 D x 12 D, and 8 D x 15 D spacing.

(Source: NREL) 
Figure 24 and Figure 25 are plots of the array efficiencies on a turbine-by-turbine basis for Alternative 2 and 3 delineations under the phased development analysis, respectively. The plots compare the array efficiencies for the three spacing scenarios: $8 \mathrm{D}$ x $8 \mathrm{D}, 8 \mathrm{D}$ x $12 \mathrm{D}$, and $8 \mathrm{D} \times$ $15 \mathrm{D}$. The progression of plots shows how the array efficiencies improve as the spacing increases from $8 \mathrm{D}$ x $8 \mathrm{D}$ to $8 \mathrm{D}$ x $15 \mathrm{D}$.
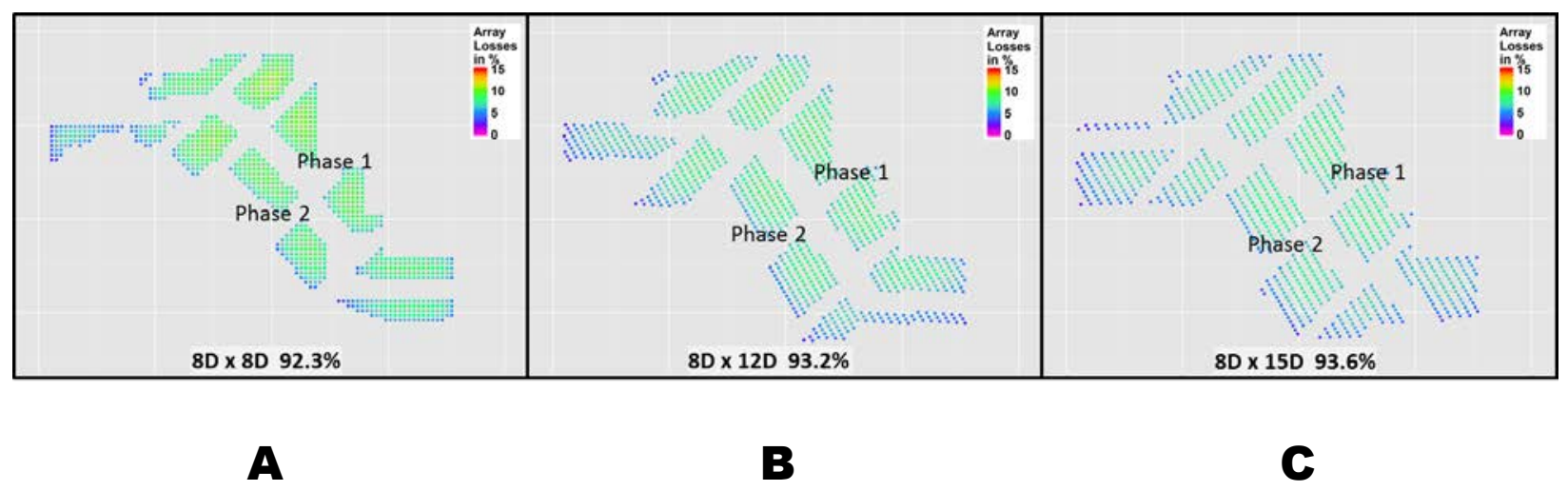

Figure 24. MA WEA for Alternative 2 leasing area delineation showing the effect of turbine spacing and buffers on array efficiencies with two 500-MW projects in each leasing area: (A) 8 D X 8 D spacing; (B) 8 D X 12 D spacing; and (C) 8 D x 15 D spacing (Source: NREL)

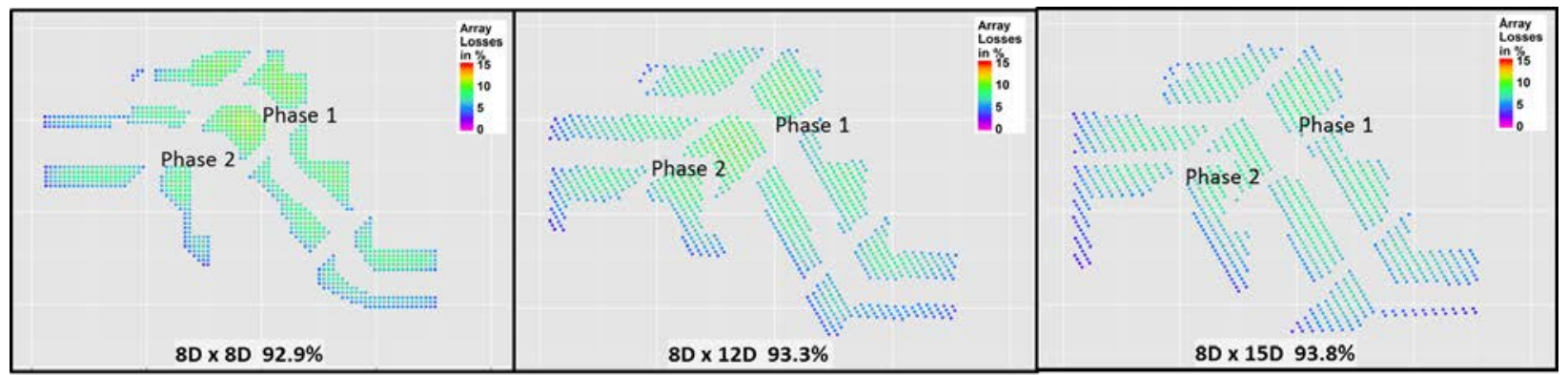

A

B

Figure 25. MA WEA for Alternative 3 leasing area delineation showing the effect of turbine spacing and buffers on array efficiencies with two 500-MW projects in each leasing area: (A) 8 D X 8 D spacing; (B) 8 D x 12 D spacing; (C) 8 D x 15 D spacing

(Source: NREL)

For the $8 \mathrm{D}$ x $15 \mathrm{D}$ spacing, the $50-\mathrm{D}$ buffer that was imposed earlier could not be maintained in some cases because the turbines consume the buffer area with extra wide spacing.

Generally, turbine array spacing is increased for the primary purpose of reducing wake losses within a given array, and the biggest tradeoff of this is often between lost energy and added cable cost. However, as the array spacing is increased, a significant tradeoff also appears between wake losses and water depth. The increased space between the turbines means that more area is needed to build a 500-MW plant. The analysis of the MA WEA shows that wider spacing requires that the arrays be built in deeper water. So in addition to longer cables, there may be 
additional construction cost because of the water depth associated with wider spacing. For the 8 $\mathrm{D} \times 8 \mathrm{D}$ spacing, the maximum depth range of phase 1 was $44 \mathrm{~m}-47 \mathrm{~m}$ for Alternative 2 and $42.0 \mathrm{~m}-45.0 \mathrm{~m}$ for Alternative 3. By comparison for the $8 \mathrm{D}$ x $15 \mathrm{D}$ spacing, the maximum depth ranges were $48.0 \mathrm{~m}-50.0 \mathrm{~m}$ for Alternative 2 and $46 \mathrm{~m}-48.0 \mathrm{~m}$ for Alternative 3 , an increase of $3 \mathrm{~m}$ to $4 \mathrm{~m}$. Note that phase 1 of Alternative 1 would have the same characteristics as Alternative 3 because the delineation boundaries are identical except for the carve-out of leasing area 5 in Alternative 3 . When the comparison was made between the $8 \mathrm{D} \times 8 \mathrm{D}$ and $8 \mathrm{D} \times 15 \mathrm{D}$ array spacing options for the two-phase development the ranges increased. For the $8 \mathrm{D} \times 8 \mathrm{D}$ spacing, the maximum depth range was $51 \mathrm{~m}-55 \mathrm{~m}$ for Alternative 2 and $50 \mathrm{~m}-51.0 \mathrm{~m}$ for Alternative 3 . By comparison for the $8 \mathrm{D}$ x $15 \mathrm{D}$ spacing, the maximum depth ranges were $55.0 \mathrm{~m}-62.0 \mathrm{~m}$ for Alternative 2 and $53 \mathrm{~m}-62.2 \mathrm{~m}$ for Alternative 3, an increase of up to $10 \mathrm{~m}$ in some leasing areas.

In addition, installing turbines into deeper water in the MA WEA means that the turbines are farther from shore. Therefore, as array spacing increases, the average turbine's distance-to-shore also increases. This is likely to have implication for operations and service, as well as the cost of the export cable. As a result, for a unit 500-MW project in the MA WEA, the cost to add extra cable length and perform construction and service at greater water depths and distances from shore should be weighed against the increased energy capture of lower wake losses caused by higher array spacing.

\subsubsection{Effect of Turbulence Intensity on Wake Losses}

Studies have shown that the turbulence intensity of the wind flow can have a significant effect on the wake losses in offshore wind power plants (Barthelmie et al. 2013; Hansen et al. 2012). Measurements of power production and wakes in European offshore wind power plants have verified that wake losses are typically greatest for low turbulence intensity wind flow conditions and lowest for high turbulence intensity wind flow conditions. In the Baltic Sea offshore areas, where high-quality tall-tower measurement data have been analyzed, the annual average turbulence intensity at turbine heights is typically less than $6 \%$ and decreases with height (Hansen et al. 2012). Furthermore, turbulence intensities have been shown to be lowest at wind speeds between 8 and $12 \mathrm{~m} / \mathrm{s}$. This implies that for wind speeds in the frequently occurring range of $8-12 \mathrm{~m} / \mathrm{s}$, in which wake losses are relatively high, low turbulence intensity can potentially delay dissipation of turbine wakes and further increase wake losses.

Although turbulence intensity and how it might affect wake losses and wake dissipation under varying atmospheric conditions may be critical in modeling wind turbine array efficiency and structural loading in the deep array, no high-quality wind measurements on turbulence intensities and atmospheric stability were available for the MA WEA study. Therefore, the lack of good, site-specific metocean data and a high-fidelity model to properly represent the physical effects of turbulence and atmospheric stability remains a potentially significant source of error and uncertainty in the OpenWind analyses and this study.

Some $60-\mathrm{m}$ data measured offshore in the U.S. Atlantic northeast region indicates that the annual average turbulence intensity is approximately $6 \%$, with turbulence intensities from the southwest directions averaging between $4.5 \%$ and $6 \%$. Moreover, as observed at the European sites, the lowest turbulence intensities are found at wind speeds between 8 and $12 \mathrm{~m} / \mathrm{s}$. Turbulence 
intensities typically decrease with height, and are expected to be slightly lower at the 90-m hub height than those measured at $60 \mathrm{~m}$.

For this study, NREL conducted a preliminary analysis of the sensitivity of the OpenWind model simulations of wake losses for a large array of $8 \mathrm{D} \times 8 \mathrm{D}$ spacing to different turbulence intensity values of $5 \%, 10 \%$, and $15 \%$. This analysis did not show any significant differences caused by turbulence intensity. However, the large array and resultant deep array effects on the wake losses may have overwhelmed any effects caused by freestream turbulence intensity in the simulations. Further simulations using smaller arrays and more open spacing should be evaluated using different turbulence intensities to examine if the results are similar or not to the preliminary findings. In the absence of data for this region and generally low model sensitivity to turbulence intensity, NREL assumed an average turbulence intensity of $10 \%$ for the model simulations of the wake losses and energy production. 


\section{Qualitative Considerations}

There are several other criteria that could influence the leasing area value and the ability to develop the MA WEA, but most of these criteria, such as fisheries, military use, ecological impacts, and traffic were not considered as part of this study by NREL and did not influence the delineation strategy.

Sites with longer distances to shore will likely add project development cost because of the extra export cable length needed and longer transport times to and from the turbines for construction and service. An analysis of this factor would require a specific definition of where the land-based grid connections are made or specifics on ports and harbor staging areas but are not covered in this report extensively.

Technology challenges and development cost as the result of deeper water are covered in various sections in this report and conclude that deeper water will add costs to project development; however, cost increases may be non-linear with depth because technology challenges often occur in steps as vessel specifications are often exceeded at specific depth increments.

Finally, development timing is covered in Section 2, under the phased development scenario in $\underline{\text { Section } 5}$, and in Figure 6. Generally, the deeper water technology will slow the shallower water development, but researchers remain optimistic because technology is constantly advancing (see Figure 6). 


\section{Key Findings}

Below are the key findings of the NREL analysis for the assessment of the MA WEA and provide considerations for BOEM, policy makers, and stakeholders involved in the Massachusetts offshore wind energy development process.

- Massachusetts is the largest BOEM WEA under consideration at this time $\left(3,006.7 \mathrm{~km}^{2}\right)$ and can feasibly accommodate at least ten 500-MW wind projects $(5,000 \mathrm{MW})$ under a phased development scenario using up to five leasing areas.

- The biggest challenge for offshore wind developers in the MA WEA will be water depths that range between $35 \mathrm{~m}$ and $65 \mathrm{~m}$.

- The MA Wind Energy Area can be delineated into four to five leasing areas with equitable divisions of shallower water (less than $50 \mathrm{~m}$ ), wind resource potential, and exposure to unobstructed freestream prevailing wind (Alternative 3 is an exception, with leasing area 5 presenting a potential upwind obstruction).

- The leasing areas in the western part of the MA WEA may have a greater advantage if export cable interconnection points off Cape Cod and the islands are favored. It may be prudent for state or federal regulators to consider options for coordinating cable routing strategies and possible easements among the leasing areas. Within the MA WEA, interconnect access could be a strong driver in appraising leasing area value.

- The maximum nameplate development capacity for Alternatives 2 and 3, the five leasing area options, ranged from 1,220 MW to 2,295 MW. For Alternative 1, the four leasing area option, the maximum nameplate development potential ranged from 1,695 MW to 2,955 MW. This represents a large overall disparity in total area per lease area even though the shallower water (less than $50 \mathrm{~m}$ ) is balanced to within $5 \%$ for each alternative.

- Diagonal delineations, which are 45 degrees to the BOEM leasing grid, appear to be the most efficient delineation strategy to create equitable divisions of water by depth, and to minimize inter-array conflicts caused by wake effects.

- Average annual wind speed for the MA WEA ranged from $9.2 \mathrm{~m} / \mathrm{s}$ to $9.4 \mathrm{~m} / \mathrm{s}$, with the highest wind speeds in eastern areas and lowest wind speeds in western areas. For each alternative, this corresponds to a typical range of capacity factors between $45 \%$ and $47 \%$ across the WEA after wake losses are subtracted using the $8 \mathrm{D} \times 12 \mathrm{D}$ spacing for a full development scenario.

- Total wake losses from projects developed at the $8 \mathrm{D}$ x $12 \mathrm{D}$ spacing in all leasing areas of the MA WEA were computed to range between $6 \%$ and $8 \%$ when 1,000 MW (in two 500MW phases) were installed in each leasing area. Wake losses in the MA WEA appeared to be lower than other areas studied in the mid-Atlantic because of higher average wind speeds and a distribution of more unidirectional prevailing winds (Musial et al. 2013b and Musial et al. 2013c).

- The grid orientation angle was found to have a negligible impact on array efficiency $(<0.1 \%)$ using the OpenWind model with $8 \mathrm{D}$ x $12 \mathrm{D}$ spacing and $10 \%$ turbulence intensity. The best grid orientation angle was 60 degrees for the $8 \mathrm{D} \times 12 \mathrm{D}$ array, but the true impacts of 
variable turbulence intensity are not well captured in OpenWind. A more rigorous array analysis approach is recommended for developers in this area.

- Wake losses increased with decreasing turbine spacing, as expected. For the full development scenarios in each alternative, wake losses averaged 7.8\% for the $8 \mathrm{D} \times 15 \mathrm{D}$ spacing and $11.2 \%$ for the $8 \mathrm{D}$ x $8 \mathrm{D}$ spacing. Most of this impact can be accounted for by lower array power density with the wider spacing.

- Additional turbine spacing may have diminishing benefits when multiple large arrays are sited near each other. This reduction in the impact of spacing is because additional turbine spacing tends to reduce buffers that separate neighboring wind plants.

- Additional development cost will be introduced with wider spacing because of longer cable length, greater water depths, and farther distances from shore. These costs should be carefully weighed against the added energy from higher array efficiency. 


\section{Recommendations}

NREL's recommendations for the MA WEA are as follows.

- Of the three alternatives, NREL prefers Alternative 2 because it is believed the development potential of the WEA would be maximized while the effects of neighboring projects on adjacent wind plants would be minimized. With the five leasing area option, each area could support at least two 500-MW projects, and some could support three (depending on the spacing).

- Any of the alternatives assessed in this report would be feasible and may be preferable to Alternative 2 for a given set of objectives.

- NREL recommends that BOEM consider methods to discount the deepest aliquots to address the probable time lag in development caused by the added cost and complexity of building turbines in deeper water.

- The analysis in this report is coarse by industry standards, therefore it is recommended that prospective lessees conduct more rigorous analysis on wake losses before judging the values of these leasing areas. This enhanced analysis should consider diurnal, seasonal, and annual variations as well as a full cost assessment to examine the additional cost due to added cable length. In addition, NREL recommends conducting further analysis on wake losses with respect to atmospheric stability conditions. 


\section{References}

AWS Truepower, LLC. (2010). OpenWind Theoretical Basis and Validation. http://www.awsopenwind.org/downloads/documentation/OpenWindTheoryAndValidation.pdf. Accessed April 6, 2013.

AWS Truepower, LLC. (2012). Wind Resource Maps and Data: Methods and Validation. https://windnavigator.com/index.php/content/file/Wind\%20Maps-Data_Methods-Validation.pdf Accessed [include date here].

Barthelmie, R.J.; Pryor, S.C.; Frandsen, S.T.; Hansen, K.S.; Schepers, J.G.; Rados, K.; Schlez, W.; Neubert, A.; Jensen, L.E.; Neckelmann, S. (2010). "Quantifying the impact of wind turbine wakes on power output at offshore wind farms." Journal of Atmospheric and Oceanic Technology, 27(8); pp. 1302-1317. DOI: 10.1175/2010JTECHA1398.1.

Barthelmie, R.J.; Hansen, K.S.; Pryor, S.C. (2013). "Meteorological controls on wind turbine wakes," Marine Energy and Environments. Special issue Proceedings of the Institute of Electrical and Electronics Engineers. Accepted June 5, 2012. DOI: 10.1109/JPROC.

Brower, M.C. (1999). Validation of the WindMap Model and Development of MesoMap, Proceedings of Windpower 1999, American Wind Energy Association, Washington, DC.

Cape Wind. (2013). Website of Cape Wind Offshore Wind Project.

http://www.capewind.org/index.php. Accessed December 1, 2013.

Churchfield, M.J.; Lee, S.; Michalakes, J.; Moriarty, P. (2012). “A numerical study of the effects of atmospheric and wake turbulence on wind turbine dynamics." Journal of Turbulence, 13, N14. http://dx.doi.org/10.1080/14685248.2012.668191.

Hansen, K.S.; Barthelmie, R.J.; Jensen, L.E; Sommer, A. (2012). “The impact of turbulence intensity and atmospheric stability on power deficits due to wind turbine wakes at Horns Rev wind farm," Wind Energy, 15(1); pp. 183-196. DOI: 10.1002/we.512.

Hasager, C.B.; Rasmussen, L.; Peña, A.; Jensen, L.E.; Réthoré, P-E. (2013). "Wind Farm Wake: The Horns Rev Photo Case.” Energies; 6, no. 2: pp. 696-716.

Jonkman, J.; Butterfield, C.P.; Musial, W.; Scott, G. (2009). Definition of a 5-MW Reference Wind Turbine for Offshore System Development. NREL/TP-500-38060. Golden, CO: National Renewable Energy Laboratory, February 2009. Accessed [include date accessed]: http://www.nrel.gov/docs/fy09osti/38060.pdf.

Manobianco, J.; Zack, J.W.; Taylor, G.E. (1996). “Workstation-based real-time mesoscale modeling designed for weather support to operations at the Kennedy Space Center and Cape Canaveral Air Station.” Bull. Amer. Meteor. Soc., 77, pp. 653-672.

Maples, B. (2012). “U.S. Balance-of-Station Cost Drivers and Sensitivities," Poster presentation at AWEA Offshore Windpower Workshop 2012, Virginia Beach, VA, October 10, 2012. 
Musial, W.D. (2013). "Proposed Methodology for Massachusetts Wind Energy Area Delineation," Webinar presentation at BOEM Massachusetts Task Force meeting, May 15, 2013. http://www.boem.gov/State-Activities-Massachusetts/. Accessed August 19, 2013.

Musial, W; Elliott, D.; Fields, J.; Parker, Z.; Scott, G. (2013a). Analysis of Offshore Wind Energy Leasing Areas for the Rhode Island/Massachusetts Wind Energy Area. NREL Report No. TP5000-58091. Golden, CO: National Renewable Energy Laboratory, April 2013. Accessed November 26, 2013. http://www.nrel.gov/docs/fy13osti/58091.pdf.

Musial, W; Elliott, D.; Fields, J.; Parker, Z.; Scott, G. (2013b). Assessment of Offshore Wind Energy Leasing Areas for the BOEM Maryland Wind Energy Area. NREL Report No. NREL/TP-5000-58562. Golden, CO: National Renewable Energy Laboratory, June 2013. Accessed [include date]. http://www.nrel.gov/docs/fy13osti/58562.pdf.

Musial, W; Elliott, D.; Fields, J.; Parker, Z.; Scott, G. (2013c). Assessment of Offshore Wind Energy Leasing Areas for the BOEM New Jersey Wind Energy Area. NREL Report No. NREL/TP-5000-60403. Golden, CO: National Renewable Energy Laboratory, October 2013. Accessed November 26, 2013. http://www.nrel.gov/docs/fy13osti/60403.pdf.

Musial, W.; Ram, B. (2010). Large-Scale Offshore Wind Power in the United States: Assessment of Opportunities and Barriers. NREL/TP-500-40745. Golden, CO: National Renewable Energy Laboratory, September 2010. Accessed [include date].

http://www.nrel.gov/docs/fy10osti/40745.pdf.

National Aeronautics and Space Administration (NASA). (2013). MERRA: Modern-Era Retrospective Analysis for Research and Applications. http://gmao.gsfc.nasa.gov/merra. Accessed April 16, 2013.

National Oceanic and Atmospheric Administration (NOAA). (2013). NOAA National Geophysical Data Center, U.S. Coastal Relief Model Volume 1 (New England), http://www.ngdc.noaa.gov/mgg/coastal/crm.html Accessed November 25, 2013.

National Oceanic and Atmospheric Administration (NOAA). (2013). National Data Buoy Center. http://www.ndbc.noaa.gov/hmd.shtml. Accessed April 15, 2013.

Phillips, G.T. (1979). “A Preliminary User's Guide for the NOABL Objective Analysis Code,” DOE/ET/20280-T1.

Schwartz, M.; Heimiller, D.; Haymes, S.; Musial, W. (April 2010). Assessment of Offshore Wind Energy Resources for the United States. NREL/TP-500-45889. Golden, CO: National Renewable Energy Laboratory, June 2010. Accessed [include date]. http://www.nrel.gov/docs/fy10osti/45889.pdf.

Tegen, S.; Hand, M.; Maples, B.; Lantz, E.; Schwabe, P.; and Smith, A. (2012). "2010 Cost of Wind Energy Review,” NREL Technical Report, NREL/TP-5000-52920, April 2012. http://www.nrel.gov/docs/fy12osti/52920.pdf 
U.S. Department of the Interior. (2013). "Interior Holds First-Ever Competitive Lease Sale for Renewable Energy in Federal Waters," http://www.doi.gov/news/pressreleases/interior-holdsfirst-ever-competitive-lease-sale-for-renewable-energy-in-federal-waters.cfm. Accessed [include date]. 